\title{
Social Architecture: aging in community
}

\author{
By
}

Orhan Hassan

A thesis submitted to the Faculty of Graduate and Postdoctoral Affairs in partial fulfillment of the requirements for the degree of:

\author{
MASTER \\ OF \\ ARCHITECTURE PROFESSIONAL
}

IN

AZRIELI SCHOOL OF ARCHITECTURE AND URBANISM

Carleton University

Ottawa, Ontario, Canada

(C2016

Orhan Hassan 
Social Architecture: aging in community 
Abstract

Sociological and epidemiological research has identified that seniors are experiencing isolation and disconnection - a form of social segregation, leading to negative health outcomes. Ongoing concerns have been expressed about presently unmet housing and housing support needs, in particular affordability, accessibility, and functionality. The socio-economic forecast and unprecedented swell of the senior demographic anticipated in the next three decades will undoubtedly exacerbate conditions. This condition urges consideration for alternative policies and planning options. Architecture is making strides to find innovative design options for seniors housing. Yet alternative housing models, which are being called for, are rarely, if at all, critically discussed. Cohousing is an emerging alternative that offers mutual support and connection - a form of social architecture, as key tenets of the model. This thesis is a speculative enquiry proposing a hybrid housing blending concepts supportive housing, conventional development and cohousing - that facilitates a social architecture for 'aging in community'. 


\section{Acknowledgements}

The successful completion of this thesis has been made possible many individuals that deserve acknowledgement:

I wish thank my family and friends for their unwavering support and belief in this academic exploration, their patience and kindness, especially my darling wife Marianne, without whom this journey would not be possible, and my two children Clare and Tarik.

I wish to express my deep gratitude and appreciation for the support provided by my academic advisor, Professor Federica Goffi, who provided the mental space for exploration, development of new insights, and made this journey incredibly rewarding.

I wish to acknowledge my academic peers (affectionately known as the "degenerates"), the faculty and administrative personnel of Carleton University School of Architecture, in including professors Yvan Cazabon and Roger Connah, Mark and Rob in the workshop, Mike and Ewa Mroz.

I wish to acknowledge the following individuals that were consulted in my investigation:

Carol Burrow, Volunteer Member of the Ottawa Council On Aging

Rich Morris, Founder and Director, Domicile Developments

Douglas James, City of Ottawa

Saide Sayah, City of Ottawa

Randolph Wong, City of Ottawa

André Fontaine, Ottawa Children's Aid

And, last but not least, my dear friend D'Arcy McPherson for his editorial support. 
Contents

Abstract

Acknowledgements

Table of Contents

Part 1. Introduction

\section{Part 2. Housing Old-Old Ideas}

Health, Healthy Aging, and Healthy Aging Environments

Old Old Seniors Housing Decisions

Aging In Place

Long-term Care

Supportive Housing

Health and The Social Impact of Isolation and Segregation

Social Currency: social capital and community

Architecture as a mediator of health:

Compounding Factors:

Demographic Shift

Diversity, Ottawa Aging Population

Social and Economic Reality and Affordable Housing

Can the Public Purse Cope?

Who Will Provide the Care?

A longer Life, but is it a better one?

The impact of ageism

Old-Old Construction Trends

Supportive Housing Boom 
Architecture's response to seniors' housing needs

\section{Part 3. What is Cohousing?}

Characteristic of Cohousing

Advantages of Cohousing

Positive Health Impacts of Inclusion

Cohousing and Co-Care

What are Cohousing Critics Saying?

Cohousing Spatial Systems

\section{Part 4. Architectural Proposition: Social Architecture}

Conceptual Design Considerations

Design Intensions

Spatial Organization: Seniors Residence and Typical Condominium Development

Social Architecture: Points of Intersection

Design Process

Location, Location, Location: The Ideal Site

Site Analysis: History of the Site; Urban Pattern; Circulation

Mixed Use Project - Developers Program

Dual Functioning Space: Connection; Integration; Engagement the Wall; Connection to the outside world New Program

Floor Plan, Elevations, Sections, and Unit design Options

\section{Part 5. Critical reflections and Conclusions}

Endnotes

Bibliography 


\section{Part 1. Introduction}

We could all agree our preference in life would be to live a full, healthy, and productive life. One might call these aspects of healthy aging. Architecture and spatial design have been shown to facilitate positive psychosomatic health and social outcomes including social capital-informed and ephemeral elements of social currency. Housing is one of the key determinants of health, and healthy aging. Yet a major inconsistency seems to exist between the capacity for healthy aging and current seniors housing strategies. Growing evidence shines a light on the experiences of isolation and loneliness that lead to negative health outcomes for seniors. The inadequacy and appropriateness of housing and the corresponding supports for seniors is a focal point for social advocacy efforts for change.

Seniors and community organisations in Ottawa, and elsewhere in Canada, are advocating for adequate investments and policy change to address the housing needs for seniorsi. This situation will likely be exacerbated by the anticipated swell of seniors in the general population as well as the socio-economic forecast that Canadian seniors are expected to face significant financial hardship in retirement. Governments around the world, including Canada and the City of Ottawa have adopted an 'Age-friendly Cities and Communities' policy direction to respond to the anticipated population swell of seniors over the next three decades. This growth is attributed to the baby boomer generation - the segment of the population born between 1946 and 1965 - that will have reached their senior years within the next two decadesii. In addition, advances in medical technologies and access to healthcare, (i.e., pharmacological, diagnostic, and treatment options for illness) as well as public 
health measures (e.g., public vaccination programs) have played a major role in changing life expectancy across the world but more particularly in developed countriesiii.

Architecture plays an important role in assisting with this policy direction with design ideas that may contribute to solving societal challenges. While good-practice examples emerging in the architectural field to respond to housing needs of seniors, replication of past housing forms continue locally. In spite of compelling evidence, there is little discussion on alternative housing models for seniors within the field of architecture.

Cohousing is one example of an alternate housing form that has emerged in response to housing needs and desires to change the ways of dwelling with others. A social architecture, namely an informal social relationship that fosters connection, social engagement, and mutual support, is a central tenet of these so called fringe housing models.

This thesis is a speculative enquiry into the insertion of a cohousing model into a conventional 'mixed-use'iv development project - forming a hybrid model. This architecture of this hybrid anticipates occupants' changing physical needs over time, and supports a social architecture that is enriching for residents and the surrounding neighbourhood - developing the currency of social capital in the community. The proposal is located in an urban area within Ottawa, Canada's national capital. Considering the perspectives of consumers, the municipality and developers alike, this thesis explores whether this hybrid model is a housing option that responds to the emerging evidence on the physical, psychological, and social dimensions of housing for those who wish to live in their communities for as long as possible. 
The thesis is organized into five parts. Parts 2 and 3 will build the foundation for the hybrid approach and architectural proposition explored in this thesis. It is important to understand current policy that dictates housing choices available to seniors, emerging evidence on the impact of segregation and isolation on healthy aging. The analysis draws the primacy of 'psychosomatic health' architectural design as discussed by Alberto PerézGoméz. It also draws on the medicalization of society and the institutions that form levels of societal control- a theory developed by the philosopher and social critic Ivan Illich. In a situation where a deficit exists, the growing demand is likely to exacerbate matters. Hence, it is necessary to explore the scale of the anticipated demographic shift; 'aging in place'; the architectural response for seniors housing, as well as the emerging interest in cohousing for seniors. Next, the architectural proposition on a selected urban site in Ottawa is discussed, including an analysis of the site; the planned program (i.e. of the developer and new proposition); and precedent studies. This thesis will conclude with critical reflections on the perspectives of those consulted, the design process. The primary question asked whether the insertion of cohousing into a conventional condominium model is possible and realistic as a possible hybrid housing option for the aging population, including what, if any, factors enable and inhibit such an option. 


\section{Part 2. Housing 'Old-Old' Ideas}

"Life is Flux"

(Heraclitus of Ephesus C. 500 BCE - C. 475 BCE) v

The above title borrows from Deane Simpson's general of critique of urban planning and housing strategies for the aging population in the United States.vi A shift in theoretical conception of life stages had to occur in order to explain changes in social attitudes (as well as expectations) toward aging. The three-phase life stratification concept (i.e. 'childhood', 'adulthood', and 'old-age') held up until the 1970s, was modified to include 'young old' as a fourth phase reflecting the emerging group of seniors seeking socially active lives. This is to say that social attitudes are subject to change due to the changes in the cultural, socio-economic, environmental and political landscape. This notion of change establishes a position for this thesis, questioning attitudes and housing alternatives by exploring another option for the so-called 'young-old' to contemplate life in two decades and beyond. Therefore, change is needed.

This segment begins with an exploration of concepts of health, housing, the negative consequences of current housing strategies for seniors, social problems associated with present strategies and consequences, compounding factors, and delves into the role architecture in promoting health. 


\section{Health, Healthy aging and Healthy Aging Environments}

How healthy one feels is a subjective concept. According to the World Health Organization (WHO):

"Health is a state of complete physical, mental and social well-being and not merely the absence of disease or infirmity".

A broad range of factors can determine and predict health. These fall into three interrelated thematic areas: social and economic environment; physical environment; and a person's genetics and behaviours. In reality, many determinants of health are beyond an individual's control, such as the quality and safety of the living environment, access to health services, housing and education among others. vii

The WHO established a series of initiatives to promote 'Active Ageing' including a policy framework healthy aging.

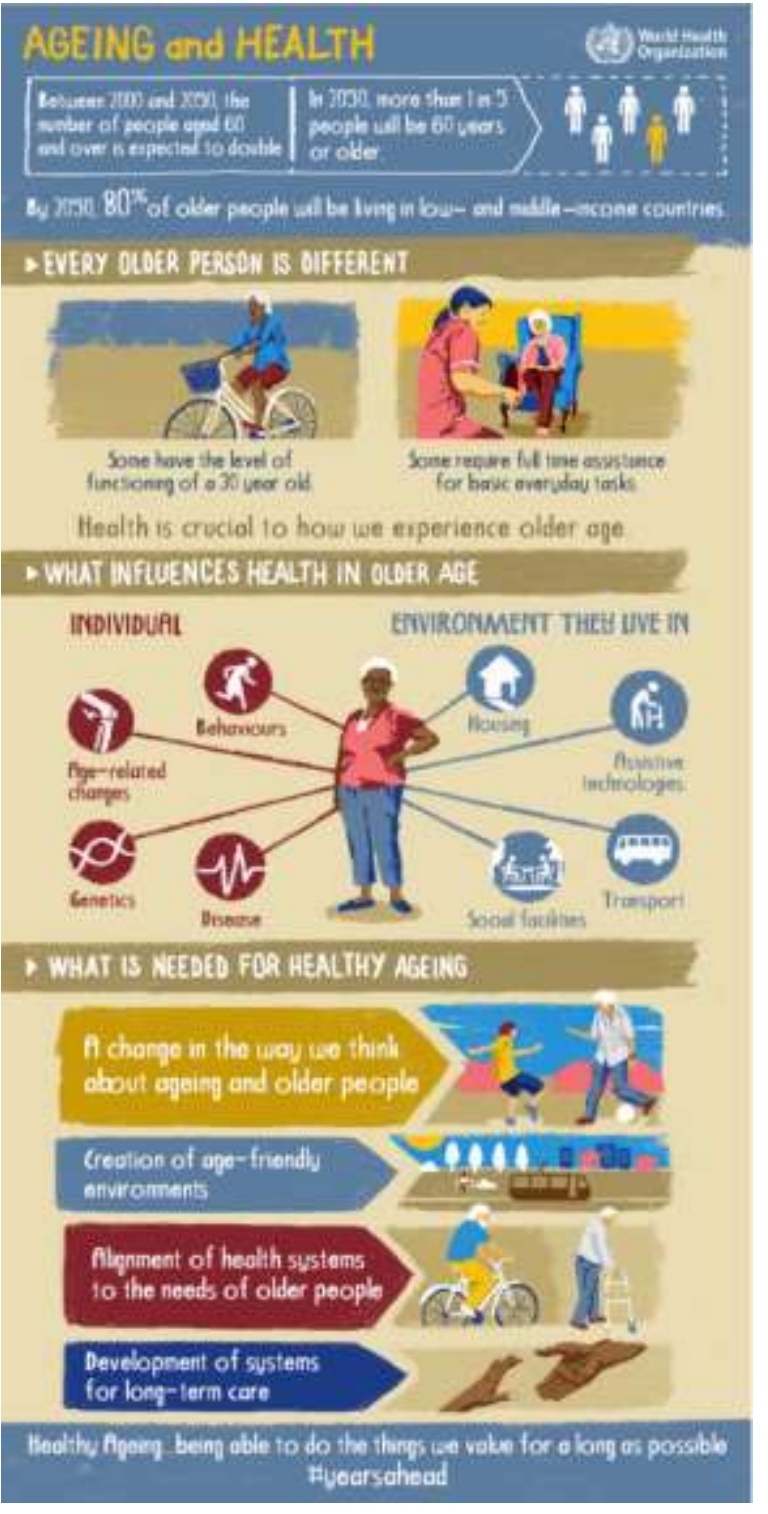

Figure 1. An Illustrated information guide on Ageing and Health, produced by the WHO 

Active aging is defined as:

"...the process of optimizing opportunities for health, participation and security in order to enhance quality of life as people age".

Healthy aging extends the definition of health to include environmental conditions - physical and social, that support active aging, as can be seen Figure 1. Ottawa and other cities in Canada are engaged in an international effort to act on this aging philosophy.

The City of Ottawa's 'Older Adult Plan' describes priorities for action to support healthy ageing environments. Examples of action taken to date: Enhanced Road Signage program (Figure 2) to increase visibility of road signage to promote safety; Community Connect (Figure 3) promotes safety and early identification of vulnerable seniors through a referral and call line; Installation of additional park benches in public spaces (Figure 4); Snow Angels (Figure 5) a volunteer program that encourage community members help with snow removal for seniors.

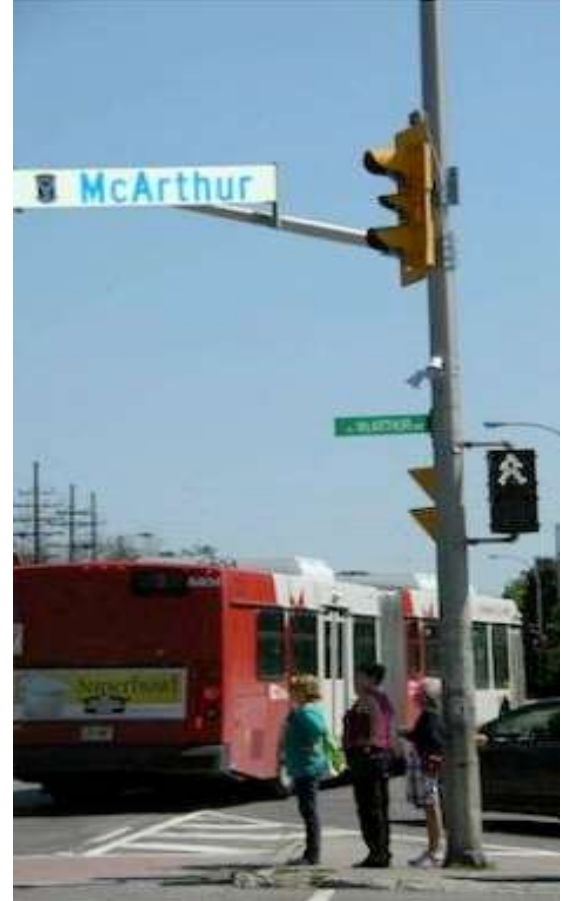

Figure 2

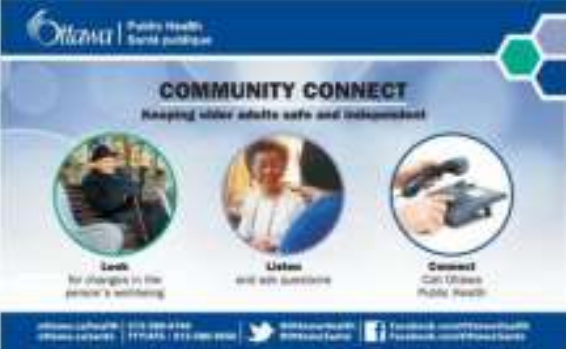

Fiaure 3

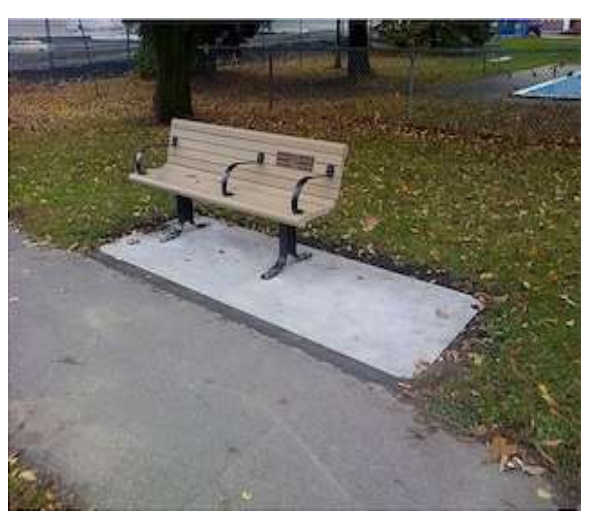

Figure 4

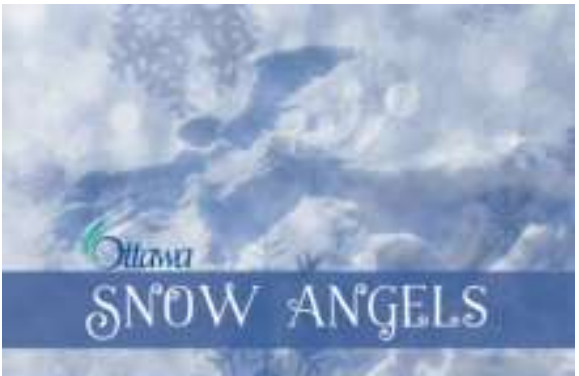

Figure 5 
Urban planning; land use; infrastructure maintenance and development; public transportation; Affordable housing; and the provision of programs and services fall under the City's responsibility. Housing is one of the key priorities for seniors, seniors advocates, and the City alike. However, there seems to be an inconsistency in policy objectives and development trends - to be discussed further. Initially, we need to examine current 'Old-Old' housing strategies for seniors.

\section{Old-Old Seniors Housing Decisions}

According to the 2011 census data, there are over 320,000 households in Ottawa and of these 19\% are occupied by seniors 65 years and older. The proportion of seniors who own versus rent is $72 \%$ and $28 \%$ respectively. $25 \%$ of seniors live alone, and female seniors are twice as likely than males to live alone.

Like many countries, Canada's housing policy for seniors consists of three main strategies: support for 'aging in place'; access to long-term care facilities; and, supportive housing. According to Canada Mortgage and Housing Corporation (CMHC), housing options seem to be age dependent. Among Ottawa's seniors, 9,400 individuals (or $9 \%$ of the senior population) live in institutional settings, and of these, $33 \%$ are aged 85 years or older. 
Many seniors downsize and leave their family home for a smaller home. They often opt to purchase a condominium with the expectation of not having to deal with home and maintenance, or switch tenure from ownership to rental, for example. This may provide the flexibility needed to suit particular lifestyles. Older seniors (i.e., those 75 years and up) are more likely to relocate to seniors homes due to progressively diminishing capacity to live independently. Few will move in with adult children and/or other family members. These options all involve some level of out-of-pocket expenses to the end user, their informal care networks, and to the public purse. The quality and range of services offered by seniors homes will depend on the individual's ability to pay. In Ontario, privately financed residential care can range from $\$ 2,000$ to $\$ 5000$ per month. Seniors on low income have fewer options and are more likely to enter state-funded long-term-care facilities - even if they are better served through other options.

One-size does not fit all. This is true for housing types as well as for services associated with supporting seniors with their housing decisions. Cost effective strategies must be tailored to meet the unique set of circumstances of the seniors concerned 8 .

\section{Aging in Place:}

According to Canada's Seniors Strategy:

'Aging in place' means having the health and social supports and services you need to live safely and independently in your home or your community for as long as you wish and are able'.

Aging in place is the preferred housing choice for $85 \%$ of Canadians aged 55+, who wish to live at home and within their communities for as long as they can (i.e. until such time as they are unable to care for themselves 
independently (or with home-based support). Remaining in familiar surroundings maintains a strong sense of community connection and has a positive effect on health'. Aging in place is also a preferred option for different levels of government within Canadal as it is more cost effective compared to state funded long-term care facilities.

Home care is a form of support available to assist seniors with the activities of daily living, including help with bathing, cooking, and shopping. Older seniors more frequently need support for daily living activities. The CMHC reports that the level of support increases from $8 \%$ to $44 \%$ among seniors aged $65-75$ years and $85+$ years respectively 10 . Home care is a service purchased by seniors. Seniors on low income can access services for free or through some co-paying arrangement. However, the level of support is reported as being inadequate and having long waiting list for access, due to underfunding - in some instances services are scaled back or reprioritised due to budgetary constraints (Champlain LHIN).

The practical challenge is that current housing stock in Ottawa will not meet housing requirements from an architecture perspective, in that $52.1 \%$ of present homes are built prior to 198111 , and accessibility legislation in Ontario did not take effect until 2005'2. Therefore, it is likely that the majority of the existing homes will form a physical challenge for aging in place. According to the $\mathrm{CMHC}$, many homes do not comply with current building codes and require costly adaptations and modifications to accommodate accessibility needs and safety. The City of Ottawa has implemented an ongoing program to assist seniors with funding for such adaptations however this program is based on household income (i.e. means-tested). The routine home maintenance can be costly 
for those seniors on a fixed income and homes can fall into disrepair and become potentially hazardous. Aside from potential risk to the seniors, the decline in the general state of homes may affect housing prices in the neighbourhood. The City of Ottawa is testing interest and will likely amend the zoning bylaws to enable the construction of 'coach houses' which are secondary units that can be added to an owner's lot, used for income property for seniors ${ }^{13}$ (Figure 6).
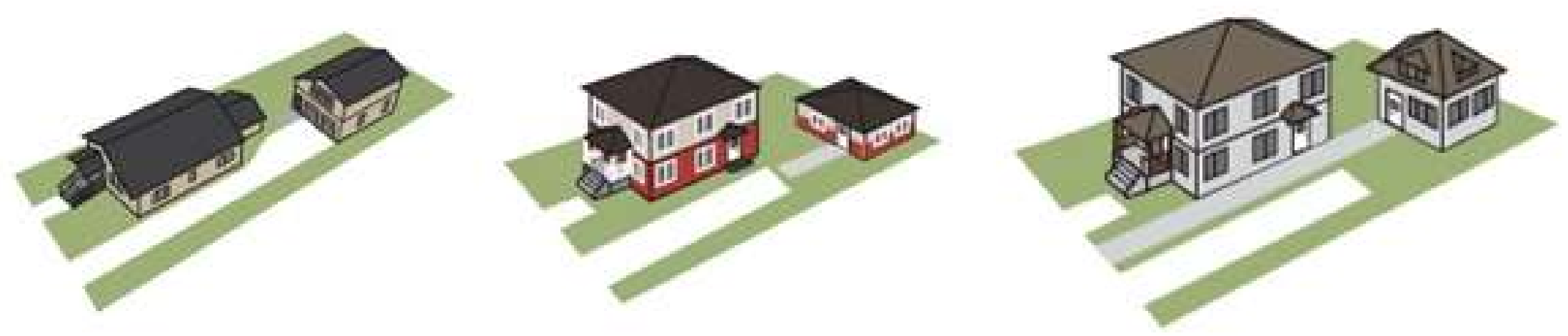

Figure 6. The images provide an illustration of The City of Ottawa's proposal

for 'coach houses' and corresponding placements according to lot types.

Source: City of Ottawa

According to the CMHC survey, $23 \%$ of people aged 55 years and older, would use a secondary unit for an aging family member and $44 \%$ of people in the same age group indicated that they would live in such a unit. 


\section{Long-term care facilities}

Long-term care facilities (LTC) provide a range of residential care, targeted at individuals with advanced care needs. The population in LTC tends to be 75 years of age and older. These facilities are in the main private forprofit enterprises, and until 2010, were unregulated in Ontario. According to the National Seniors Council, there is a shortage of long-term care beds in Canada ${ }^{14}$ According to the City of Ottawa, there is a great demand LTC for seniors. The funding for LTC beds is insufficient relative to the number of seniors that are in need. Between 2007 and 2014 , there was a modest increase by $3 \%$ in Ontario, from 78,001 to 75,863 beds, and 21,500 people were waiting for placement into this form of housing. This lack of funding is having an impact on other parts of the health care system including the capacity of hospitals to carry out routine medical treatments. In the Champlain Region ${ }^{15}$, which geographically includes the City of Ottawa, $34 \%$ of acute care ${ }^{16}$ hospital beds are occupied by individuals waiting for long-term care placement17.

\section{Supportive Housing}

Supportive housing is a generic term describing a range of purpose-built environments combining a range of care services in assisting seniors with the activities of daily living (e.g. meals, cleaning, and laundry). These may be called retirement homes, seniors residences, and nursing homes. This option offers housing for individuals with diminishing physical capabilities. Research suggests that supportive housing is preferred over long-term care facilities ${ }^{18}$; however, in many instances these may be cost prohibitive as the cost in Ontario for a space in such a 
facility is $\$ 2,000$ per month for a low care facility and $\$ 4,847$ for a space in a heavy care facility 19 . The ability to pay supportive housing may force some seniors to relocate to a facility outside of their community that is more affordable.

The architecture of long-term care facilities and supportive housing share similar genetics, in that these facilities are, in the main, rationally constructed to minimize construction costs and - a special concern for publicly funded facilities - to maximize profitability. Functional efficiency is a key design driver that creates warehouse-like spaces for residents and care providers where centralized services are provided. Construction of larger facilities is popular with developers and governments, as evidenced by the lack of questioning or policy overtures that call for a rethink on present seniors housing in government strategy documents. It is fitting to reference Marco Frascari's observations in 'Places for Thinking' that architecture's emphasis on rationality and economy in construction, at the risk of neglecting the quality of spaces that we experience ${ }^{20}$. With that said, well-designed supportive housing examples are emerging thanks to the efforts of architects who are sympathetic to the experience of end users or the quality of spaces people inhabit. Though many of the published works, are given as examples of good design ${ }^{21}$, in the main they replicate a centralized institutional model of segregation of seniors from the rest of the community. 


\section{Health and Social Impact of Isolation and Segregation}

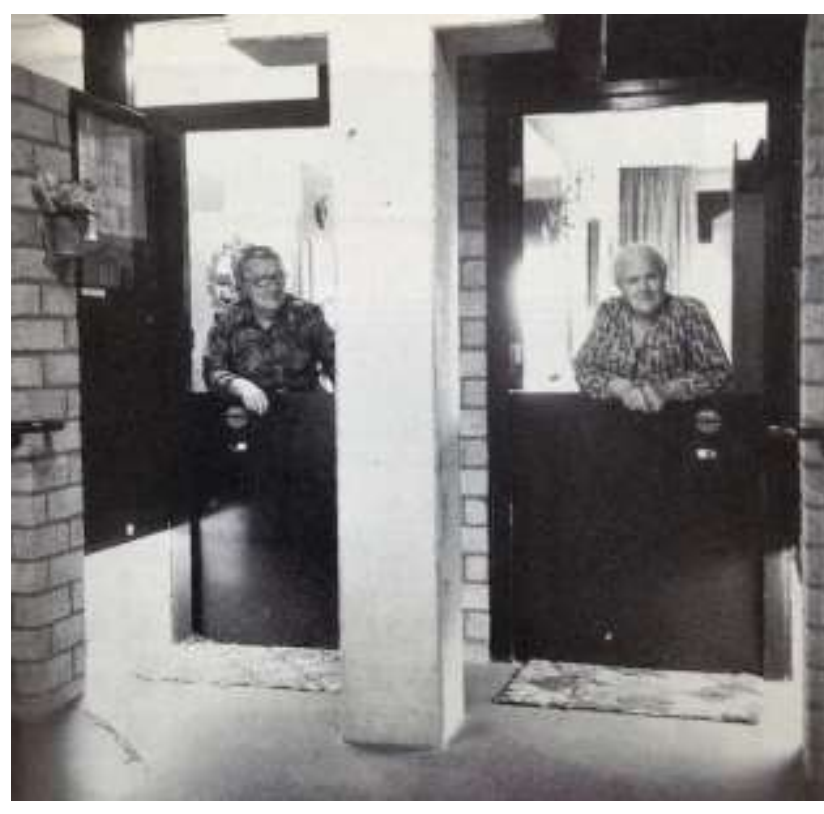

Figure 7

Source: Lessons for Students in Architecture, Herman Hertzberger 1980)
We are social animals and even with the advent of the technological age that aids social connection through the digital and virtual world, we need human-to-human contact. Evidence by research highlights that people with close social networks and strong interpersonal relationships (i.e. regular contact with people with whom one has strong connections or affinity) experience favourable outcomes for health and wellbeing 22 .

A growing body of evidence is also emerging into the experience of isolation and disconnection of seniors leading to negative health outcomes that are associated with conventional choices for aging in place 23 . According to the National Seniors Council of Canada Housing types seem to play an important role in the isolation of seniors. Diminishing social networks of seniors and changes of health and declining physical abilities can lead to less independence and opportunities to connect with others. Household composition, (e.g. a senior living alone) and the lack of contact can lead to feelings of isolation. 
Individuals can feel lonely even in large apartment complexes particularly in those without social gathering spaces 24 . Research demonstrates loneliness and isolation are independent risk factors for mortality - in the same category as smoking ${ }^{25}$. Lonely seniors are more likely to engage in behaviours potentially resulting in detrimental to health and wellbeing, such as addictive behaviours poor nutrition, injury, mental illness, and cognitive decline. ${ }^{26} \mathrm{~A}$ Canadian study reported $44 \%$ of seniors in residential care feel some Ioneliness, isolation, and had symptoms of depression ${ }^{27}$. Simple architectural strategies (Figure 7) can have a significant effect enhancing a sense connection - communicating a desire to connect with others - while maintaining some boundaries of personal space.

\section{Social Currency: Social Capital and Community}

Seniors are an asset to multigenerational communities. Seniors are more likely than young people to volunteer, to give back to communities, and there are opportunities to continue civic engagement through various programs, such as youth mentorship, sharing knowledge, life skills, and lived experience. In this sense, 
seniors contribute the generation of social capital in the communities. Social capital is defined as:

"the network of social connections that exist between people, and their shared values and norms of

behaviour,

which enable and encourage mutually advantageous social cooperation" 28

Social capital is an intangible form of currency. Epidemiological studies have shown that people who live in neighbourhoods with high ratings (i.e. perceived by individual members within the neighbourhood) of social capital are likely to benefit in terms of social outcomes (particularly for individuals with lower levels of income) including physical health, mental health, cognition, and increased community participation ${ }^{29}$. However, the study of social capital is an evolving area of research, and researchers caution us from drawing direct conclusions - e.g. a cause and effect ${ }^{30}$. That said, it can be argued that the policy of 'aging in place' has relied upon social capital, namely the voluntary contributions of friends and family assisting aging in place. 


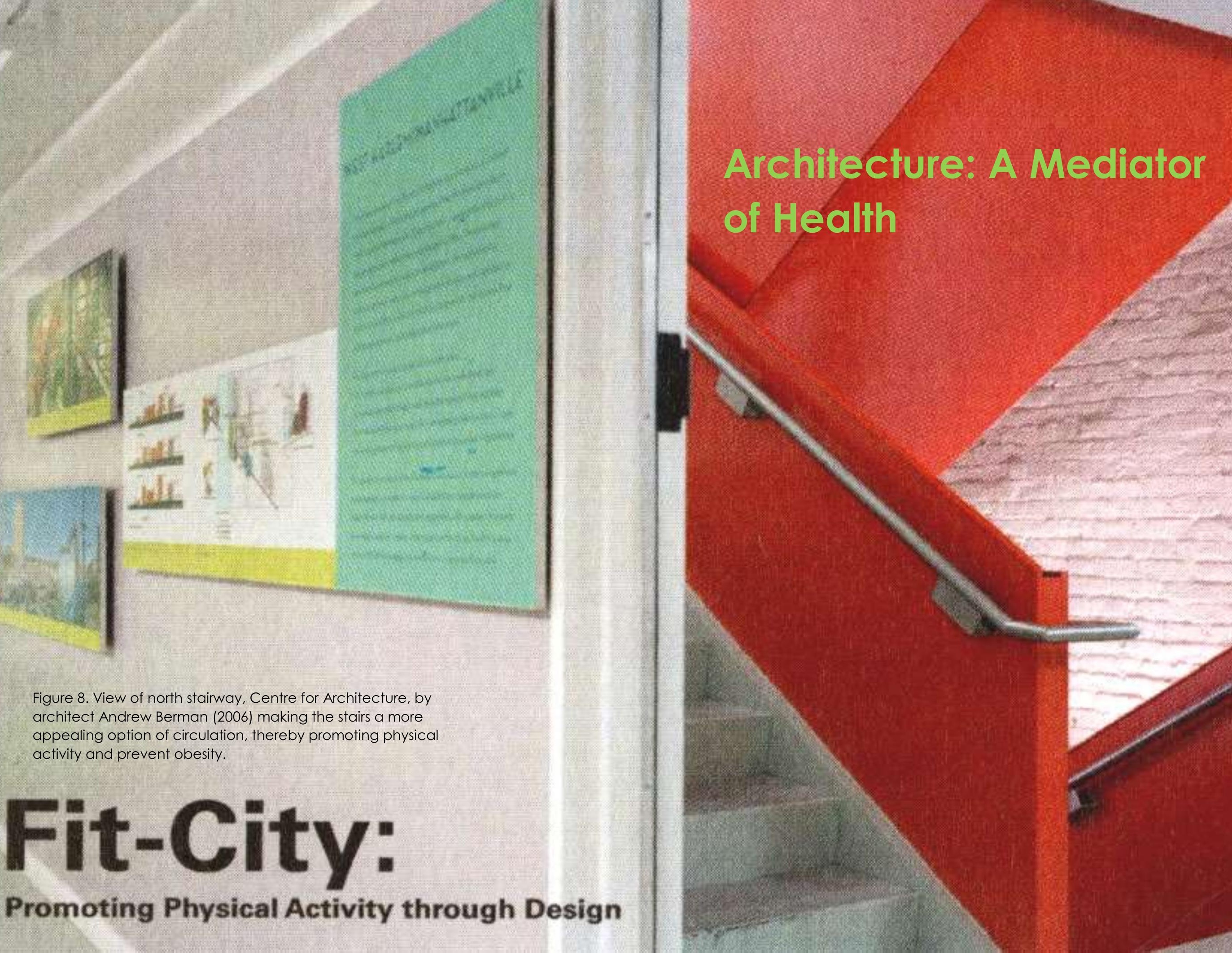





\section{Compounding Factors}

Several factors will play a role in compounding the already challenging current condition of meeting the housing needs of seniors: the demographic shift projected in the proportion of seniors in the population; the socioeconomic forecasts; and the prevalence of ageism in society. It is unclear how others factors such as climate change will affect individual behaviours and needs. As a result, public policy will likely shift focus in the years to come.

\section{Demographic Shift}

The demographic swell in the proportion of seniors is a global phenomenon. The total number of seniors globally (i.e. people 60 years and over) will rise from 901 million (in 2015) to 2.1 billion (by 2050) ${ }^{34}$ (Figure 10).

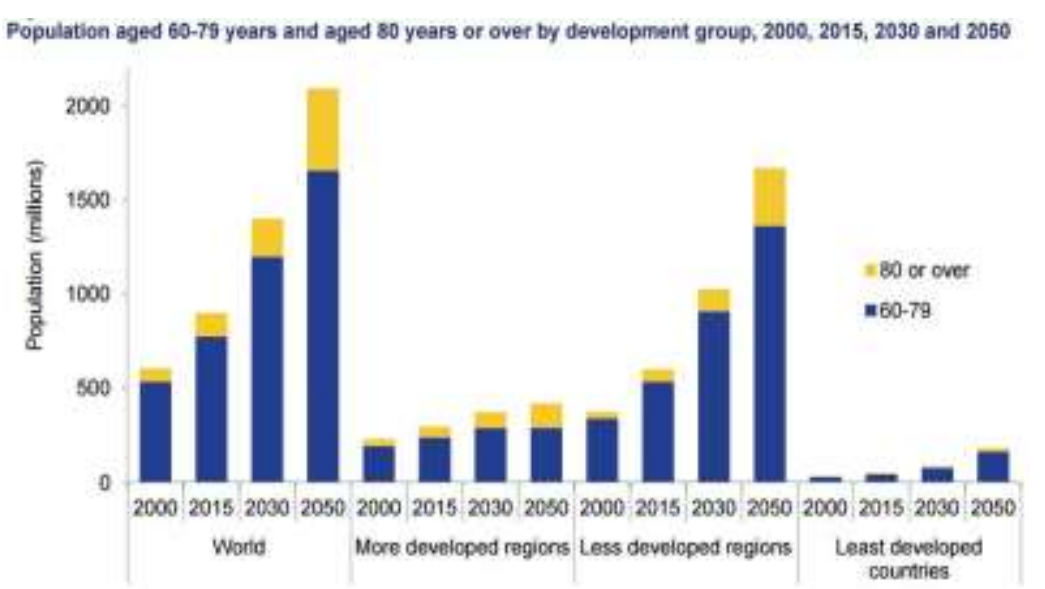

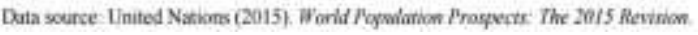

Figure 10: Source: United Nations

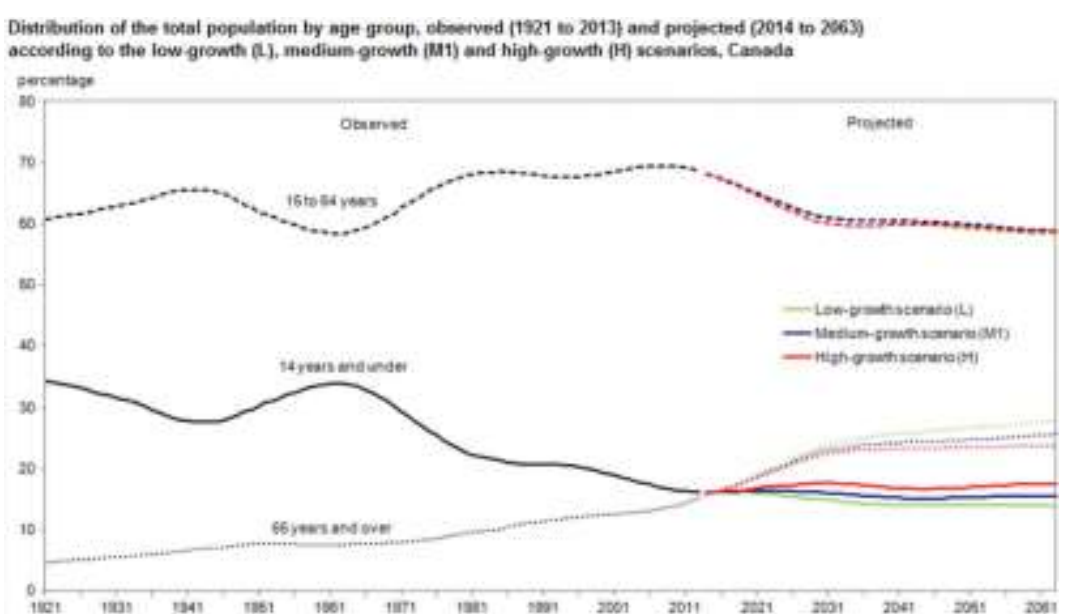

Figure 11: Source: United Nations 
The number of seniors 65 years of age will double and seniors 85 years and older will triple by 2050 . While Canada's population will continue to grow to an estimated 46.9 million by 205635 , attributed to an active immigration program that aims to attract skilled workers, the projected age distribution will change significantly. These projections are based on two growth scenarios: medium and high. The proportion of seniors in Canada will grow from $14.8 \%$ to $25-30 \%$ of the overall population (Figure 11 ).

Ottawa is home to 883,395 people of which 116, 585 individuals are seniors, or $13.2 \%$ of the population (based on 2011 Census data). There are more female seniors than males (14.5\% and $11.8 \%$ respectively) ${ }^{36}$. This represents a growth of seniors by $15 \%$ as compared to $8.8 \%$ of the general population since 2006 . By 2036 the number of seniors in Ottawa is projected to reach 253,95037 (Figure 12).

\begin{tabular}{|c|c|c|c|c|c|c|c|c|c|c|}
\hline & 2011 & 2018 & $\begin{array}{l}\text { Change } \\
2011-18\end{array}$ & 2021 & $\begin{array}{l}\text { Change } \\
2016-21\end{array}$ & 2028 & $\begin{array}{l}\text { Changes } \\
2021-28\end{array}$ & 2031 & $\begin{array}{l}\text { Chenges } \\
\text { 2028-31 }\end{array}$ & $\begin{array}{l}\text { Total } \\
\text { Change }\end{array}$ \\
\hline $45-54$ & 143,520 & 140,210 & $-2.3 \%$ & 133,650 & $-4.7 \%$ & 137,010 & $2.5 \%$ & 150,660 & $9.9 \%$ & $5.0 \%$ \\
\hline $55-64$ & 110,080 & 125,660 & $14.1 \%$ & 139,760 & $11.2 \%$ & 137,280 & $-1.7 \%$ & 131,610 & $-4.1 \%$ & $19.6 \%$ \\
\hline $65-74$ & 63,210 & 84,190 & $33.2 \%$ & 102,710 & $22.0 \%$ & 118,530 & $15.4 \%$ & 132,910 & $12.1 \%$ & $110.3 \%$ \\
\hline $75-84$ & 37,510 & 41,990 & $11.9 \%$ & 52,180 & $24.3 \%$ & 70,400 & $34.9 \%$ & 86,820 & $23.3 \%$ & $131.5 \%$ \\
\hline $85+$ & 17,430 & 19,890 & $14.1 \%$ & 22,630 & $13.8 \% \%$ & 26,500 & $17.1 \%$ & 34,220 & $29.1 \%$ & $96.3 \%$ \\
\hline $65+$ & 118,150 & 146,070 & $23.6 \%$ & 177,520 & $21.5 \%$ & 215,430 & $21.4 \%$ & 253,950 & $17.9 \%$ & $114.9 \%$ \\
\hline
\end{tabular}


The proportion of seniors aged $75+$ is expected to reach $52.4 \%$ of the overall seniors population (Figure 12) which is a very significant factor for housing choices and needs that have been shown to be age-dependent38. Increasing levels of care and support associated with declining health are the primary reasons affecting housing decisions.

\section{Ottawa's Aging Population and Diversity}

Ottawa is increasingly diverse (i.e. gender, sexual, cultural, ethnic, and socio-economic). The projections for different population sub-groups will increase at different rates and likely reflect various needs and housing options.

\section{Socio-economic Reality and Affordable Housing}

Half of all seniors in Canada will face significant financial hardship due to inadequate retirement savings and will need of government assistance in old age ${ }^{39}$. There are 40,000 households (in Ontario) waiting for rent geared to income, $25 \%$ are seniors ${ }^{40}$. In Ottawa, there are 630,000 social units, one-third of which occupied by seniors. The average wait time for a subsidized unit, according to the

\begin{tabular}{|l|ccc|}
\hline & 2031 & $\begin{array}{c}\text { Growth } \\
2011-31\end{array}$ & $\begin{array}{c}\text { Growth } \\
\%\end{array}$ \\
\hline Population 65+ & 254,000 & 135,900 & $115 \%$ \\
\hline Immigrant & 77,400 & 40,000 & $106 \%$ \\
Francophone & 47,600 & 26,000 & $109 \%$ \\
Aboriginal & 3,300 & 2,700 & $415 \%$ \\
On low income & 15,700 & 8,300 & $113 \%$ \\
With disabllities & 44,500 & 24,000 & $116 \%$ \\
Living in rural area & 30,900 & 20,000 & $183 \%$ \\
\hline
\end{tabular}

Source: Hemson Consulting, 2010

Figure 13. Population Projections, Sub-Groups of Seniors populations 2011-2031, Source: City of Ottawa Report "A portrait of older adults: demographic and socioeconomic characteristics" (2011) 
City of Ottawa official is $-/+5$ years, and there are 10,000 households waiting for placement. Many of these units require upgrading and adaptations to meet new building standards (such as accessibility) and to meet the needs of seniors wishing to age in place. The City of Ottawa provides a home renovation program to support eligible seniors. ${ }^{41}$ However, if the abovementioned economic forecast is realized more affordable housing units for seniors will be required.

\section{Can the public purse cope?}

A rise in public expenditures for health and social service associated with seniors is expected. Concern is expressed about the capacity for governments to afford these costs 42 . Changes to transportation (such as new routes, stop locations, and schedules that work best for seniors will need to be included), urban planning (comprising land use priorities, zoning, bylaw changes for accommodations and modifications to existing housing stock), and infrastructure investment (such as senior friendly sidewalks) will be required 43 . The municipality pays the larger amount of

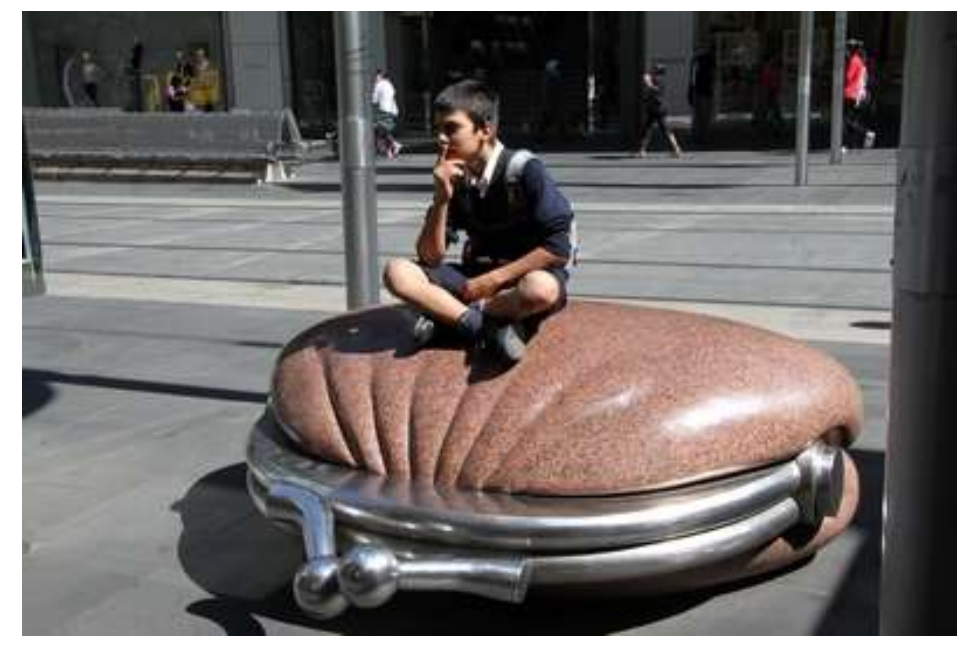

Figure 14. The Public purse, Installation by artist Simon Perry (1994) as seating, was a commentary on competing demands and public expenditure on the Arts. Source: Unknown 
housing assistance through municipal property taxes. The present $\$ 2.4$ billion spent on home care support is expected to rise within the next two decades ${ }^{44}$. The $\mathrm{CMHC}$ reports that the level of disability among seniors increases with age. One quarter of seniors aged 65-74 years, have significant mobility problems, which increases among seniors aged $85+$ to $30 \%$. Falls account for $80 \%$ of hospitalisation of seniors 45 . The Government of Ontario is concerned about possible bankruptcy if it does not manage to contain the issue ${ }^{46}$.

In 2005, per capita healthcare spending was the highest at the beginning and end of life but, in general, it also increased exponentially with age. While 65 - to 74 -year-olds consumed $\$ 6,000$ per capita, those seniors 75 to 84 and $85+$ consumed $\$ 11,000$ and $\$ 21,000$ per capita respectively. By comparison, for those aged 1 to 65 years, the average per capita healthcare spending $\$ 1,700$. The increased public spending will likely result in increased taxation - property, business, and income taxes ${ }^{47}$ as well as cuts to programs and services. The degree to which the seniors housing needs is prioritised from the public purse (Figure 14), remains to be seen given many competing interests.

\section{Who will be able to provide care and support?}

Labour force participation is also expected to change. The Canadian workforce is projected to decline to $60 \%$ of present day levels by 2030. In 2006 there were five working-age people (i.e. aged 20-64 years) for every one senior. This is to result in a projected decline to two working-age people for every one senior by $2056^{48}$. A decrease in the workforce of this magnitude raises the question: How will sufficient government revenues be generated (i.e. from personal and business taxes) to pay for the care and support of the aging population? Who 
will provide this support? The indications are that many baby boomers do not wish to retire at 65 years of age, which will result in fewer jobs opportunities for younger generations that retirement would have created ${ }^{49}$. The 'Old-Old' family structure has steadily changed over time. Unlike their parents' generation, baby boomers have been less likely to marry, and have had fewer children (if any at all). This will likely impact the capacity for informal supports (e.g. family and friends) 50 . 


\section{A longer, but is it a better one?}

The evidence is that life expectancy has risen and is expected to rise ${ }^{51}$. Life expectancy in Canada is 81 years (women) and 78.8 years (men) in 2009, as compared to 61 and 59 respectively, in $1922^{52}$. The question above will evoke an entirely subjective response. It seems our genetic disposition to age is inconsistent with our idealized body image of self. According to Ivan Illich, individuals are obsessed with the prevention of their deaths, perpetuated by a structural apparatus that continues the fight against aging (e.g. institutions, the market place, policies, programs, and services) ${ }^{53}$. In commerce, for example, the global market value of anti-aging consumer products is projected to reach $\$ 191$ billion by 2019 , purported to generate an average return of $7.8 \%$ to its investors 54 .

In other words, we value youthfulness and these seem only to exist in the young, which inversely reinforces prejudicial attitudes toward aging (i.e. ageism) and treatment of the aged.

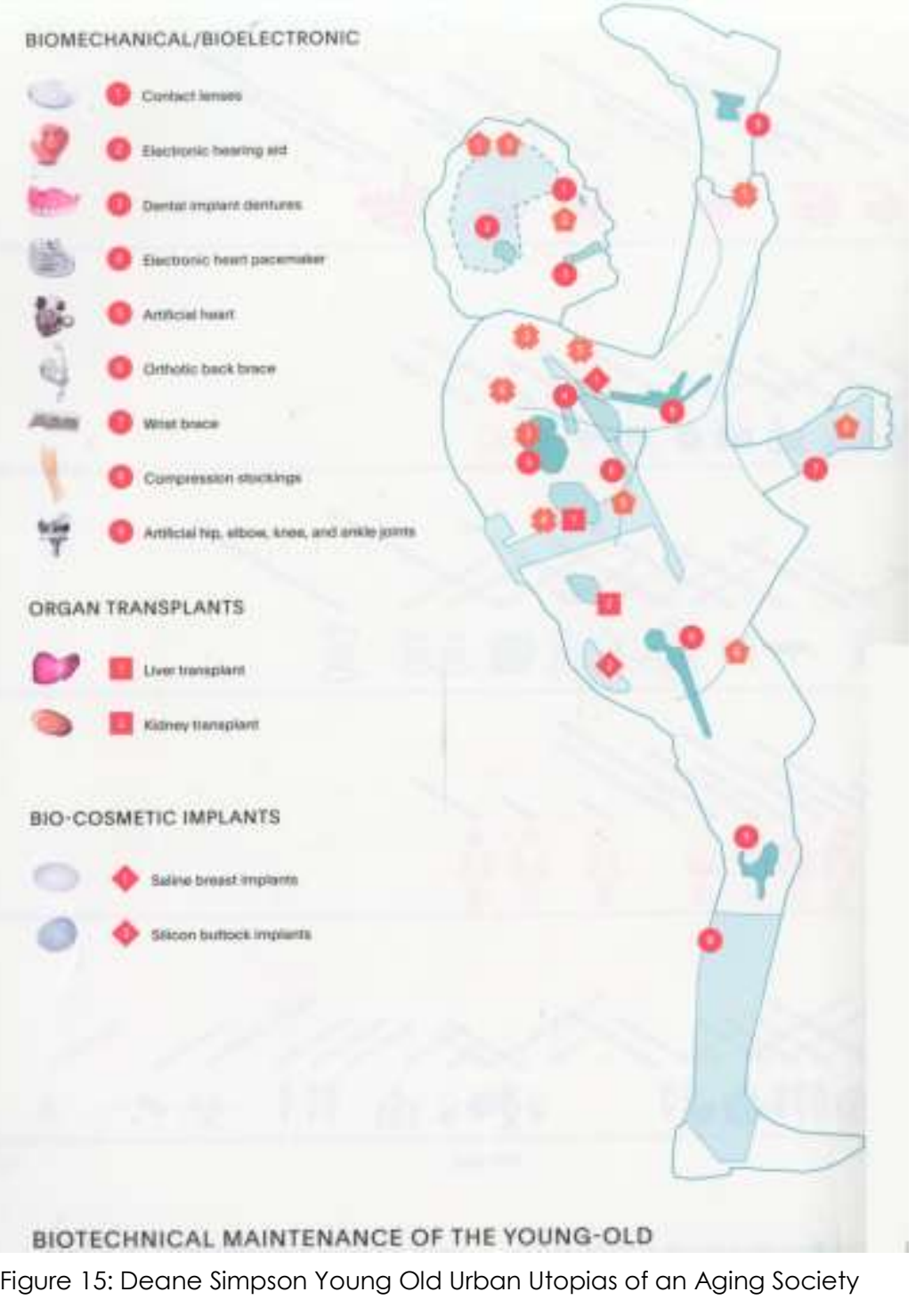


Living longer may not necessarily directly translate to living better than the previous generation. For example, seniors will often develop chronic illnesses as they age, which has a compounding impact on health and capacity for self-care. Those living longer may also have to cope with often debilitating effects of chronic illness that affect quality of life 55 , while contending with other social factors that add to the burden of life experiences such as the pervasiveness of ageism. Is living longer living better?

\section{The Impact of Ageism}

Ageism is described as:

a) Discrimination against persons of a certain age group; and,

b) A tendency to regard older persons as debilitated, unworthy of attention, or unsuitable for employment 56

Ageism is alive and well. In fact, research suggests ageism is the most tolerated form of discrimination in Canada $^{57}$. Given its prevalence in society, it is likely a factor influencing public policy and financial investment decisions associated with housing seniors, programs, and services. According to the Ontario Human Rights Commission, seniors face levels of prejudicial treatment in their everyday interactions with other individuals, service providers, institutions, and the government. In spite of a body of research spanning 30 years providing the necessary evidence to address this serious social issue, it seems to have produced a 'backfire effect' 58 or fallen on deaf ears. A consistent theme within theories on ageism is that contact with the elderly - or issues related to elderly - reminds people of their own mortality. In response, internal fear of death forces people to create a 
psychological distance any associated issue. Stereotyping and marginalization of the aged allows the structural, social, and cultural mechanisms that enable ageism to continue ${ }^{59}$. Juhani Pallasmaa suggests the architectural use of non-traditional construction materials, that do not provide any indication of decay with time, may be associated this fear of death60. Pallasmaa is really arguing that the use of traditional materials (i.e. consistent with our biological norms) produces a psychosomatic effect - we relate to the material with our bodies. Architecture can find a balance in building sustainably and accepting aging as a factor of time in construction through the disposition of natural elements and architectural details that we experience directly - that is, through our bodies.

\section{Old-Old Construction Trends}

In spite of changing demographics, the residential development market continues to replicate past behaviours. In Ottawa, condominium and rental development constituted 55\% of the overall residential construction completions in $2015^{61}$. The CMHC is calling on the public and private sectors to collaborate in order to find innovative approaches and to increase the range of housing options for seniors, including design solutions that respond to the emerging research ${ }^{62}$. Urban planning and policy needs to be examined at more critically, especially as developers seem to be replicating construction patterns. This critique is not unique to Ottawa. The lack of a proactive response to the anticipated needs among planner and urban development in the United States has been strongly criticised by Deane Simpson ${ }^{63}$. This shifting demographic and socioeconomic landscape will undoubtedly be a catalyst for shifting societal attitudes toward aging, including housing and tenure options. 
The City of Ottawa's Official Plan articulates priorities for land use and development. In an effort to contain public expenditure on growth management, to provide infrastructure and ensure quality of the environment, the city aims to prevent urban sprawl and has prioritised urban intensification. Mixed use developments are favoured as supporting 'Building Liveable Communities' to facilitate urban regeneration and renewal initiatives meeting a diverse range of population needs and providing the space to live, work, and play within communities ${ }^{64}$. This seems to make logical sense as it has the potential to reduce the need for motorised transportation, promote active transportation, encourage small business development, and build a sense of community. This policy direction promoted a flurry of condominium development initiatives in Ottawa, to the point where, according to City of Ottawa officials, this segment of the housing market became saturated (i.e. developers overestimated the demand for condominiums) ${ }^{65}$. Anecdotal evidence is that there is now a shift toward developing rental properties, though hard evidence needs to be obtained to support this observation ${ }^{66}$.

However, seniors are frustrated with the current development in the city as indicated by remarks made at an Age Friendly Ottawa meeting, by a representative of the Ottawa Seniors Council:

"...The City seems to be committed to municipal design criteria which best facilitate architectural plans of commercial property developers...." 


\section{Supportive Housing Boom?}

\begin{tabular}{|c|c|c|}
\hline \multicolumn{3}{|c|}{ Ten Largest Senior Living Operators - } \\
\hline 1 & Revera & 22,631 \\
\hline 2 & Chartwell Seniors Housing REIT & 19,703 \\
\hline 3 & Maestro (operated under Allegro) & 7,136 \\
\hline 4 & Extendicare & 11,851 \\
\hline 5 & El Ad (operated under Cogir) & 7,700 \\
\hline 6 & Diversicare & 4,719 \\
\hline 7 & Leisureworld & 4,396 \\
\hline 8 & Group Savoie & 4,048 \\
\hline 9 & Holiday Retirement & 3,871 \\
\hline 10 & Retirement Concepts & 3,426 \\
\hline \multicolumn{2}{|c|}{ Total Top Ten } & 89,481 \\
\hline \multicolumn{2}{|c|}{ Top 10 , as a $\%$ of the entire market } & $25.8 \%$ \\
\hline Entire $\mathrm{Ca}$ & adian Senior Living Industry & 347,000 \\
\hline
\end{tabular}

Entire Canadian Senior Living Industry Source: Altus Group

Figure 15. Table showing market share by operator in Canada.
The indications are that the retirement home companies are embarking or planning on major developments to respond to the growing seniors population. Supportive housing is seen as opportunities for profit. The excerpt below is taken from a presentation to the developers in the Canadian Home Builders Association in June 2012, presumably to stimulate interest in the seniors housing market where long-term care was seen as less "elastic" client movement:

"LTC tends to be a more homogeneous product, with a needs-driven demand. Given the frailty of residents in an LTC environment, they are less likely to relocate to a competitor. Conversely IL, ISL and AL homes differentiate based on offering the best customer experience value proposition. Consumers are price sensitive" 67.

The subtext of this statement seems to be that individuals in LTC will put up with anything and will continue to use the "product" regardless of the service quality - hence making a sound investment opportunity. Taken from an urbanism perspective, the clustering of seniors into these residential facilities facilitates the marginalization of seniors form multigenerational communities as well as a division of seniors by virtue of income status - "a societal distortion caused by specialization, mechanisation and institutionalization of old-age"68. The retirement 
residence industry generates significant profits for shareholders. Ross Marowits, a journalist with the online Canadian Business Journal, reports that CEOs of retirement homes are expecting a development boom. Chartwell Retirement Residences, for example, is among the top 10 largest supportive housing providers in Canada (Figure 15).

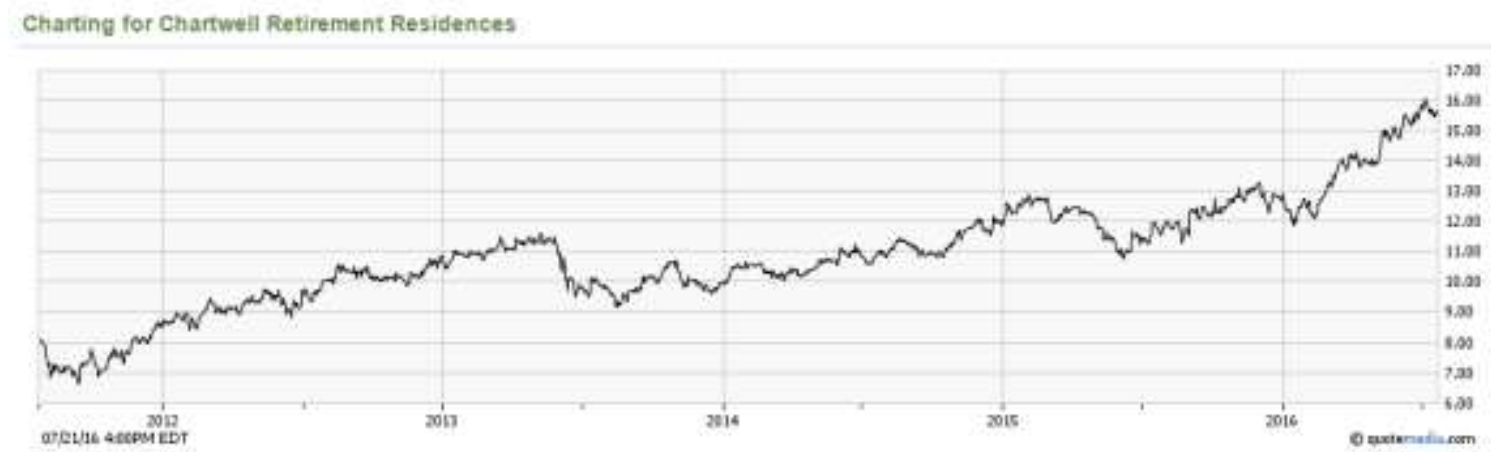

Chartwell's share prices have increased gradually within the last five years (Figure 16). Given the potential profitability of such enterprises, it can be argued that the tried and tested option since 2008 has been regulated, in Ontario, and an entire management system of operations and support services has been established. There is no intention to demonize this housing sector. Many seniors find residential homes a housing option that is appropriate for their needs. The issue is the lack of alternate options and the sustainability of present housing models. 


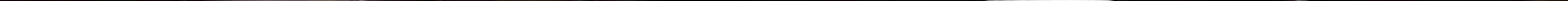




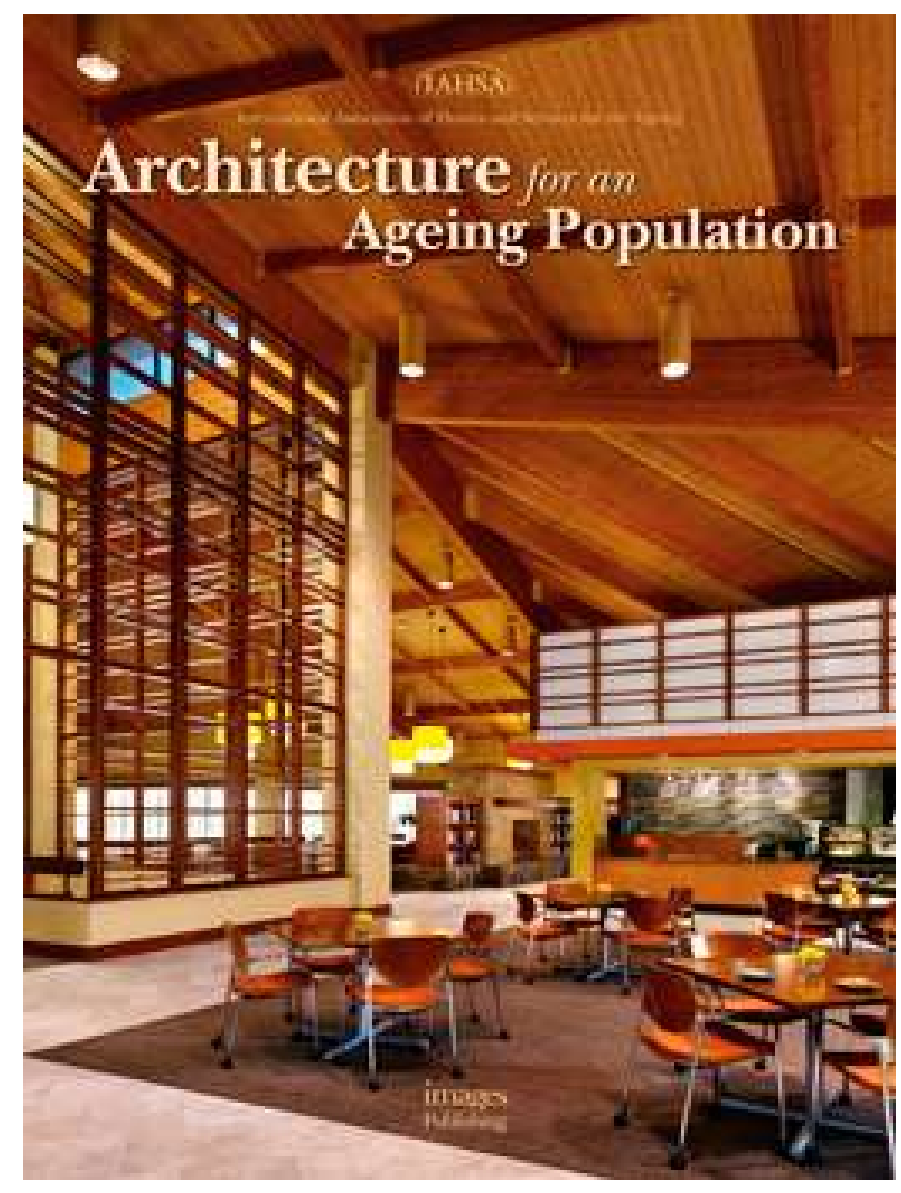

Architecture has an important role in assisting with this policy implementation with imaginative designs that respond to needs.

Earlier evidence of the relationship between architecture and health was established. In this segment, the focus will turn to architecture and the aging population, namely to explore what is emerging in the field of practice.

The International Association on Housing for the Ageing is a nonprofit charitable organization that has produced several publications to disseminate these as samples of good practice to stimulate design interest, research, and advocate for change in housing and services that enhance the quality of life for the aging population ${ }^{69}$. In the 2014 publication, 23 different housing projects were presented as examples of good practice.

Architectural bodies are also taking action to stimulate thinking in this area through competitions and dissemination of innovative practice. 
Figures 19-21: A sample of numerous books published to disseminate good practice and stimulate a shift in architectural responses meeting the housing needs of the ageing populations.

Figure 22: Work at the MIT AgeLab the development of the 'Age Gain Now Empathy System'

This is a suite that restricts movements and senses to gain better insights into the experience of seniors to assist design.

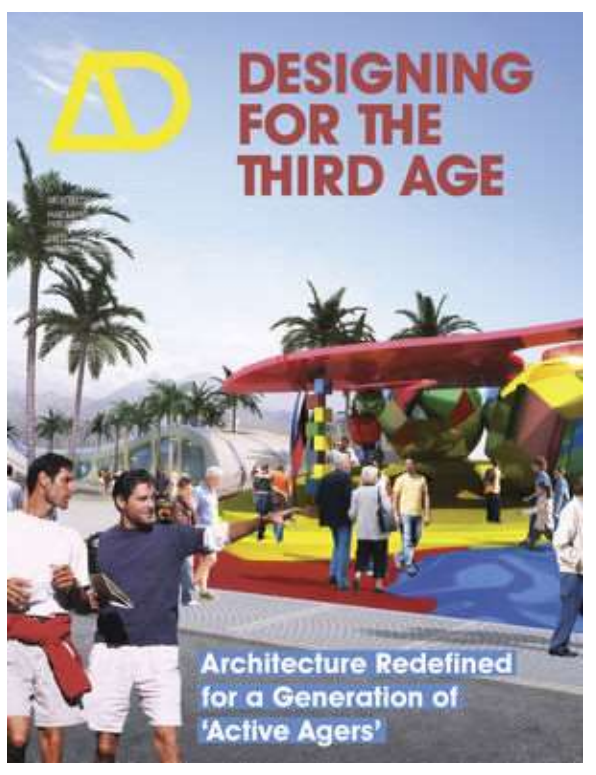

Figure 19

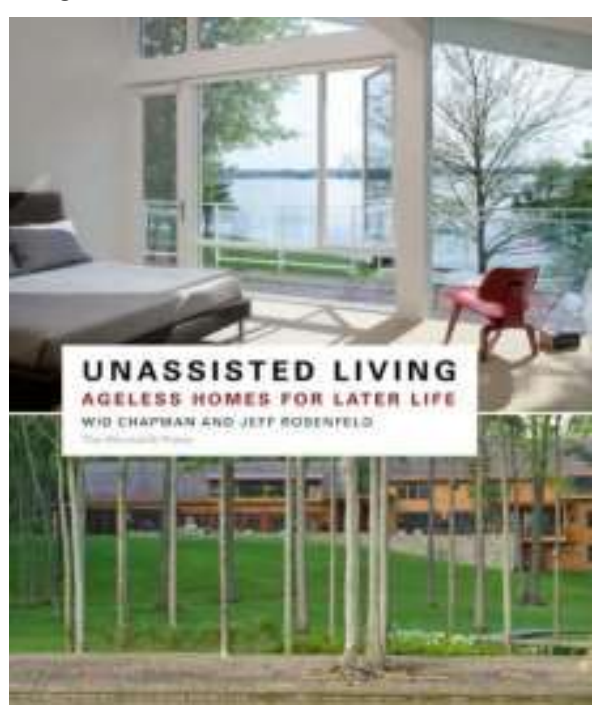

Figure 21

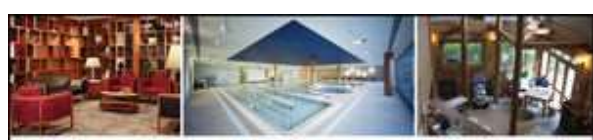

EFFREY W ANDERZHON, IA . DAVID HUGHES, STEPHEN JUDD, AD - EMI KROTA, NO - MONIQUE WINTTEES, *OT

\section{Design for Aging}

INTERNATIONAL CASE STUDIES

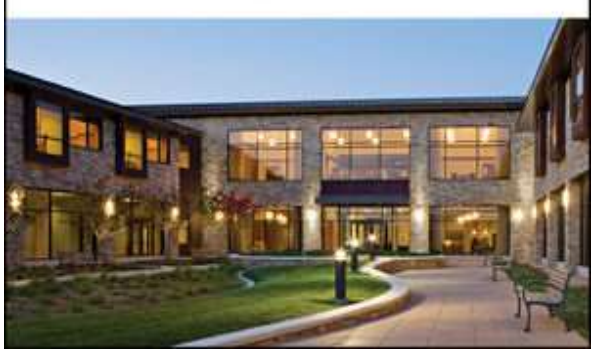

Figure 20

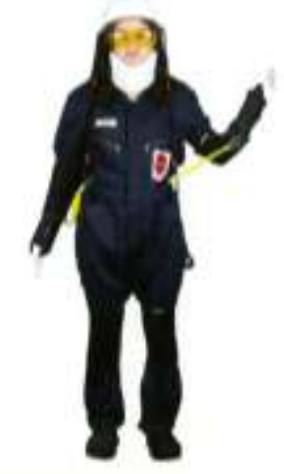

By 2050, for the first time in history there will be more seniors than children on earth.

Figure 22 
Architectural Design, devoted an entire edition to seniors housing, entitled 'Designing for The Third Age' in 2014(Figure 19). A body of international architectural design work on housing for seniors was featured including emerging ideas 'ageing' Design Challenge 2012, hosted by Melbourne University, related to dementia and architectural strategies for strengthening communities.

Scholarship and research in architecture, industrial design, and engineering have increasingly been focused on designing for the elderly - these have largely concentrated on: evidence-based design; related spatial and functional organization; accessibility and ergonomics; and advancing building standards. MIT AgeLab (Figure 22) has developed 'AGNES' (Age Gain Now Empathy System) to gain insights into the limitations imposed by age-related physical degeneration. Research initiatives are beginning to occur between neuroscience and architecture to gain better insights into the functional mechanism of the aging brain and develop evidencebased architectural design strategies that adequately respond to naturally declining senses (e.g. Brain Landscape, The Coexistence of Neuroscience and Architecture, Brian Eberhard's 2009). 
Architectural design guidelines are being developed as a result of cross-disciplines collaboration and research leading to evidence-based design for aging people and age-related to disease such as dementia - way-finding strategies to prevent cognitive strain, confusion and anxiety $^{70}$ (Figure 23).

Building codes are updated on a cyclical basis and have been revised and continue to be reviewed to ensure accessible design is implemented in new buildings. Dwell (Designing for Wellbeing in Environments for Later Life) is a research project, led by Architect and academic, Sarah Wigglesworth, who is challenging the role of building codes and aging, Wigglesworth is: advocating for a shift for codes to include both life-safety issues in building performance standards, as well as quality of life factors - a more aspiring approach that supports well being (Figure 24).
Approsch to the dwelling

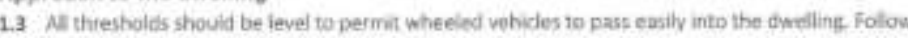
tre guidance given in $A D_{-} M$

1.4 Externat entrance threshoids to dwellings strall prowide sufficient space to allow for parsonalication. They shat be generous enough to prowide a pace to fest, to chat to nezinbous theiler frotn the weanther and irow plants: if possible they sbouid provide sufficient apace to itore and charge a motsity wehicies.

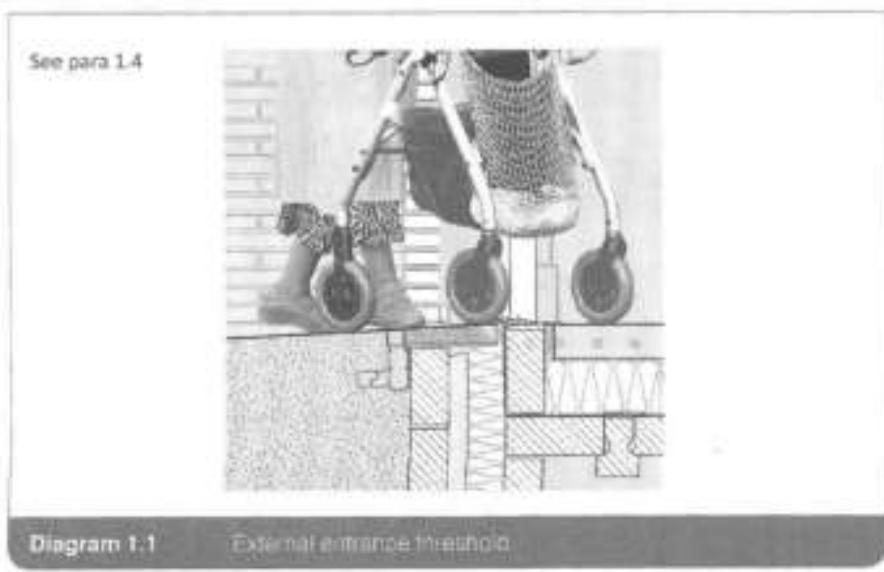

Figure 24 Demonstrating an age-friendly threshold

for a new building standard, in Unapproved

Document $O$ : Designing for Ageing, Sarah Wigglesworth 2016 
Building standards are continually amended in line with new research and advances in construction. Driven by human rights legislation, accessibility has become a key focus in building codes, which fall, in the main, under the jurisdiction of provincial governments in Canada. Accessibility in the Ontario Building Code was amended in $2013^{71}$ for example. However, these not only represent 'minimum' standards, but they also focus on physical needs of inhabitants and do not include broader quality of life factors of dwelling. Evidence emerging from epidemiological72 studies show that falls on stairs are a major cause of injury and harm for seniors. Falls from stairs

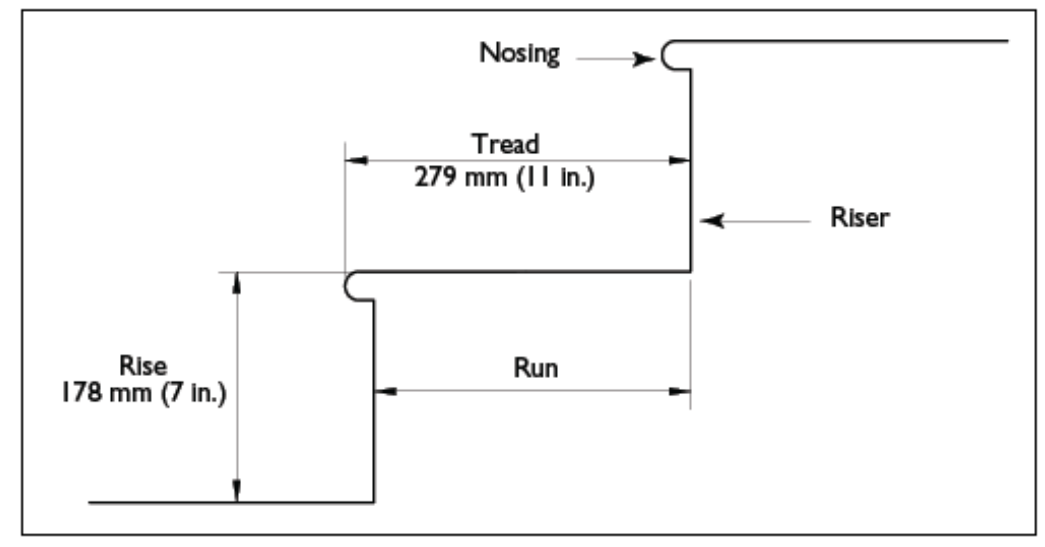

Figure 25:

Recommended for

new stair

dimensions

reported by $\mathrm{CMHA}$

are considered to be the second most significant 'driver of costs' in Canada, estimated to be $\$ 695$ million annually ${ }^{73}$. This does not include indirect costs such as productivity and loss of income, or the psychosomatic impacts. In 2014, the Canadian Commission on Building and Fire Codes accepted recommendations to increase the minimum tread width of stairs from 8.25" to a minimum of 10" as a strategy to prevent injuries from falls among seniors. A modification in this way will have financial implications for construction - additional materials and floor space allocated to vertical circulation and ultimately will eat into the bottom line of development projects. 
However, it fell short of the evidence-based minimum recommended depth of 11 "74 (Figure 25). The old idiom "an ounce of prevention is worth a pound of cure'75 often cited in public health, is one that is hard to argue against within this context. However, it might be difficult for architects to argue for the additional costs associated with deeper stair treads to their clients (i.e. the developer) with whom architects have an ethical-legal duty. Rather than providing a minimum, if building codes provided a range - from minimum to preferred depths - and referenced this with evidence, architects would have a stronger case for better design.

Publications of architectural projects are emerging, showcasing innovative, consumer-oriented design solutions for seniors residences including the involvement of the residents in the design process. ${ }^{76}$ These illustrate: sensitivity toward designing for a human scale; the use of material palettes that are intended to lead to positive outcomes (e.g. natural materials); attention to spatial accommodations that meet a variety of needs from independent living to high degrees of care; and enhancing spatial qualities and experience through traditional design strategies (e.g. optimising the use of natural light, orientation of buildings, connections to nature).

There also seems to be an increased level of attention to the potentially lucrative business and development opportunities of responding to the demographic shift, including new technologies addressing isolation and safety, such as connectivity and accessing to social media, occupant alert and monitoring systems, as well as exploring the use of artificial intelligence. 
This thesis acknowledges the potential market trends responding to consumer needs, and challenges the 'developer's view' with the intent to engage residents who may have a say in the design process towards creating engaging social environments for aging in place.

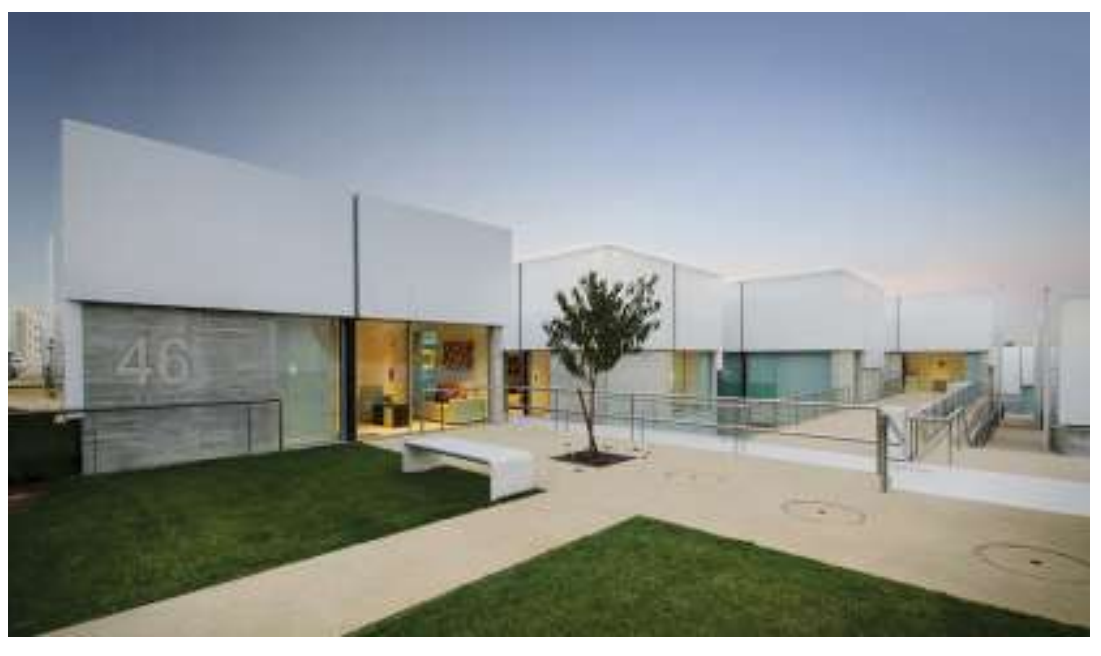

That said, as it would be a concern if 'demand giving way to supply77' of such services and consumer products, we see a different kind of pseudo-reality of needs and conflicting interests.

A shift in thinking is occurring and architectural projects that consider the needs of seniors for a better future is beginning to emerge. Azure Magazine devoted a significant portion of its September 2015 issue to showcase seniors related architecture and technologies including the work of a Toronto based architect's forever home for aging in place; ergonomically correct seniors products; and futuristic seniors homes (Figure 26). 
The Royal Institute for British Architects (RIBA) recently sponsored a competition for retirement communities that foster "mutually supportive community" and creative design (Figure 27 and 28).

These proposals seem to replicate historical notions of the segregated retirement communities - a voluntary segregation of seniors into singular locales where seniors may provide peer support to one another and an ability to deliver targeted services much like institutional residential settings mentioned earlier. This is a phenomena that Deane Simpson has identified as a problematic urban planning approach in North America ${ }^{78}$. Little focus is noted in the architectural discourse on alternative options for housing seniors - models that embrace the inclusion, collaboration, and connections within intergenerational communities.

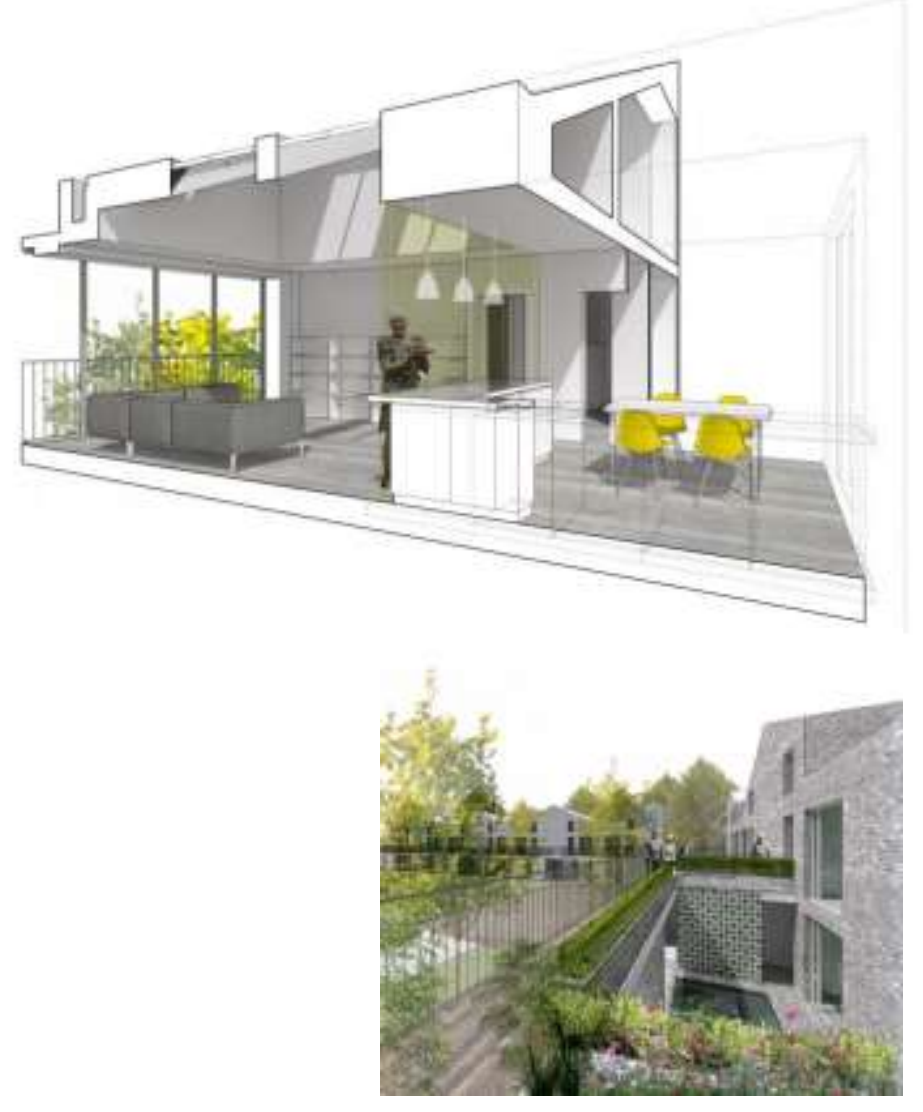

Figure 27 and 28

RIBA Competition Winner for retirement homes,

Emmet and Russel Architect. 
There are several questions that need to be posed in this regard. What expectations will the future cohort of seniors have for housing? Will the next generation of seniors demand that legislators, policy makers, urban planners and developers strike a balance between the minimum requirements that address the physical and environmental needs, with the psychosomatic health needs as dwelling requirements that aspire for optimal habitat for aging? Who will advocate for them then and who is advocating now? This would surely include spaces that are flexible and adaptable to changing needs, and facilitate a social connection and engagement between inhabitants and their communities. Cohousing is a marginal housing model that claims to respond to, at the very least, the emotional health of inhabitants. We will now examine the cohousing characteristics and approaches to understand what makes cohousing work and what lessons can be learned that inform architectural practice. 


\section{Part 3. What is cohousing?}

According to the Canadian Cohousing Network cohousing is defined as:

"....neighbourhoods that combine the autonomy of private dwellings with the advantages of shared resources and community living"79.

Individuals and families become involved in cohousing as they wish to live in purposeful communities in which there is a strong sense of social connection, community collaboration and mutual support80.

Cohousing has a long history in Denmark. The architect Jan Gudmand-Hoyer led the concept circa1965, and other architects followed suit, purportedly out of frustration with available housing options based on public and utopian ideas of collaborative communities.

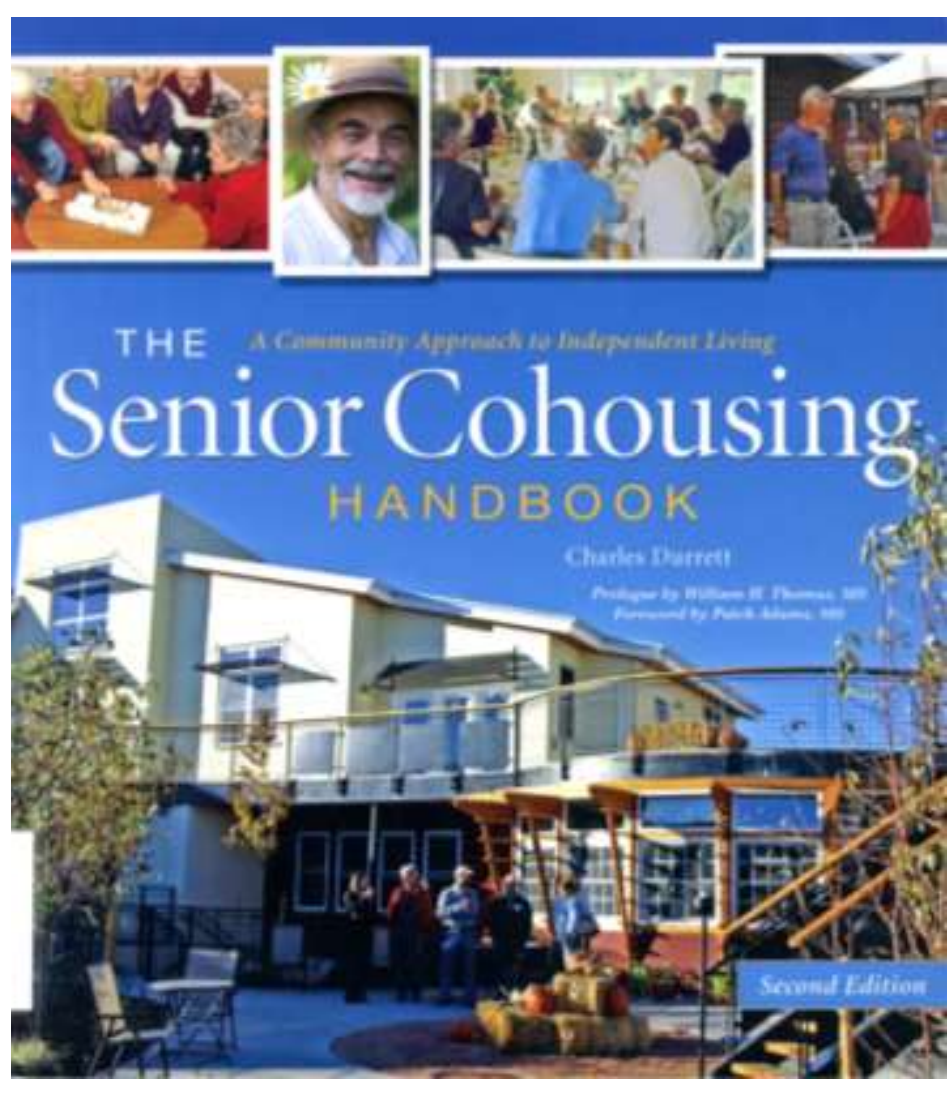

Figure 29: Front cover of Charles Durrett's Book on cohousing 
By the 1980s there were approximately 20 projects in Denmark, including one that consisted of a rental cohousing complex, and these are examples for housing strategies in large-scale housing developments ${ }^{81}$.

Architect Charles Durrett, who studied cohousing in Denmark, introduced this housing model to North America circa 1980. There are approximately 220 completed projects, including seniors cohousing. A number of these are included in a guide to cohousing for a book published by Durrett (Figure 29). Cohousing is also appearing in Canada, including 13 seniors cohousing communities in British Columbia, Alberta, Saskatchewan, Ontario, Quebec, and New Brunswick.

\section{Characteristics of Cohousing}

Cohousing has no particular architectural typology per se. Development projects can range from adaptive re-use of existing buildings, multi-level, row homes, and single-family homes, or a composition of several different dwelling types.

Projects are purpose-built including site planning and custom designed buildings. Housing units (typically 10-20) tend to be small and efficient, as 
larger common spaces are multi-purpose and meet programmatic needs.

Facilitated usually by an architect, all designs, from inception to completion, involve a collaborative process, where residents are authors of a collective vision of site, dwellings and spatial organisation.

Governance and ongoing management of cohousing communities are non-hierarchical and consensus-based rules are generally established in cohousing communities. However, these rules may not be rigid and can be modified to meet changing needs. Shared ownership (in financial and legal terms) is more common in cohousing communities. Several communities also include rental units, often at below market prices.

Spatial composition seems to share a pattern of private dwelling units and common spaces, such as: a shared cooking and dining rooms; social and recreational spaces (typically referred to as the common house): amenity rooms (laundry, workshops, etc.): and common gardens. These are typically arranged to foster a 'community feel' and hence spaces for gathering and interaction is an important spatial design consideration 82 .

\section{Advantages of Cohousing}


Cohousing is reported to provide economic, social, and environmental advantages to the cohousing residents. In financial terms, costs associated with planning, design, and development is shared between the initiators of the development. Construction is delivered 'at cost'83. Ongoing maintenance is shared - in much the same way as a condominium - by the owners. Routine maintenance can be collaboratively carried out by residents. In ecological terms, Charles Durrett suggests cohousing projects have the capacity for reducing energy consumption and the carbon footprint. First, private units are typically $10-15 \%$ smaller than conventional dwellings as common spaces provide the additional space for programming. Second, economies of scale can result from collective activities such as cooking and cleaning. In addition, these developments are not profit motivated and are concerned with long-term sustainability. Hence, designs tend to opt for sustainable materials, design strategies, and building systems that keep operating and maintenance costs as low as possible. Perhaps more significantly, a high degree social connection,

collaboration and mutual support are consistent themes of cohousing communities. Single parent families, aging people and women tend to find the social support (i.e. capacity to generate social capital) and have been shown to find the community orientation of cohousing particularly beneficial. 
Consensus decision-making is a key feature of processes and operations.

Cohousing populations can consist of multi-generational populations, people of different social, economic, and cultural backgrounds, but for the most part they typically share common values and desires for community.

\section{Positive Health Impact of Inclusion and Participatory Design}

Among the many benefits of cohousing is the notion of inclusiveness and engagement of all participants. A recent study found that Involvement by seniors in design process can yield positive health and social effects, including improved cognitive skills and active participation in the use of facilities - this suggests ideas of self-worth and self-efficacy as well as collaborative ownership 84 . 


\section{Cohousing and Co-care: Caring for One's Self and Others}

Research shows that individuals with strong social connections are more likely to adopt and maintain behaviours that affect health and quality of life. It is likely that social connections facilitate capacity for self-care. The anthropologist Margaret Critchlow Rodman, a professor at York University in Toronto and a seniors cohousing advocate suggests that seniors cohousing is '...a housing model whose time has come...' In Critchlow Rodman's experience the amount of supports seniors require for successful aging in place is relatively little (e.g. picking-up medication or groceries for an individual member, checking up on neighbours, etc.) 85 . This sentiment is echoed in research by Paul Williams' that finds 'small things matter': Assistance with everyday things such as grocery shopping, home maintenance, homemaking, and transportation to medical appointments, are vital supports for successful aging at home, 'yet these are [typically] cut first....' 86 Rodman estimates that co-caring has the capacity to reduce public expenditure by $\$ 50,000 /$ person/year. 
The co-care model was a major feature of a cohousing initiative in France call the Baba Yaga (i.e. Slavic terminology for 'old grandmother'). This initiative originated from a feminist ideology developed by Térèse Clerk, a long-time social activist, who was driven to find an alternative housing option for women and address the known perils of aging in place. Initiated in 1999, the doors opened in 2012 to its new residents.

The goal of Baba Yaga was to provide supportive housing and co-caring, supplemented by purchased care services as needed by its members. Térèse Clerk was able to make the appropriate business case for the preventative and cost saving benefits to the French government. In addition to co-care, the Baba Yaga program includes community engagement offering French as a second language for newcomers and other supports to the surrounding community.

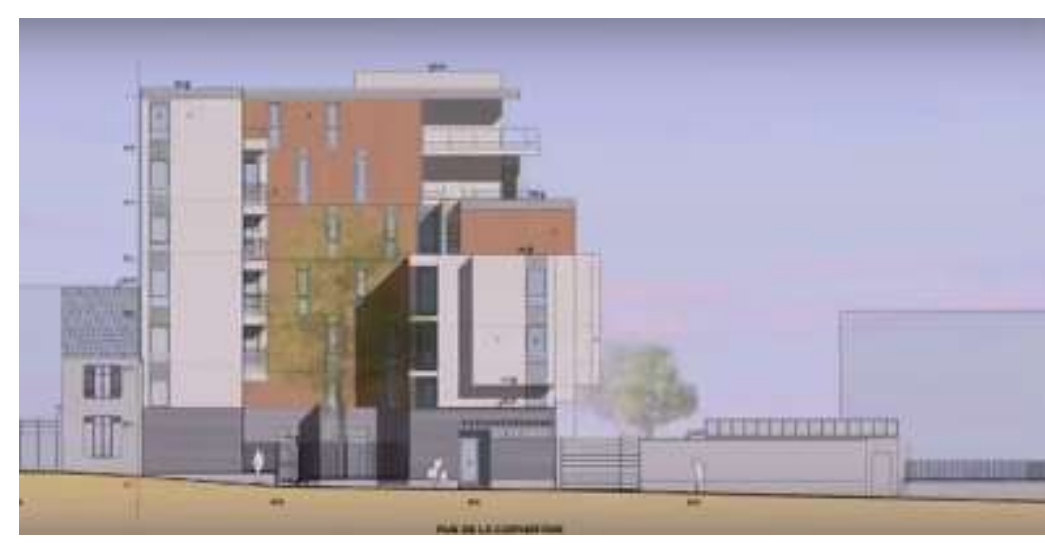

Figure 30: Architect Rendering of Baba Yaga House, Paris

Source: SeniorPlanet.org

\section{What Cohousing Critics Are Saying}




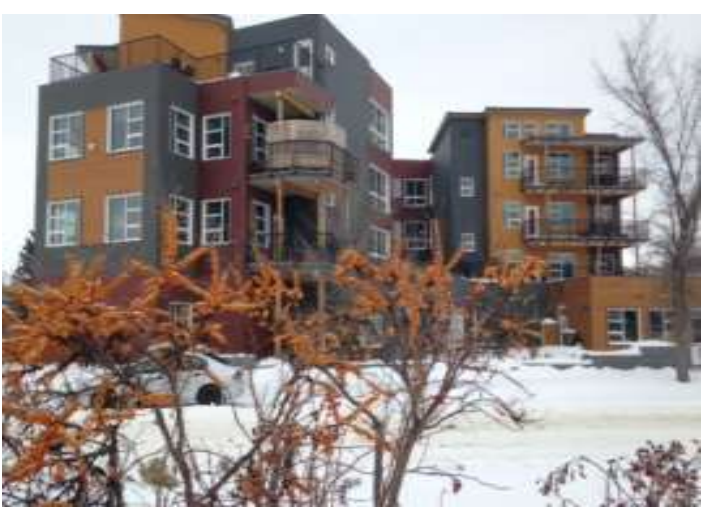

Criticisms have been made about cohousing, namely as it concerns advocacy to obtain public financing for initiatives such as policy direction for affordable housing. Critics argue that cohousing is no different than any other private residential development (e.g. a gated community) and accordingly challenge the suggestion of state support rationalized by the inadequacy of present research and the evaluation of the cost effectiveness of this model. Finally, there is concern that cohousing projects lack integration with surrounding communities. 87 Therefore, why should the state fund such developments? Even if we accept the notion that cohousing is another form of a 'gated community' and discount the positive experiences of seniors living in cohousing communities, the potential ecological benefits of sharing resources and social capital that these generate, the financial expense alone associated with 'aging in place' makes a strong case for supporting these initiatives from the public purse.

Kelly Grant a health reporter with The Globe \& Mail has found that community care (i.e. supporting people to remain at home) costs $\$ 45 /$ day/person, as compared to $\$ 150$ and $\$ 450$ for long-term care and Hospital Care respectively. Her conclusion is that community home care systems seem to be disorganized as well as being grossly underfunded 88 . 
Given the policy and public preference, governments ought to rethink the present housing approach to reinforce (by redirecting funding) and organize the community care system as a strategy to meet housing needs and contain spending associated with seniors, including the provision of support for alternative models such as cohousing. 


\section{Cohousing: Spatial Systems}

As previously noted, spatial organization is a key design consideration for cohousing residents:

What are the needs, interests and characteristics of the cohousing community?

The relationship between common and private spaces can reinforce a sense of community ${ }^{89}$. Helamm conducted a review of cohousing communities and the site planning decisions.

Preferences and site conditions largely dictate the systems used. Although the focus of this thesis is to draw upon a spatial systems appropriate for a single floor level within the same building rather than over a larger site. Therefore, a bazaar system suits the purposes for this project. It is necessary to acknowledge also that different systems are at play in this situation. As a multi level building, however, the relationships with other residents - an important part of the design calls for the vertical on bazaar system. interaction and connection
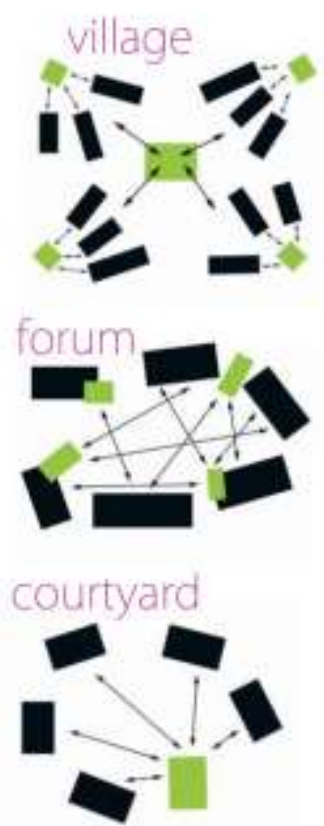

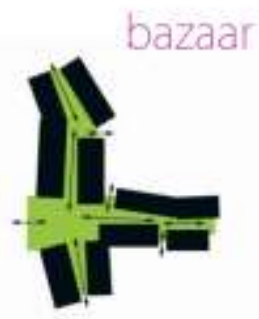

vertical on bazaar

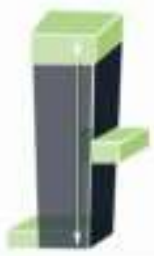

(Helamm 2013) by virtue of proximity. The next part of this thesis will draw from this analysis in determining an appropriate arrangement. 


\section{Part 4. Architectural Proposition: social architecture}

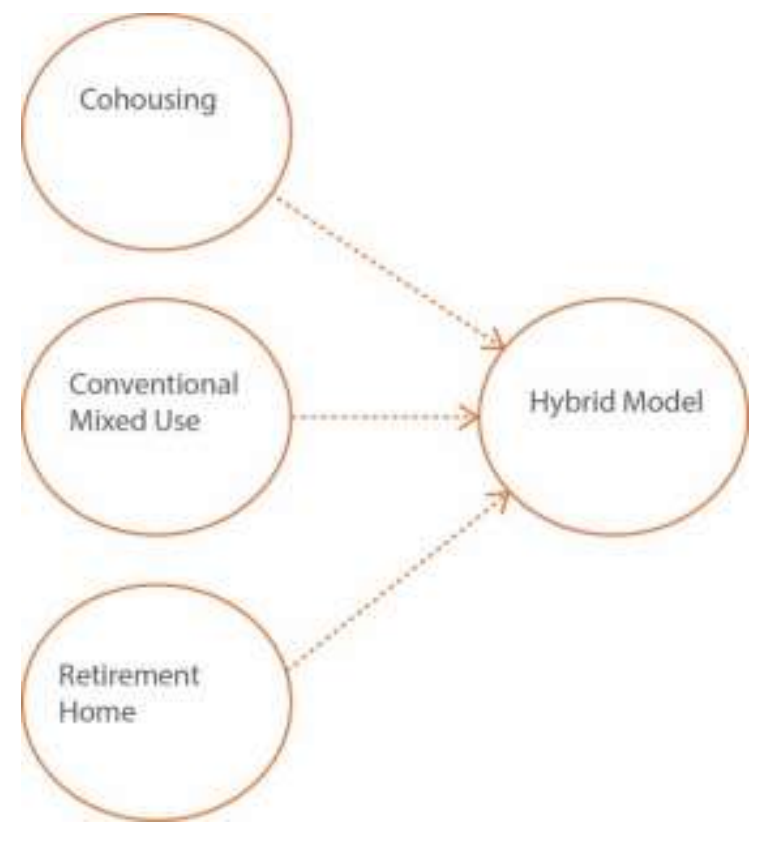

" in order to bring about change in a complex system...address the interactions within the system, between the system and other systems..."

Jay Foster 1971?

Strong interpersonal relationships and a sense of connection to others is an essential ingredient for healthy aging. The primary goal of this thesis is to form an architectural design that facilitates and supports the formation of a 'social architecture'. Social architecture, in this context, describe life enhancing informal bonds and relationships with others (i.e. residents of the building and surrounding neighborhood). Architectural strategies can assist propagate, develop and maintain social architecture among community members - e.g. convivial gathering spaces provide that feel safe and provide points of interest motivate their use.

-A hybrid model of senior cohousing represents a synthesis of architectural concepts of cohousing, conventional mixed-use residential development, and supportive housing models (figure 32). 
The scope of this thesis is restricted to urban multi-unit housing, given demographic trends noted earlier, and time constraints. However, it is important to acknowledge that alternative housing options for seniors rural communities is an equally worthy of focus.

\section{Conceptual Design Considerations}

This thesis proposal makes the following assumptions. A) Alternative housing options need to be developed and the positive attributes of seniors cohousing are transferable to a hybrid model for housing the population of soonto-be seniors, who wish to remain living in urban communities - especially for those with limited social supports. B) The municipal urban planning priority for intensification and prevention of urban spraw 190 will continue to attract mixed-use development proposals in urban areas. Therefore, it is important to engage and collaborate with developers to find innovative approaches to housing. They have to be part of the equation for two main reasons: to leverage the developers' knowledge and expertise; and capital investments. . C) Aging in community is a broader concept than 'aging in place' that in this context is a term is used to denote the reciprocity of social capital between cohousing seniors and extended to the multi-generational community; D) Last but not least, in order to meet the long-term needs of occupants, the architecture of a hybrid model needs to reflect evidencebased knowledge, design principles of aging, and changing physical, psychological, and social needs. Therefore, the spaces need to be adaptable and responsive to these needs ${ }^{91}$. 


\section{Design Intensions:}

Healthy aging calls for spatial organisation that is highly functional and supports social interaction (points of intersection) as well as architectural materials and detailing that contribute to psychosomatic health. Precedent architectural will assist with design ideas that support design concepts. The first two studies focus at a larger scale of spatial organisation circulation strategies. The third relates to the embodied experience of architecture at the human scale, including material choices that motivate the occupation of spaces. 


\section{Spatial Organisation: Seniors Residences}

Many seniors residences are very similar to condominium buildings that typically optimize the number of units available on each level. Seniors homes In Ontario are regulated and all facilities must comply with established regulations 92 specialized areas are designated for specific types of care provision within the institution,

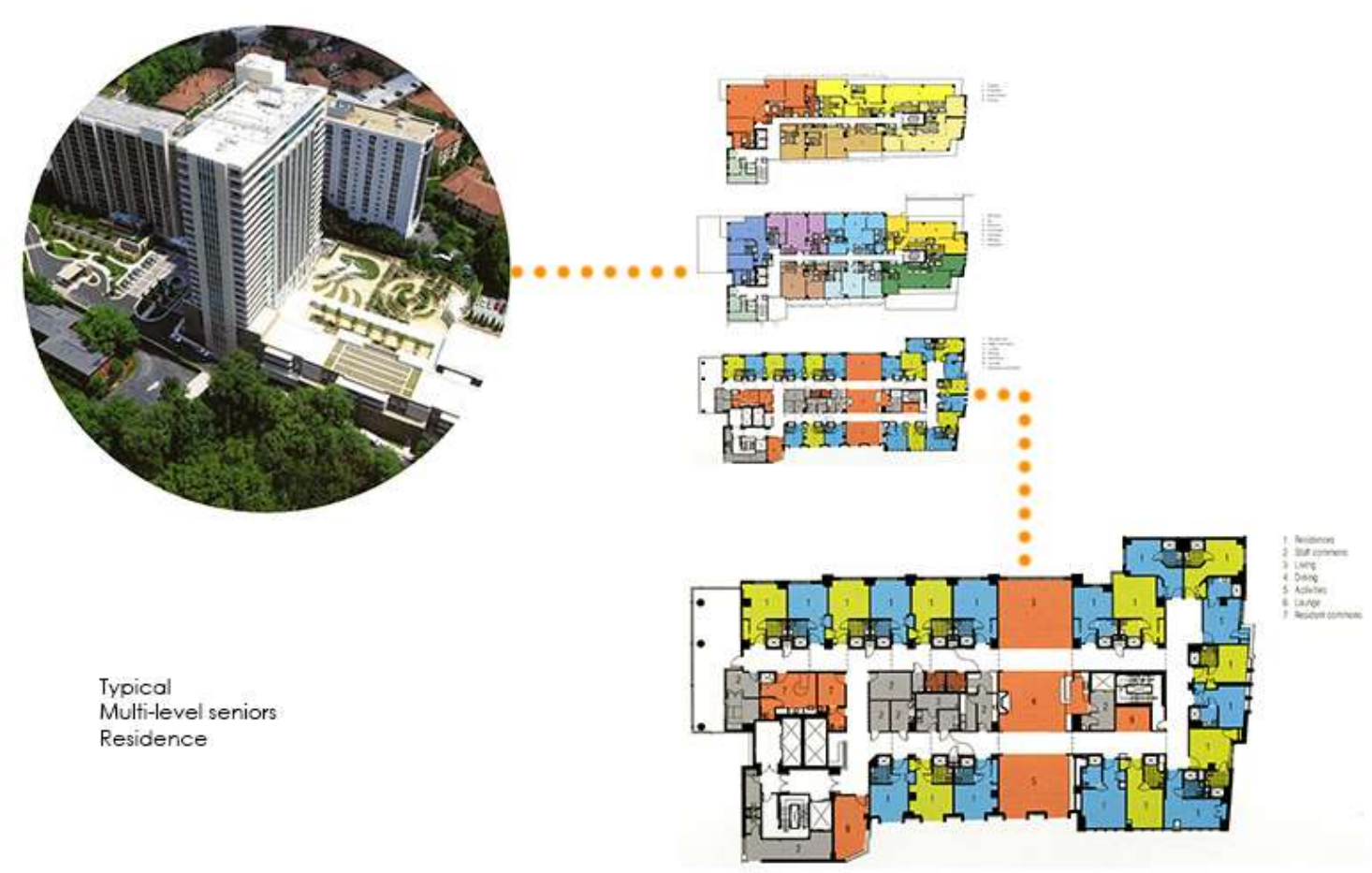


operational/management and administration spaces. In the above example, floor plans A and B consist of larger units for independent living. Plan $C$ is composed of smaller units, greater communal spaces for advanced level of care needs. Circulation pathways are efficient and limit the intended purpose of internal movement.

\section{Condominiums: Typical Floor Plan}

This typical plan is the proposed mixed-use project of this thesis and is common to condominium buildings. Circulation space kept to a minimal level, in order to maximise the number of buildable units. In the main condominiums typically consist of 1-2 bedroom units ranging from 50-150 m².

Building code requirement:

$15 \%$ of units are to be barrier free accessible units.

Circulation must be a minimum of $1100 \mathrm{~mm}$.

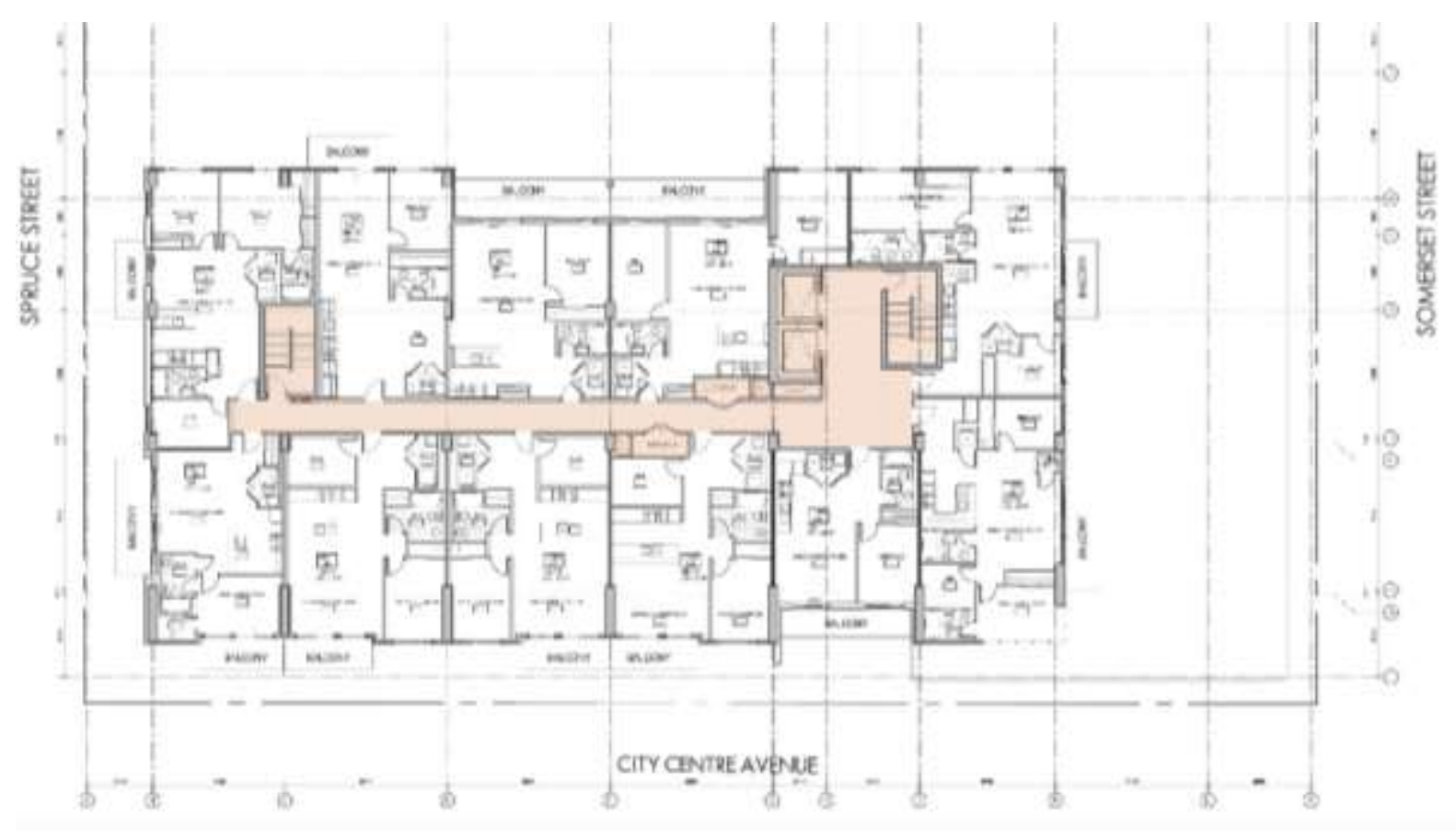

Figure 34 Source: Domicile Development 


\section{Social Architecture: Points of Intersection}

Social connection is central to reducing the possibility of isolation. The following precedent studies illustrate how physical architecture supports social architecture.

\section{Precedent study 1}

De Drie Hoven Housing Complex for the Elderly 1964-74 - Typical Floor Plan -

Herman Hertzberger Architects (Figure 34).

This particular precedent is representative of large institutional settings that house seniors and on face value is a contrary form of architecture to that proposed in this thesis. However, the architect's sensitivity toward social engagement and connection evidenced in this typical floor plan and is therefore an important source of inspiration.

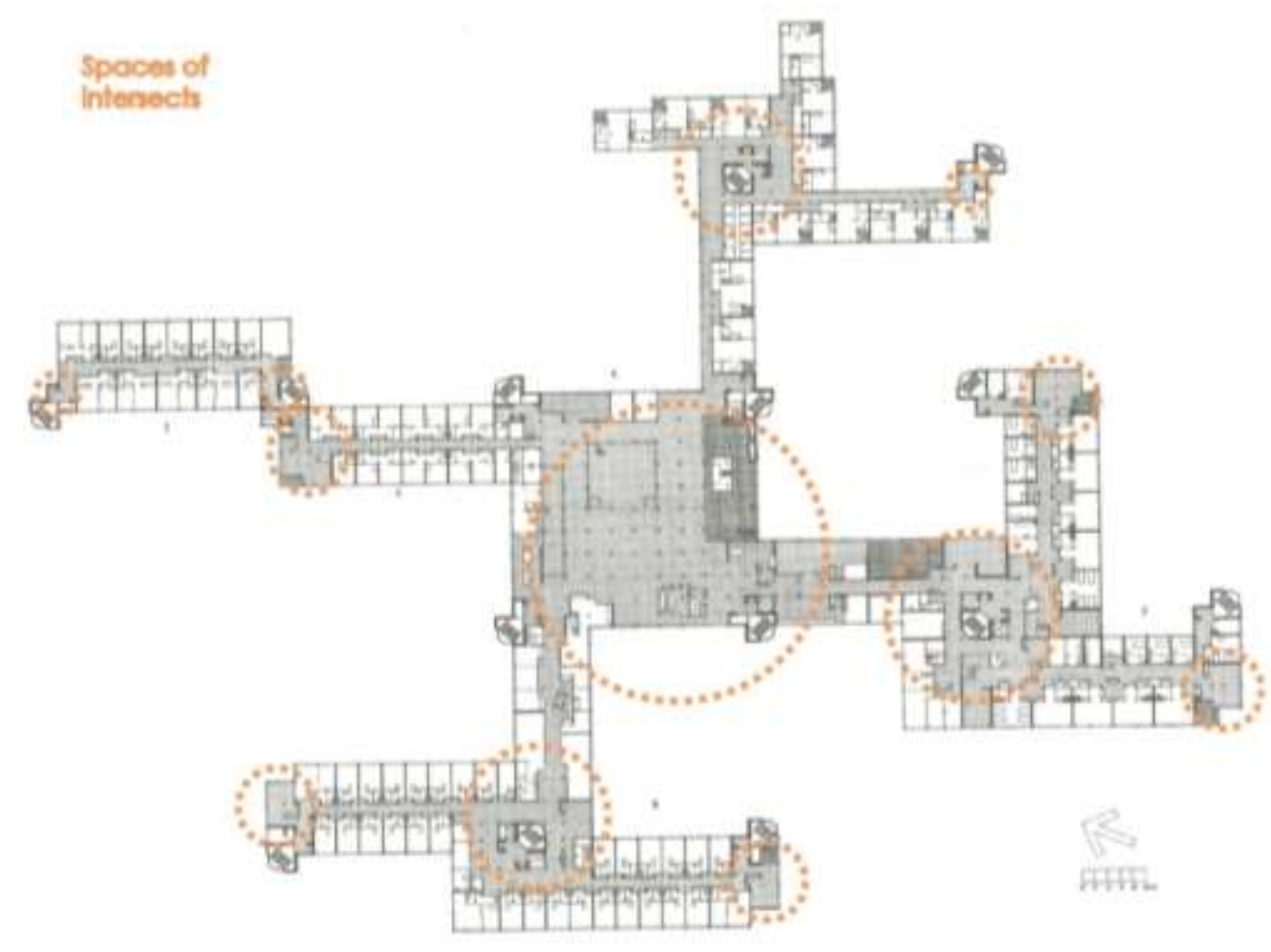

Figure 34: Floor plan image modified to indicate major points of intersection of inhabitants 
Precedent study 2 - Social Architecture: Points of Intersection

San Francisco Federal Building 2007, Morphosis Architects

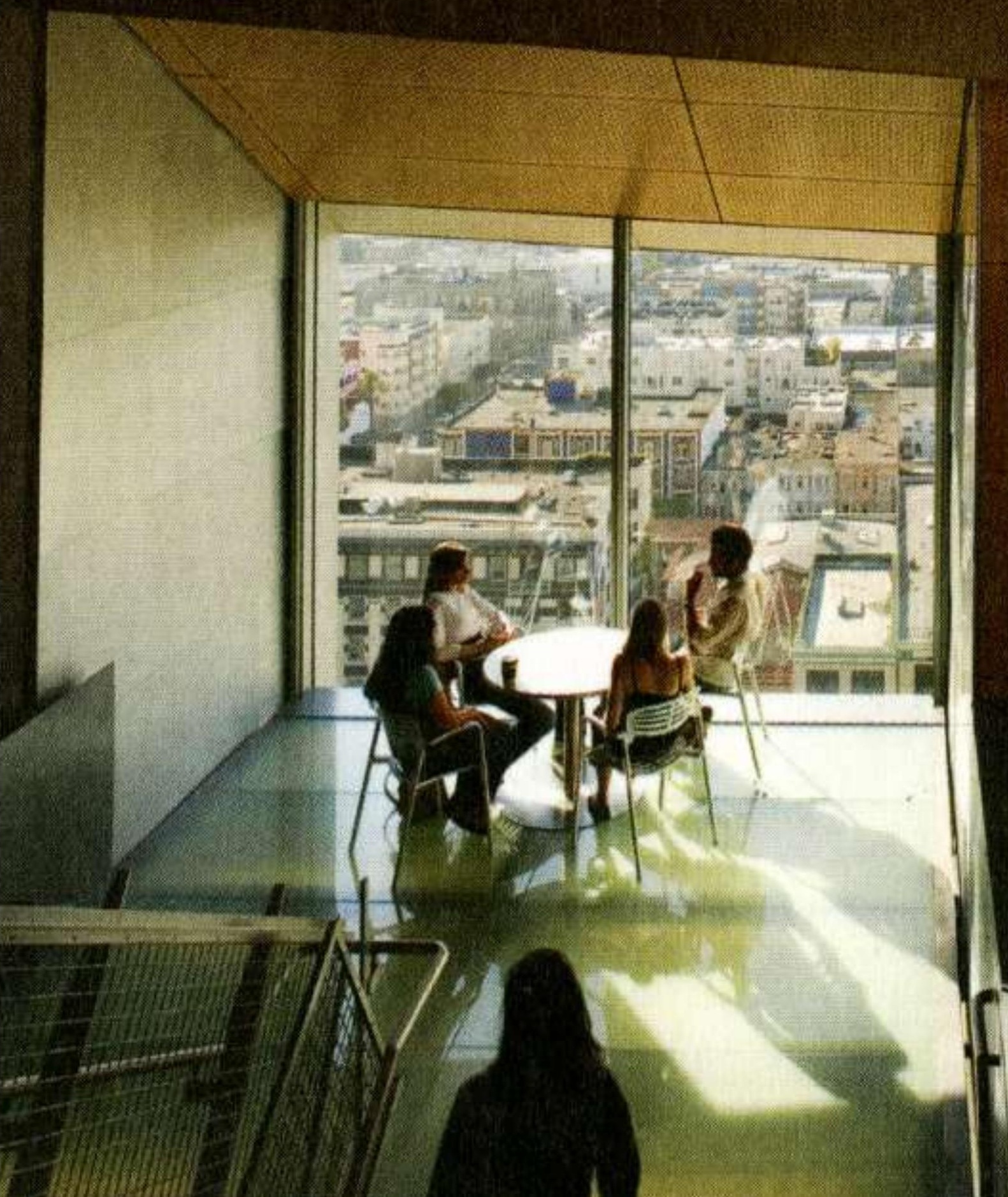




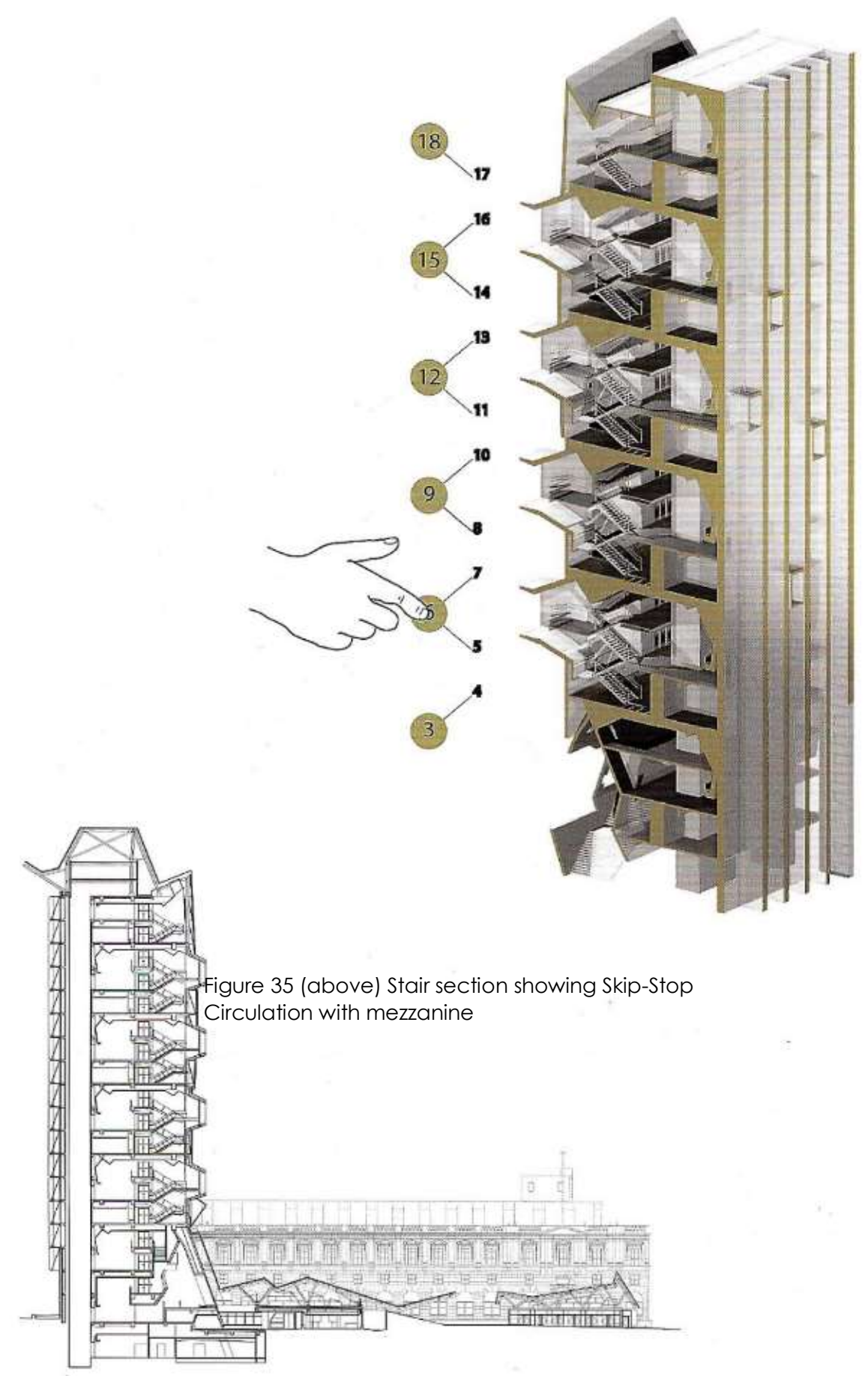

The creation of a mezzanine between floors, by Morphosis Architects in this building design provides stunning views of the cityscape - a motivating factor to use the stairs and likely to facilitate interaction with others in the building. The application of this design strategy for people who may have mobility issues is considered. 


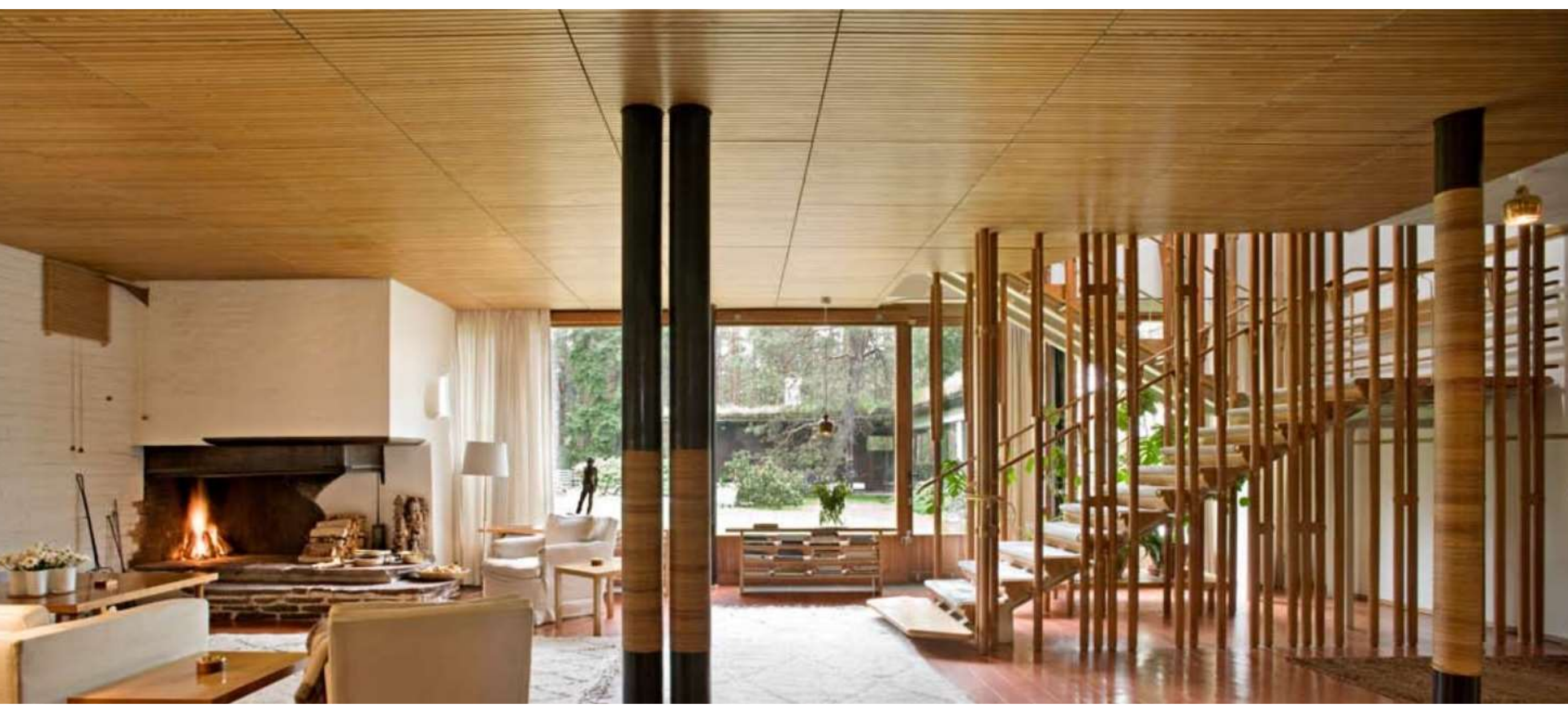




\section{Precedent Study 3 - Psychosomatic qualities of such spaces: Villa Mairea, Alvar Aalto, 1939}

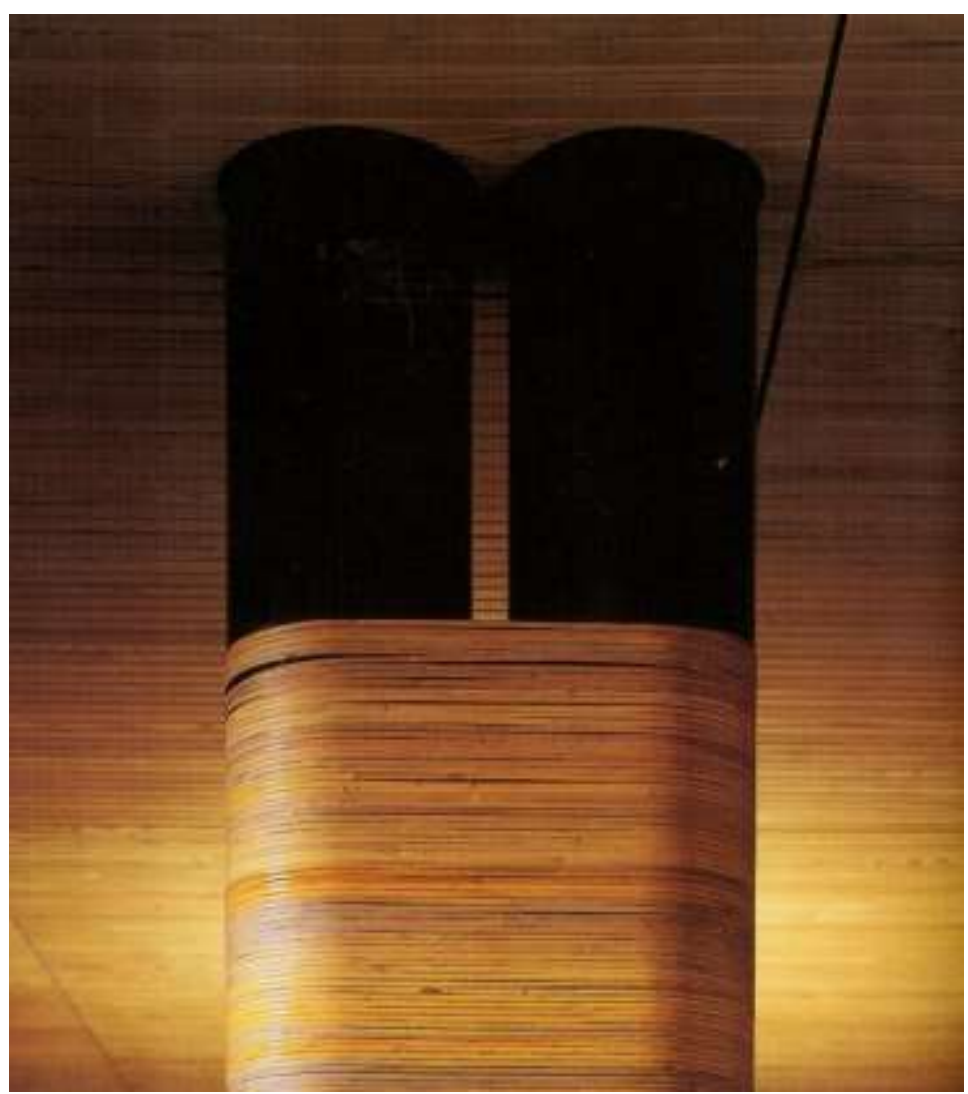

Figure 37: Villa Mairea, Alvar Aalto 1939
Alvar Aalto's architectural composition in Villa Mairea (Figure 36) provides a very fitting example of qualities of space in which we connect with natural elements and forces. The use of natural light and connection to the exterior spaces form an important sensory experience. We are able to feel the warmth of sun light and calibrate our senses to the passing of time - day moves into night, summer moves to spring, etc. This is one of many sensory experiences that Alberto Peréz-Goméz refers to in book Attunement (2016).

The column detail (Figure 37) illustrates a sensitivity of the architect toward the tactile experience of material. Not

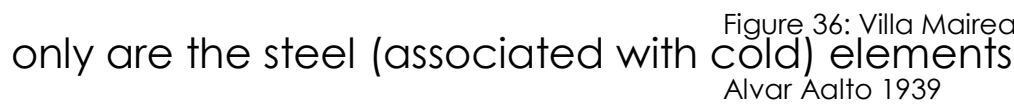
covered with a familiar natural material (associated with warmth), but the disposition of the covering is at the level of human sensation - reach and sight. 


\section{The Design Process}

The health benefits of having a say in the design of the space that seniors occupy has been stated earlier and it relates primarily with building a sense of belonging and motivates the use of space. In turn, interactions with others, creates opportunities for potentially to meaningful and mutually beneficial relationships and formation of bonds - a central theme of this thesis - that is important for healthy aging. Therefore, the design process of architecture design can also represent a form of social architecture. The inclusive nature of design represents both a value and a process - a prerequisite for successful cohousing developments 93 . Engaging developers, the city, and aging residents will be required. For the purposes of this thesis, the residents interests will be represented by the thesis author, whilst retaining the caveat that alternative design ideas will be sought throughout the process. Consultations were conducted with the Ottawa Seniors Council; City of Ottawa representatives Domicile Development, as part of the process and their perspectives are on the hybrid model is discussed in Part 5 - Critical Reflections.

\section{Location, Location, Location: Ideal Site}

For the purposes of this thesis, a mixed-use project will be found in a site that would meet the following criteria: Neighbourhood accessibility: namely a site with a high walkability ${ }^{94}$ score; access to public transportation routes; pedestrian and cycle paths; proximity to community services; public amenities; food venues; health and social services; recreational and cultural service; green spaces; and an urban area with high population density. 
Mixed-Use Project: SPRUCE CONDO,

\section{SOMERSET STREET WEST}

OTTAWA, ONTARIO, CANADA.

The Spruce Condo development proposal application, submitted to the City of Ottawa for approval by Domicile Developments (Figure 38), was found though an online search of the City's online 'development application search tool'.

Located in the West Centretown neighbourhood, the northwest of the City's Somerset Ward (Ward 14), this proposal consists of a four-floor level podium that sits at the intersection of City Avenue to the west and Somerset Street West to the south. The building typology is relatively common to mixed-use projects, where the program consists of commercial space at ground level and residential accommodations above. The project met a site selection criteria noted.

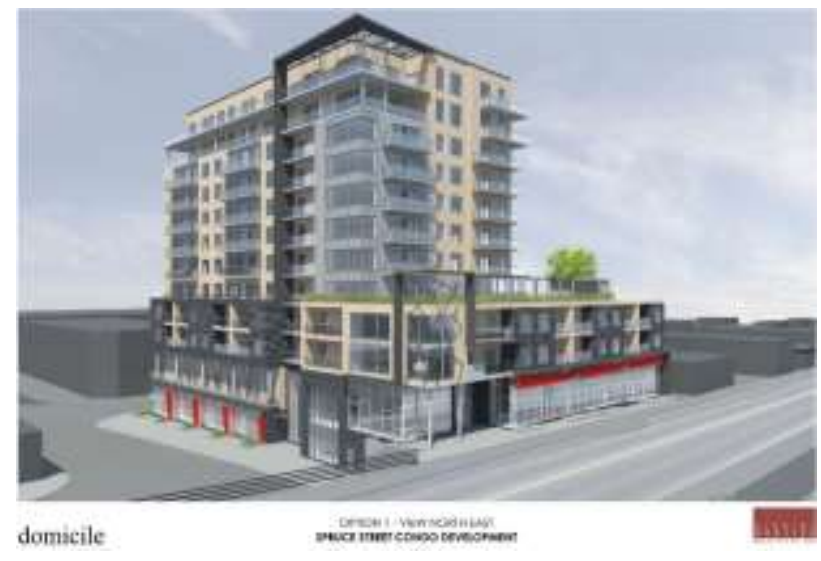

Figure 38: Architectural rendering of proposed mixed-use building 
Site: Urban Pattern

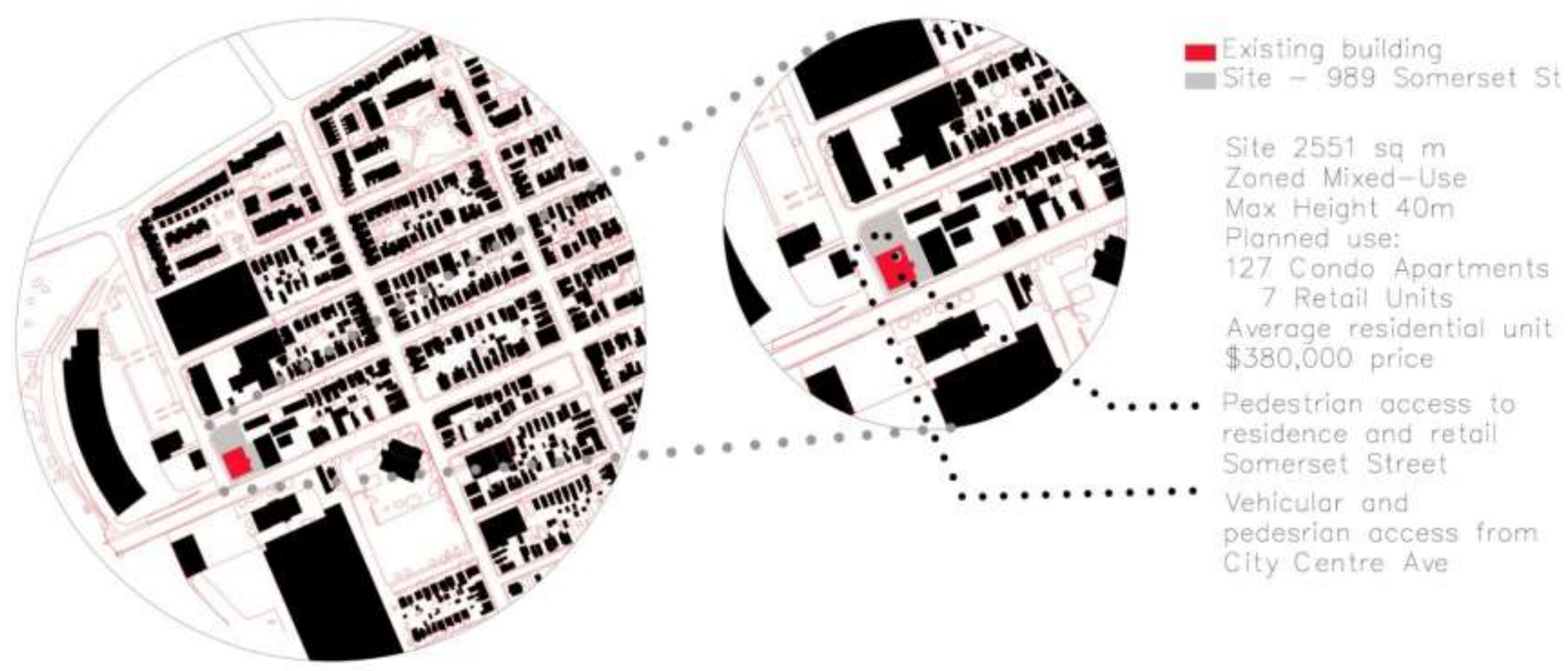




\section{Site: Circulation}

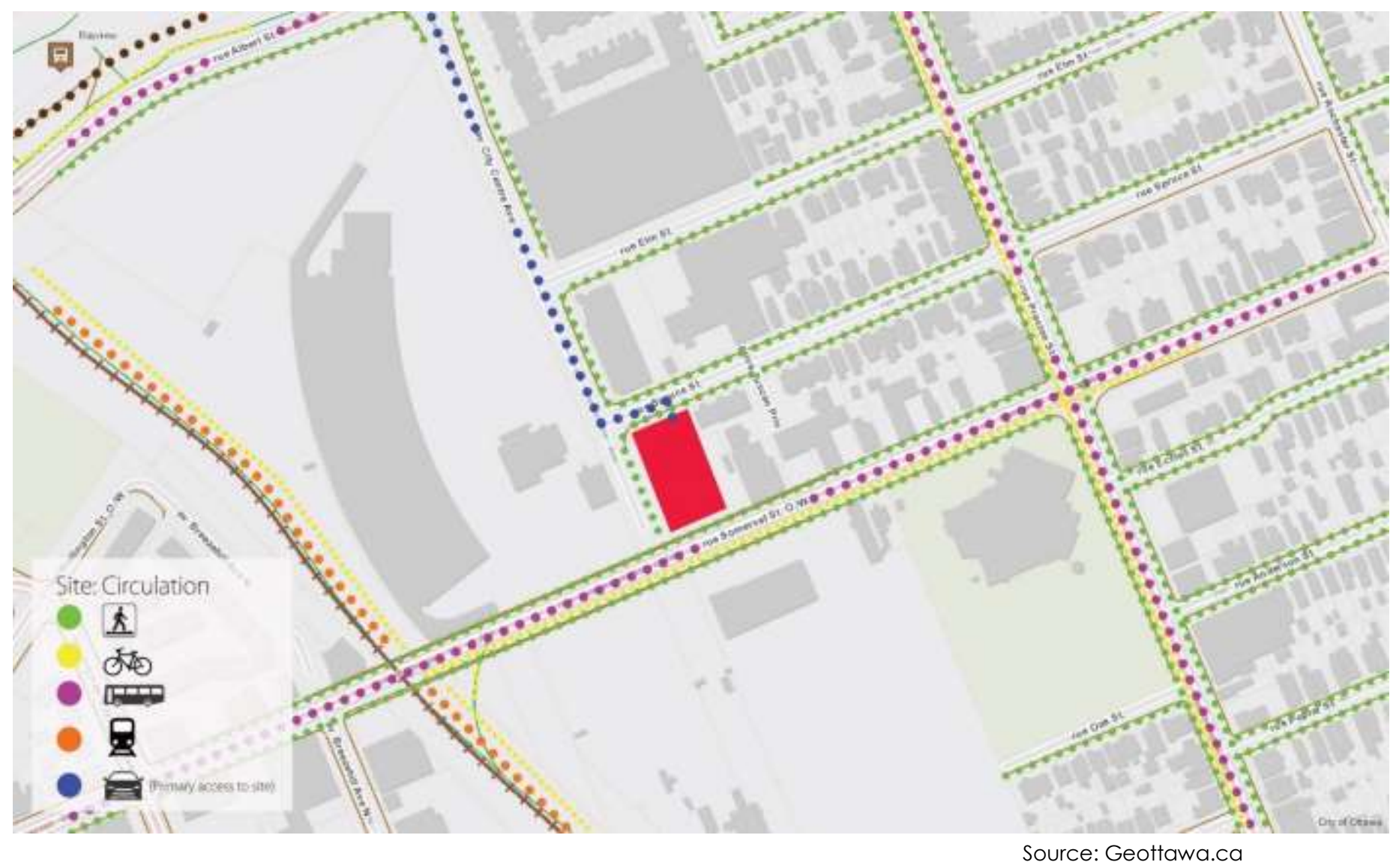

The site is a highly pedestrian urban location well served by public transportation. A bus service runs on Somerset Street West (east - west direction). Bay View rail and the transit service is a less that $800 \mathrm{~m}$ from the site. Vehicular access to the site is via City Centre Avenue. 


\section{Developers Intended Program}

The developers program represents a conventional approach to mixed-use development project, which include commercial space at street level and residential above.

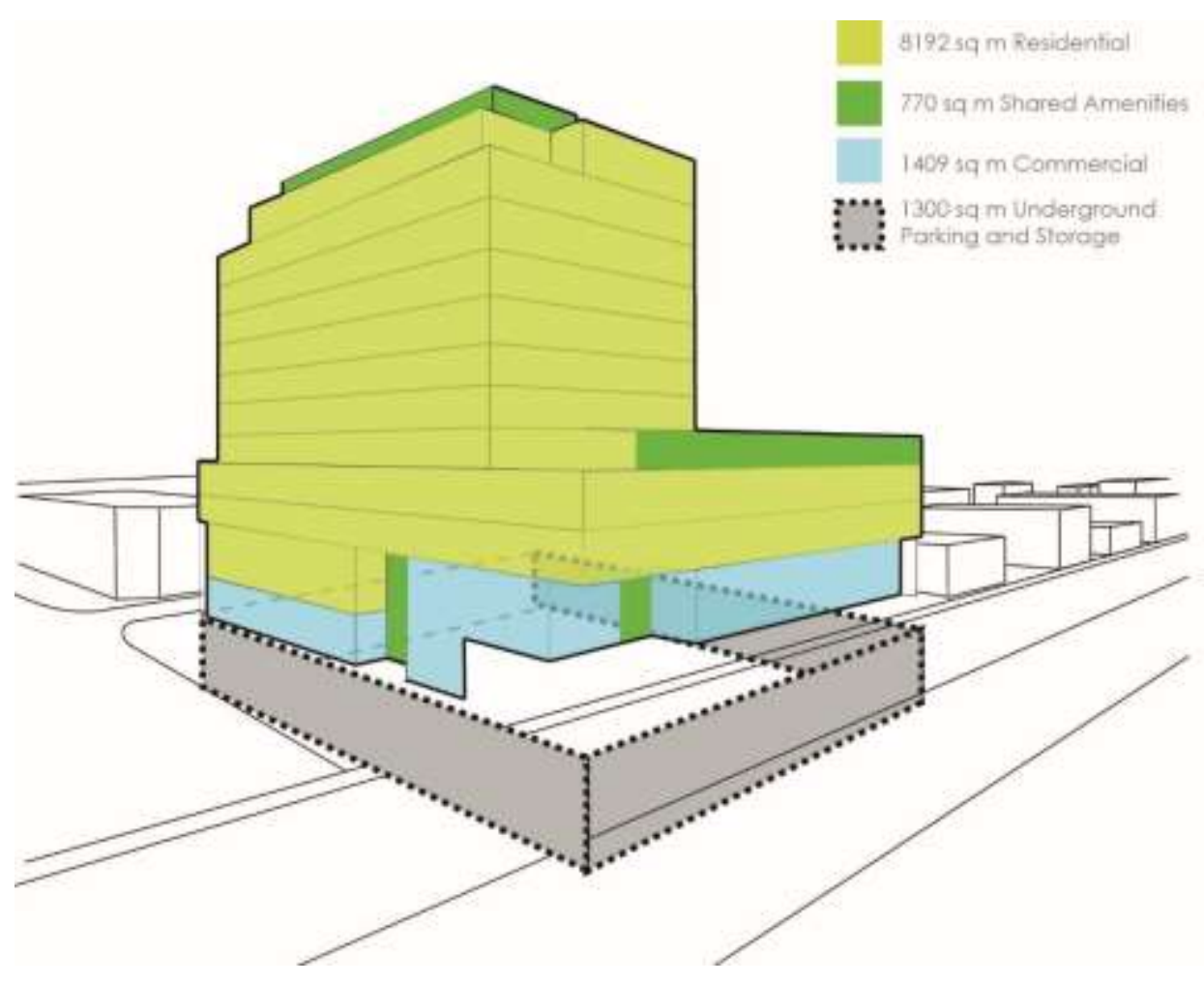


Sun Study of the Proposed Building

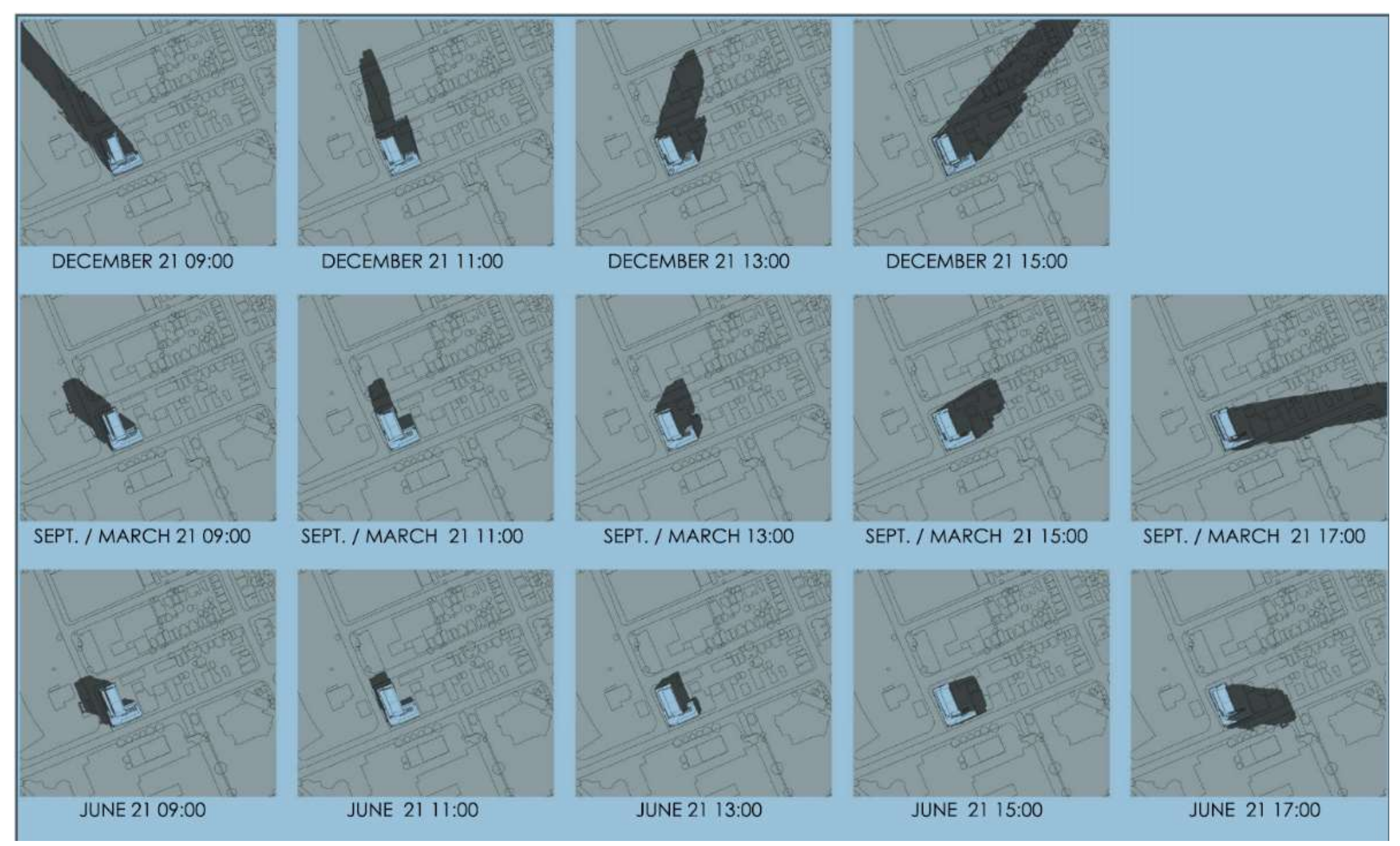

Figure 40: Sun Study, Domicile Development 


\section{Design Strategies}

The following segment will highlight some of the key design strategies and considerations for the hybrid model.

In a real setting, it is proposed that series of design options would be provided to end users. As a participatory architectural design process, space is provided to capture end-users needs and preferences. In order to achieve this series of diagrammatic alternatives provide opportunities that generate reactions and a moderated group discussion, which would be lead by the architect and/or design consultant.

The proposed intervention is to augment cohousing with existing 12-storey mixed-use development project. The proposal will included a redesign a single floor plan to accommodate a cohousing option. The project will utilize the structural grid system; floor plates; egress and vertical circulation elements. These elements form a predefined canvas upon which programmatic and spatial needs are articulated.

Design objectives:

- Application of accessible design

- Adaptive spaces that enable future modification as needed

- Utilize architectural tactics to create opportunities for intersection and connection of inhabitants

- Explore approaches to enhance the spaces for all inhabitants of the building

- Develop an appropriate program that supports the community and engages cohousing seniors 
Cohousing insertion strategy

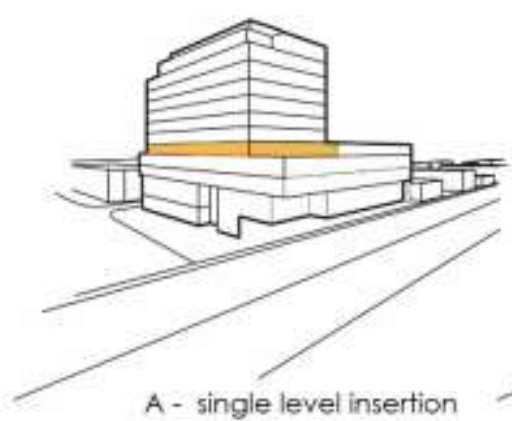

10-16 unit cohousing

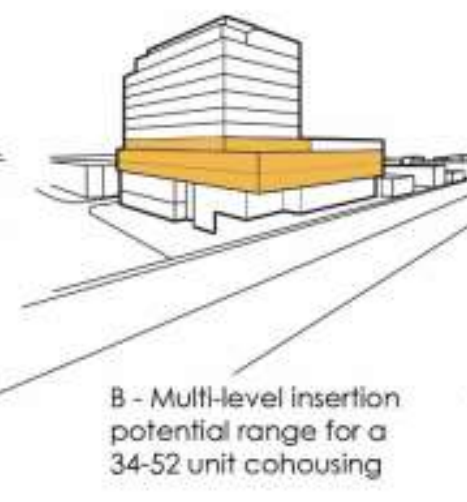

34-52 unit ro for
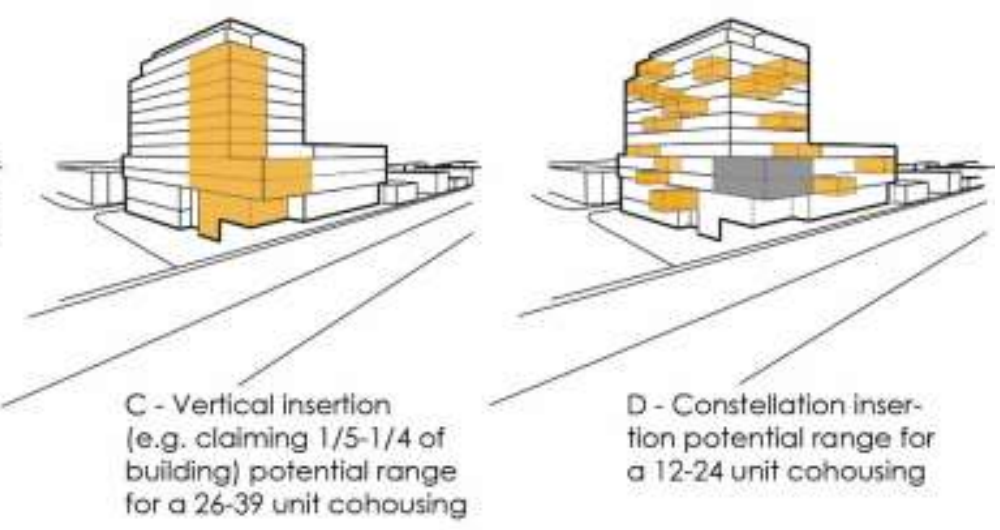

E-Occupant determined based on group size, needs and preference 
A: this level is the access point to a large terrace - a shared amenity space for all residents of the building. This spatial relationship is likely to create opportunities for interaction between all residents. 


\section{Existing Structural Grid}

The Insertion of the cohousing model into the mixed-use building accepts the conventional structural grid system planned by the developer (Figure 41). The grid acts as the defined canvas upon which program and spatial requirements for the cohousing level is articulated.

To meet the program needs the fifth floor plan extends beyond the present wall boundaries and take full advantage of the structural grid.

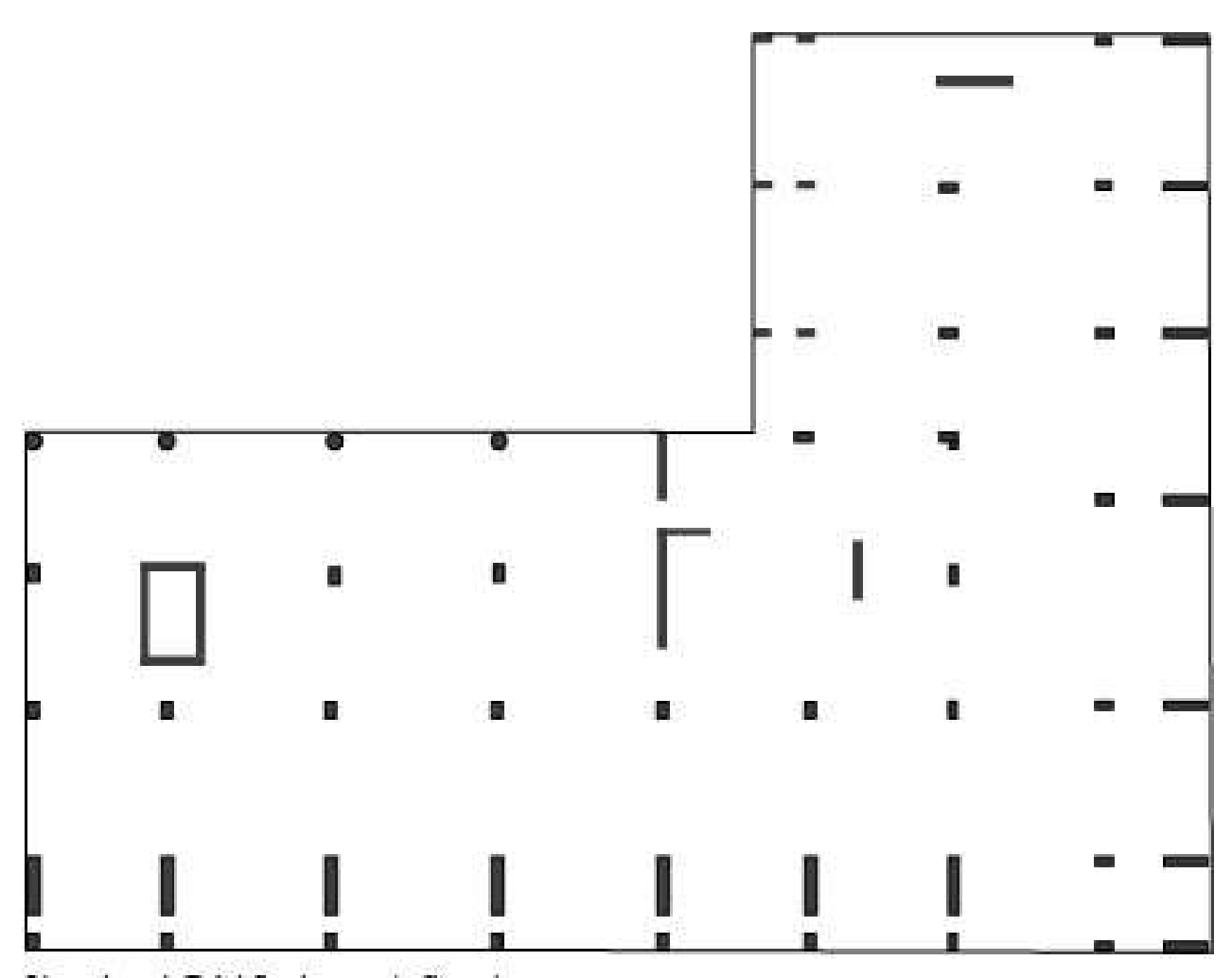

Structural Grid System: defined canvas 


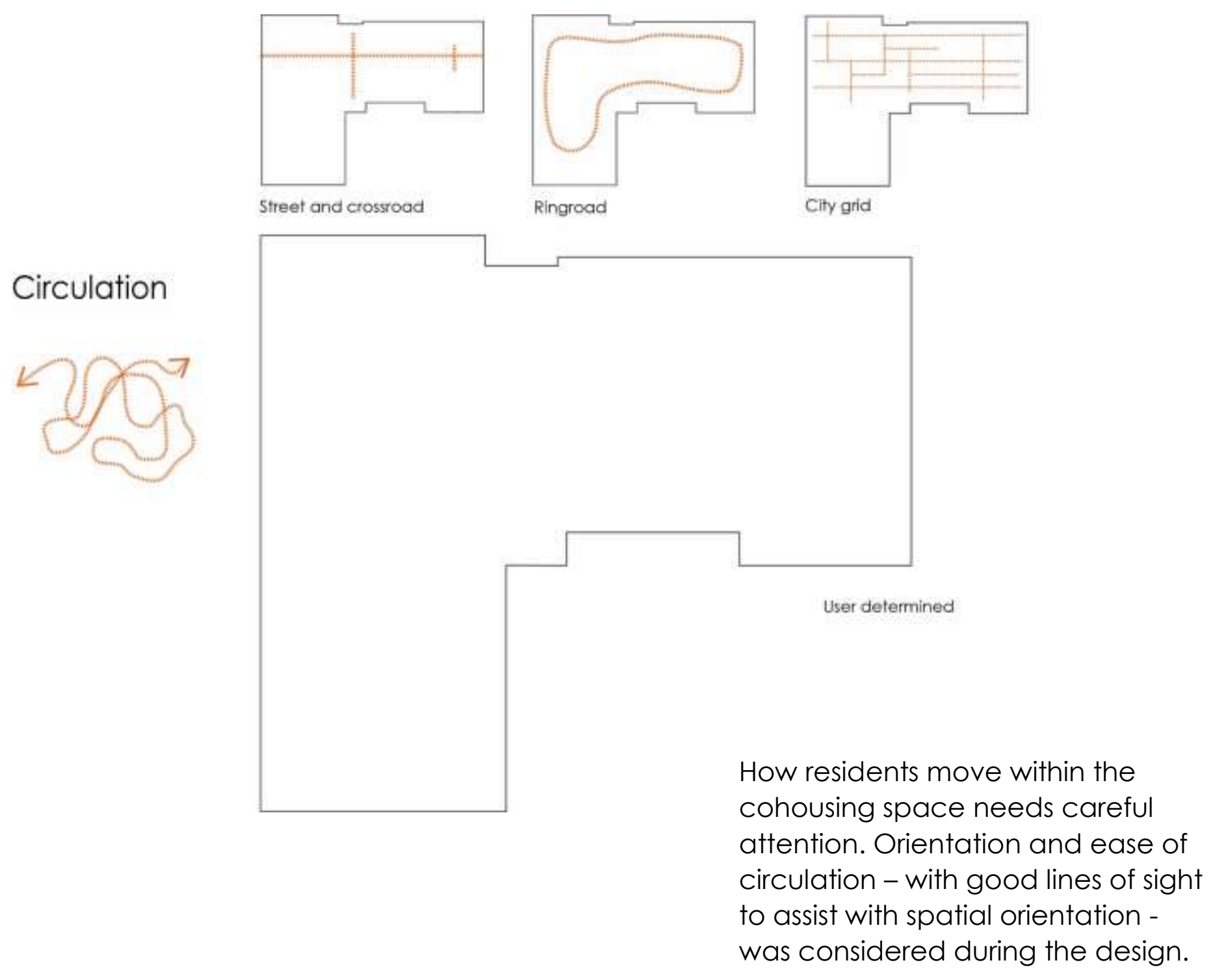



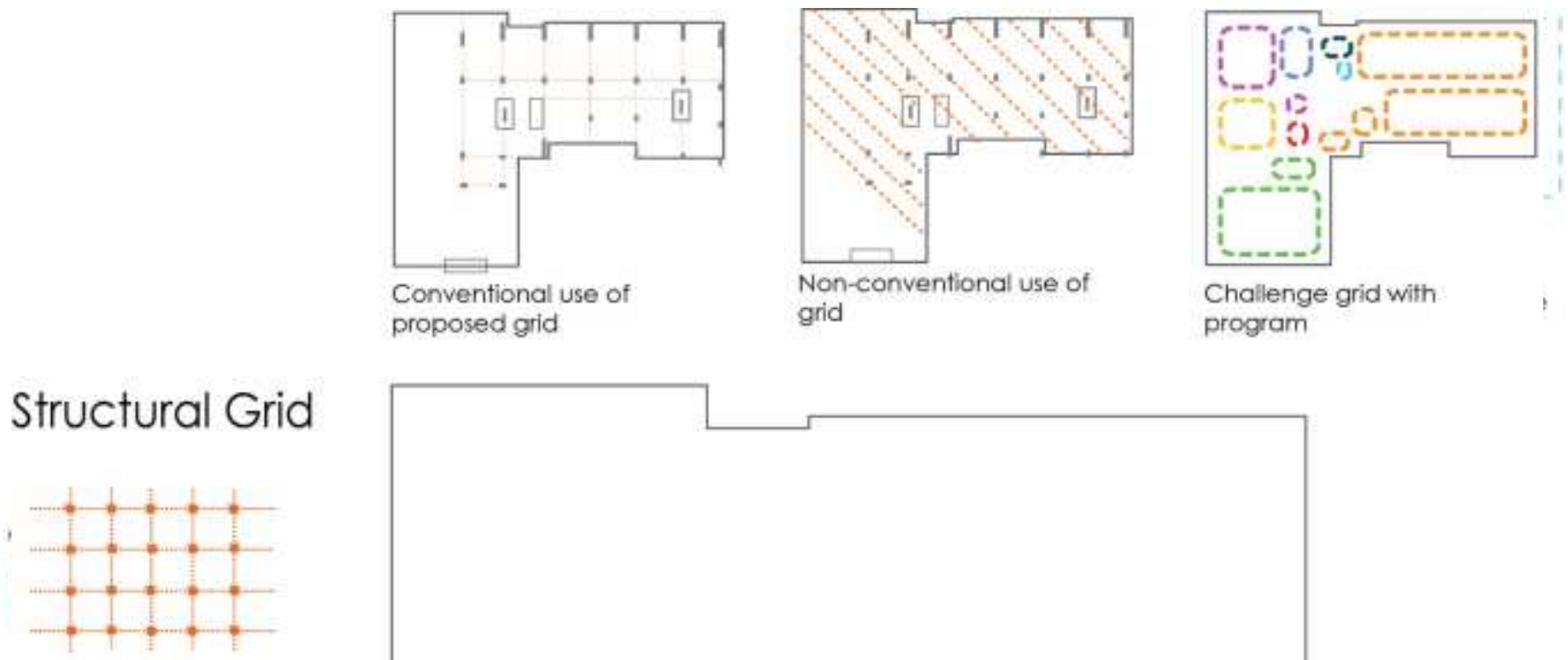

proposed grid

program
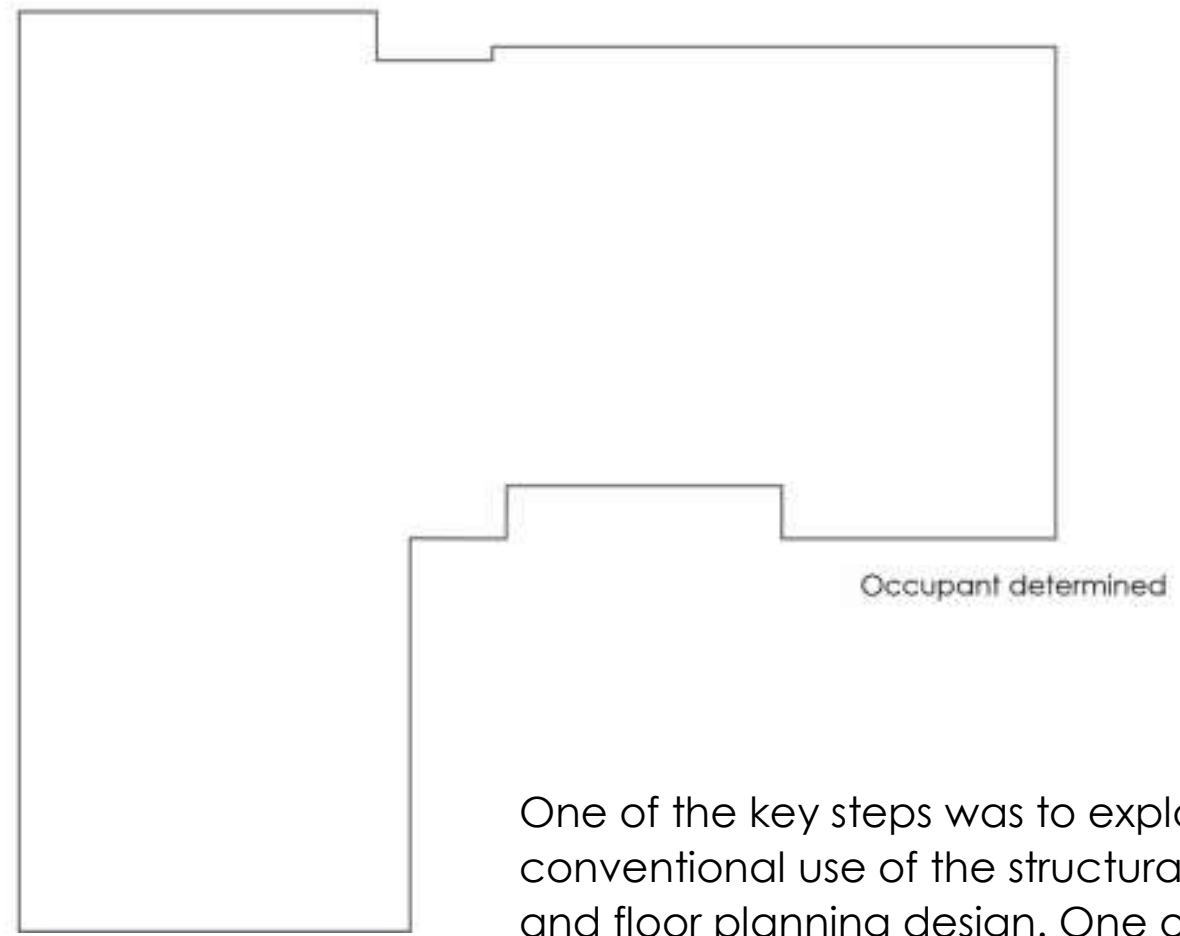

One of the key steps was to explore a nonconventional use of the structural grid for unit and floor planning design. One of the primary goals was to optimise the number of units while promoting a sense of connection. 


\section{Program Organization}
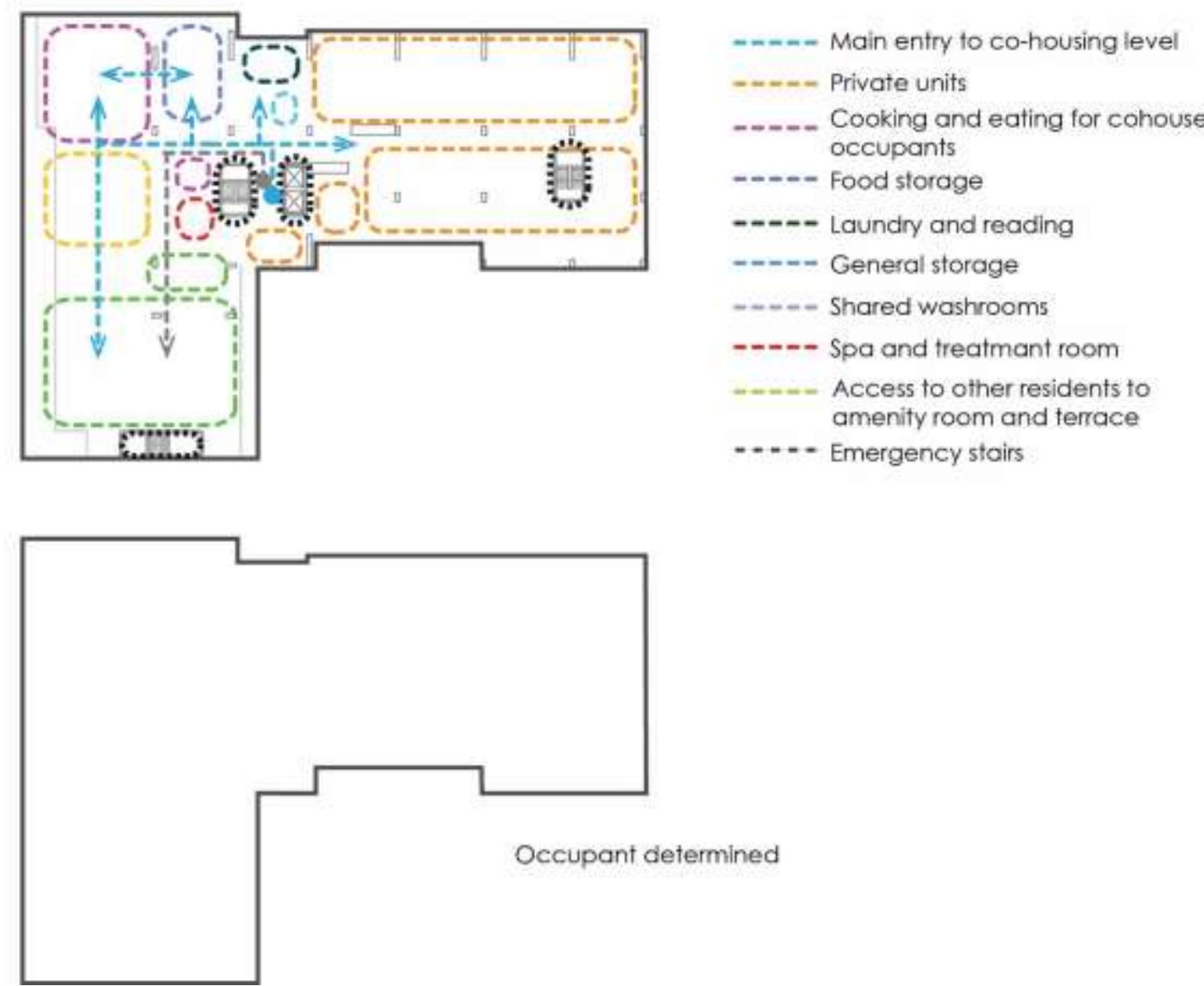

This diagram illustrates the areas of spaces intersection:

Given the nature of cohousing individuals have a good sense of their comfort zone for personal space versus public space, which is explored at facilitated meetings of residents. Factors such as personal space, comfort and safety are part of the design process. 
Sun and Light Intensity





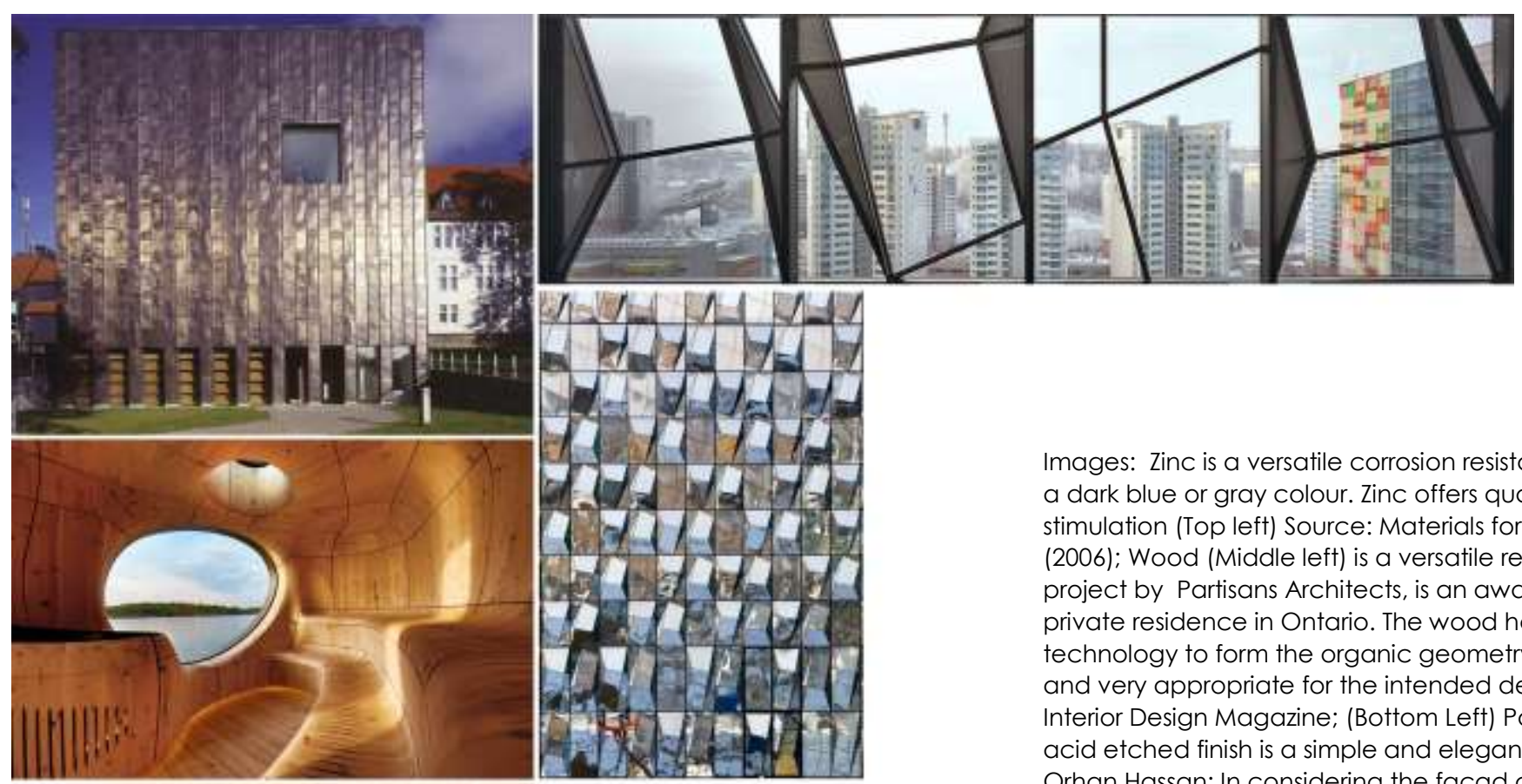

Materials
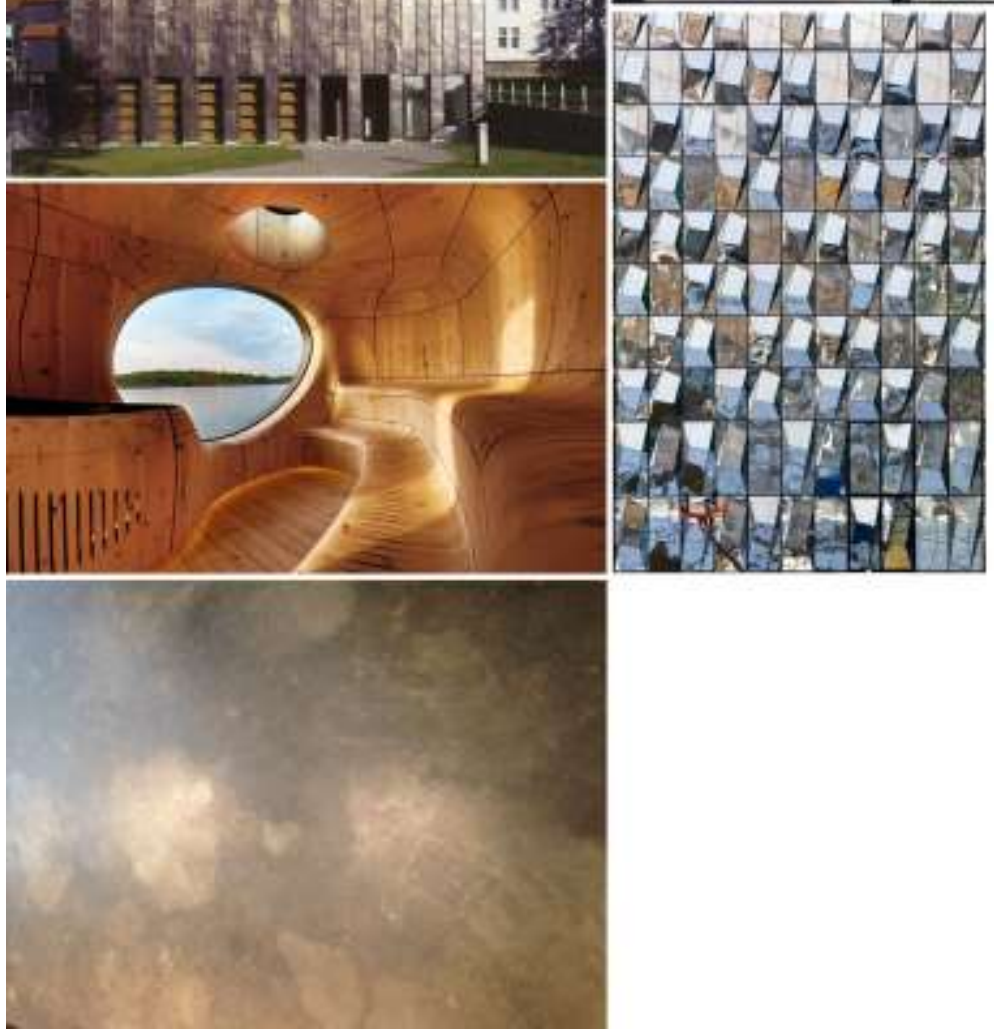

Images: Zinc is a versatile corrosion resistant - if untreated it ages into a dark blue or gray colour. Zinc offers qualities of lightness and visual stimulation (Top left) Source: Materials for Design Victoria Ballard Bell (2006); Wood (Middle left) is a versatile renewable resource - this project by Partisans Architects, is an award winning sauna for a private residence in Ontario. The wood has been sculpted using 3D technology to form the organic geometry. Wood has a warm quality and very appropriate for the intended design proposal. Source: Interior Design Magazine; (Bottom Left) Polished concrete flooring with acid etched finish is a simple and elegant flooring for units. Source: Orhan Hassan; In considering the facad as a system (Top right and bottom right) the facede for the Trutec Building in Seol, by architect Barkow Liebinger, (2007) is reflective and dynamic highrise building both internal and external views. Source: Detail 05/2007 

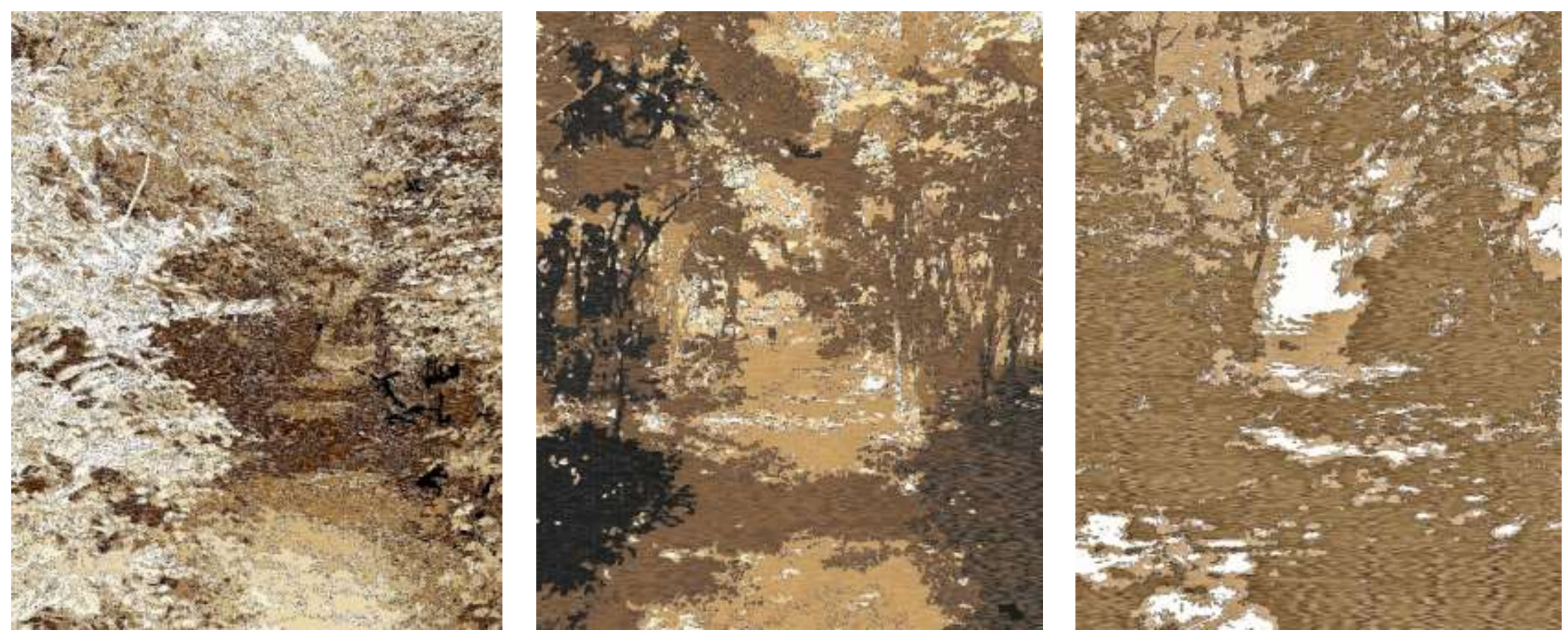

Figure 42 -Drawing Inspiration from natural elements - the experience of passage through space - in designing circulation spaces.

Source: Orhan Hassan 
Dual Functioning Spaces: Connections

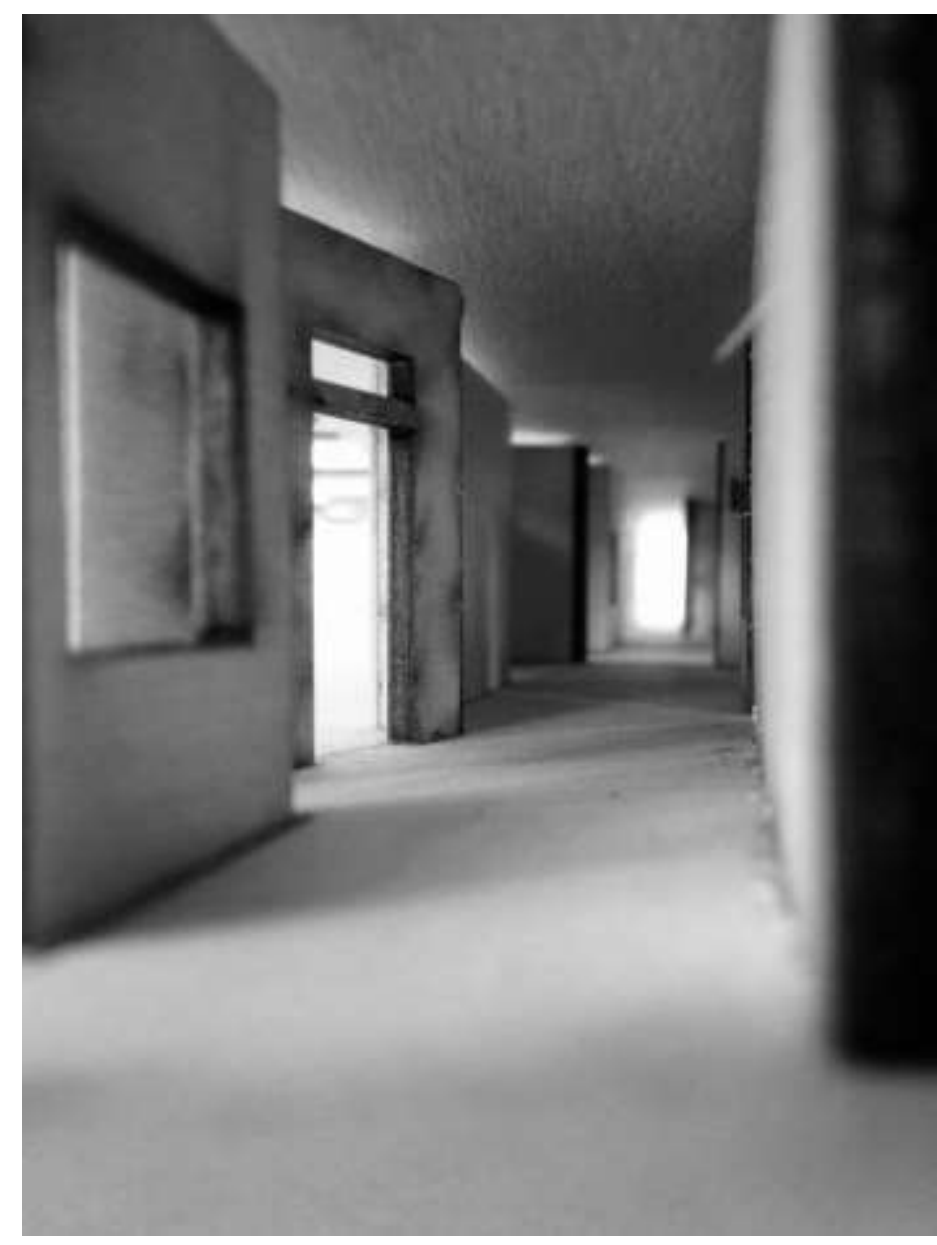

Figure 43

Perspective view of

modelled

circulation path 


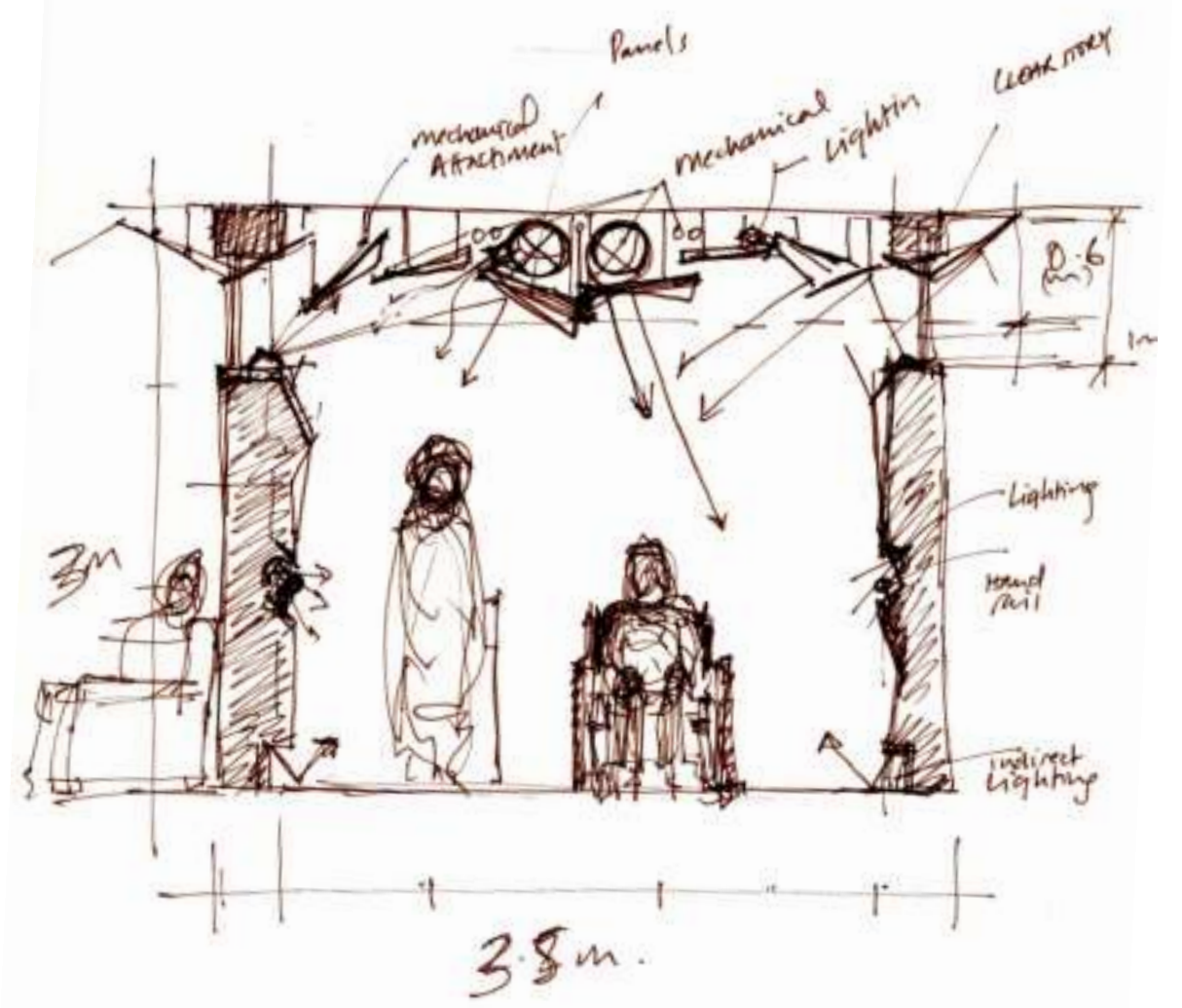

Hofigure 45 sindy

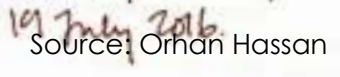

\section{Dual functioning spaces: integration}

Circulation spaces have the capacity to be spaces for connection and serve as other functions. Figure 45 is a design sketch that draws on the concept of journey through the forest with spaces that widen and constrict along the path. The sketch illustrates the connection between the hallway and individual units. The connection, achieved through the clerestory fenestration. The mechanical systems, lighting and hand rails become integral parts of the overall design. 


\section{Dual Functioning Spaces: engaging the wall}

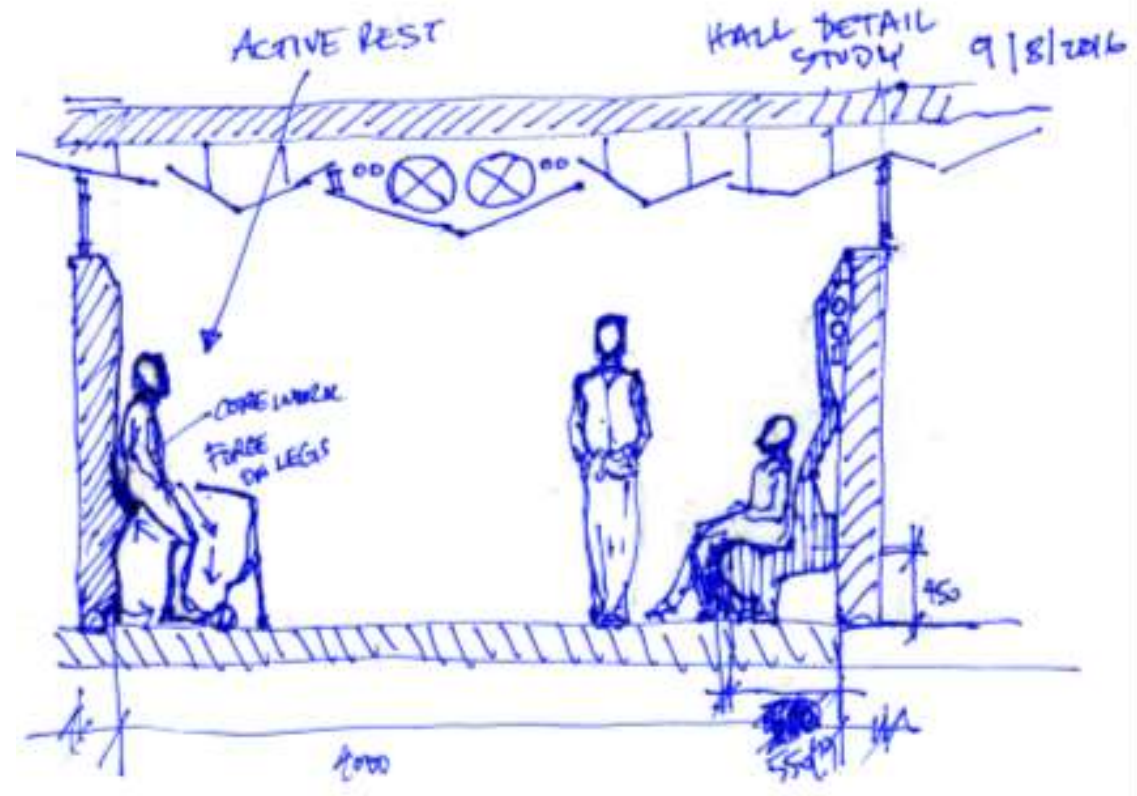

Figure 46

Source: Orhan Hassan
'According to public health officials, sitting for extended periods of time has harmful effects on the endocrine and muscular skeletal systems of the body. 'Sitting is the new smoking' - now ranked in the same category as smoking, for the risk of developing heart disease in adults. According to Marcel Mauss' observations, body movement is biologically, psychological and socially determined. Movement behaviours are observed and imitated and become "modes of life". Using this analogy, active pause seeks to promote an alternate and less harmful behaviour.

The idea of active pause (figure 46) achieves two objectives:

Individuals who have mobility issues that may affect their ability to rest through a partial sitting position

The position retains the engagement of muscles in holding the posture and thereby supporting healthy tissue development. 


\section{Dual Functioning Elements: Connection to the outside world}

The following precedents have been used in the design proposition in developing the connection of the residents to the surrounding community.

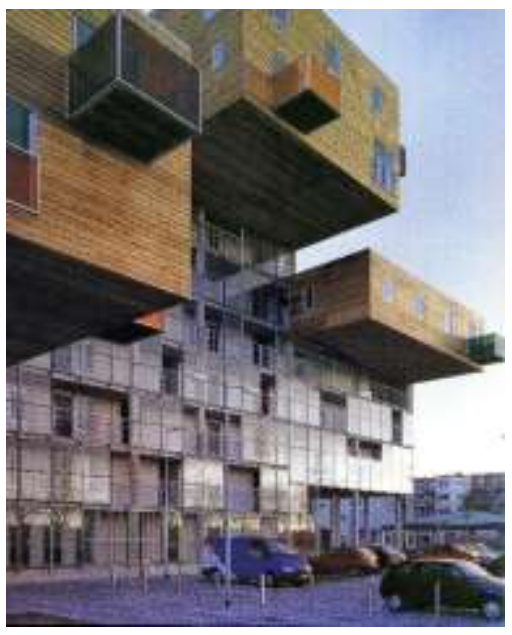

Figure 47: 100 Wozoco, Amsterdam The Netherlands by MVRDV - an apartment building for people 50 years and older. Extend the building over the street creating a spatial connection beyond the perimeter of the footprint of the building.
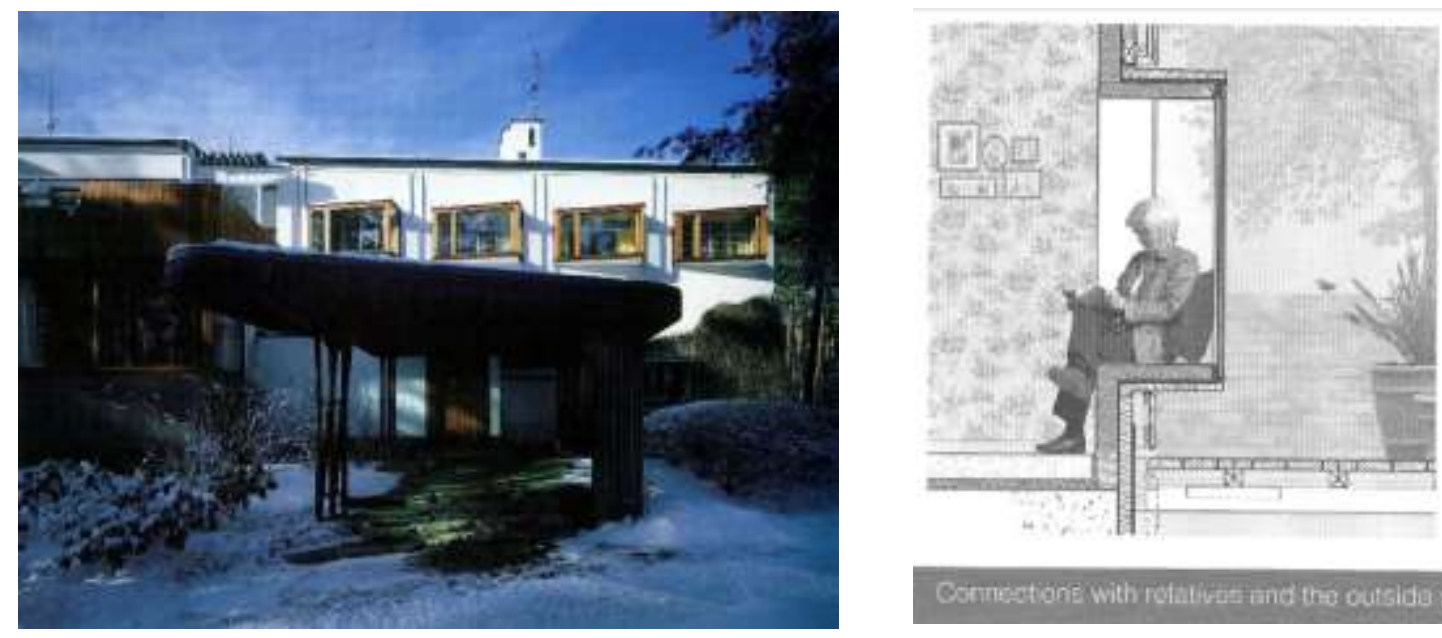

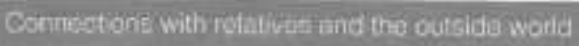

Figure 48: Alvar Aalto, uses the window as bays to facilitate an extended connection to the outside in Villa Mairea (1939)
Figure 49: Sarah Wigglesworth proposition for design for seniors 


\section{Proposed New Program}

This new proposed program adds to the existing design (as illustrated) and includes a Youth Mentorship program. This program will draw on the expertise, wisdom and knowledge of residents of the seniors cohousing. The youth mentorship is not a new concept and considered as a valuable form of community support for inner

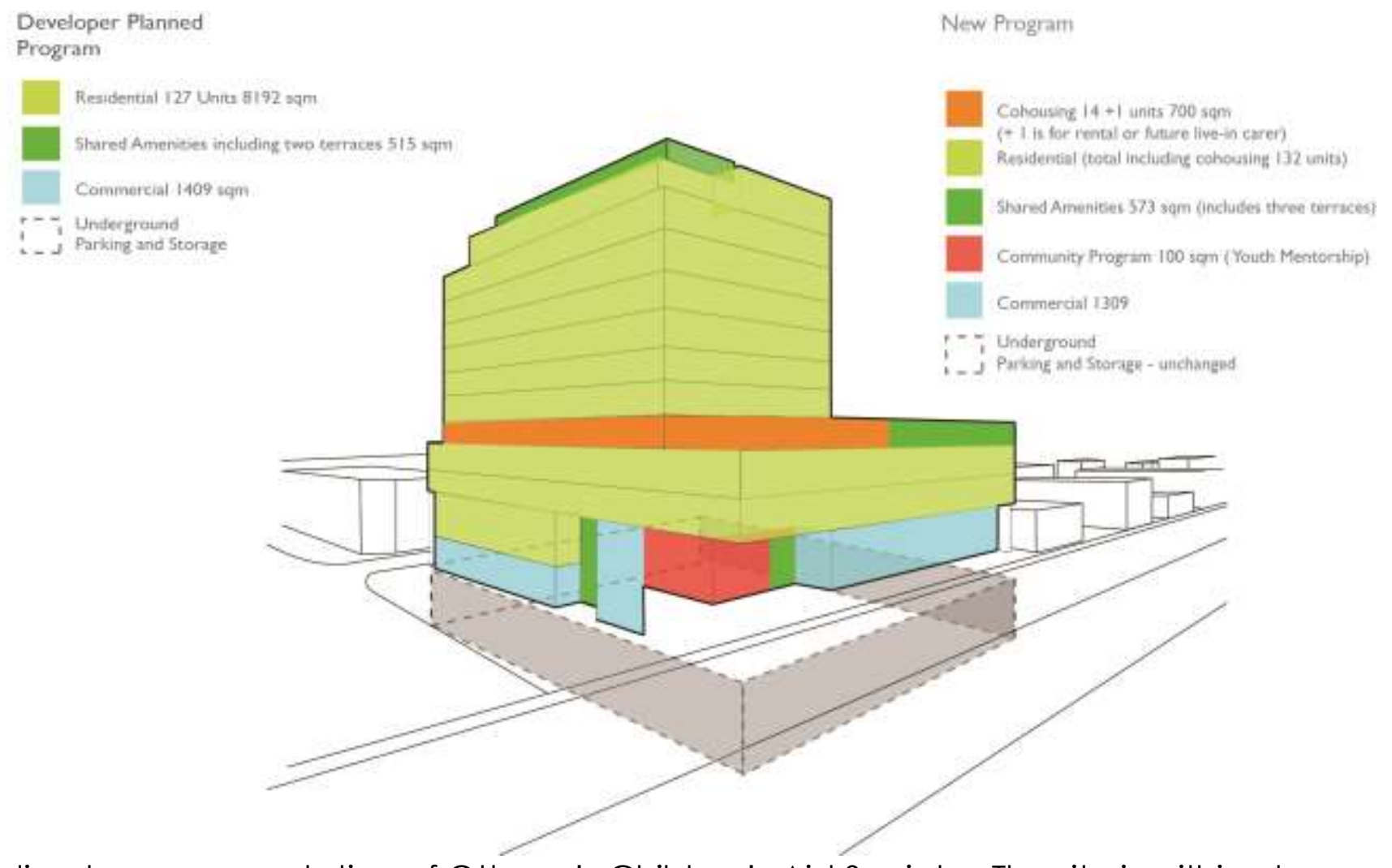

city youth - according to a representative of Ottawa's Children's Aid Society. The site is within close proximity to several high schools including the Adult High School located Gladstone and Preston Street. 
Drawing: Plans, Elevations and Sections 


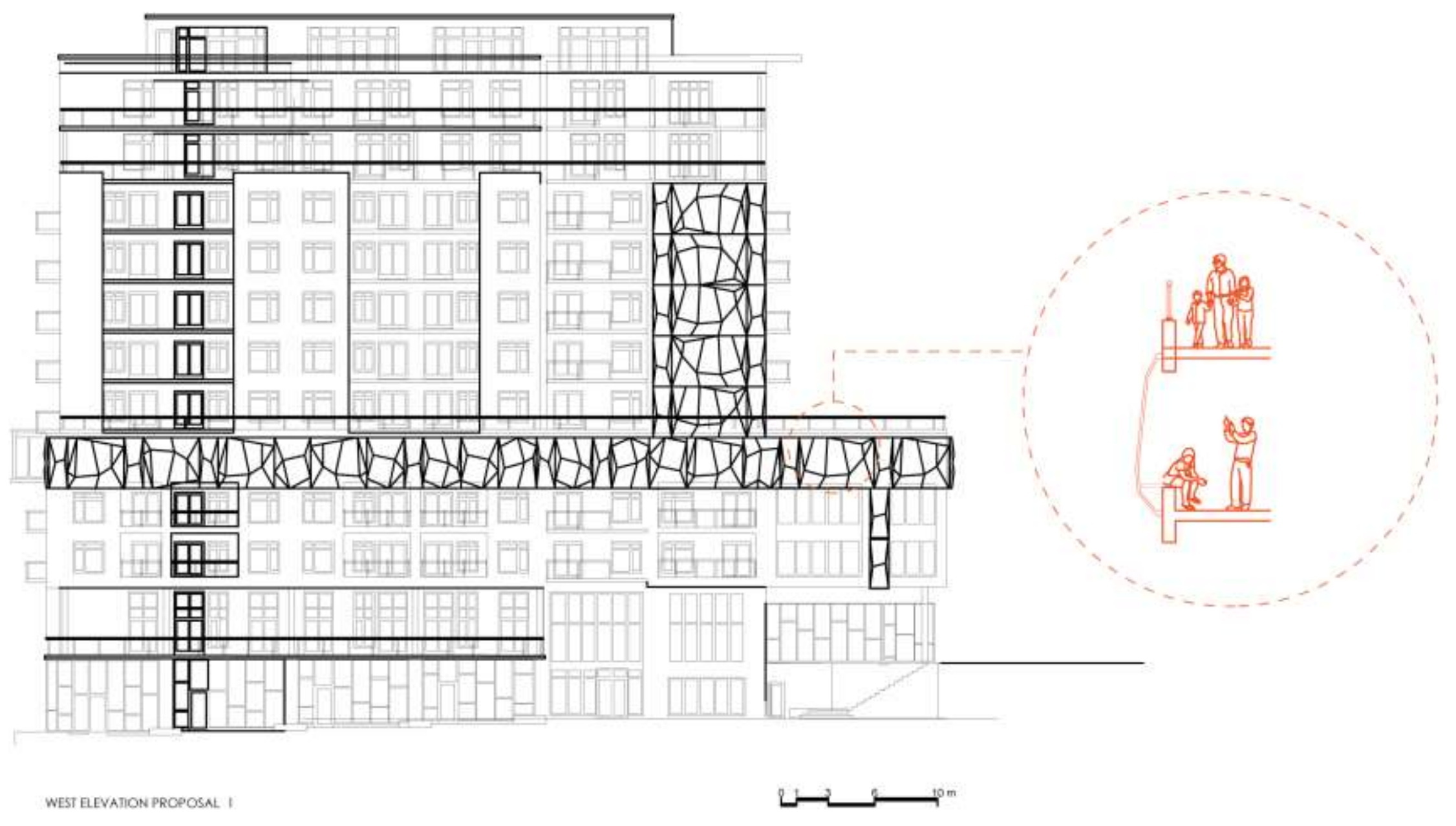




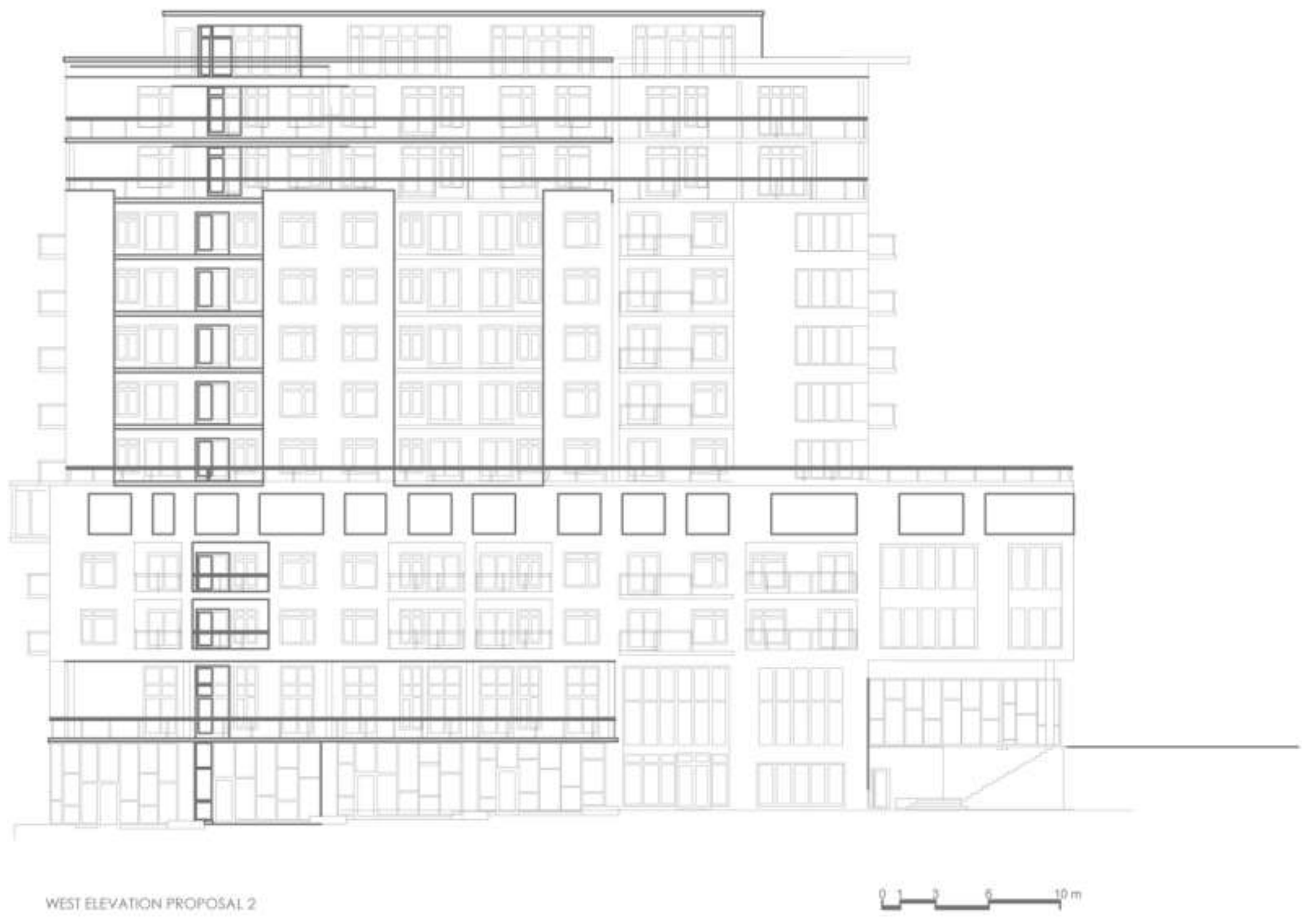




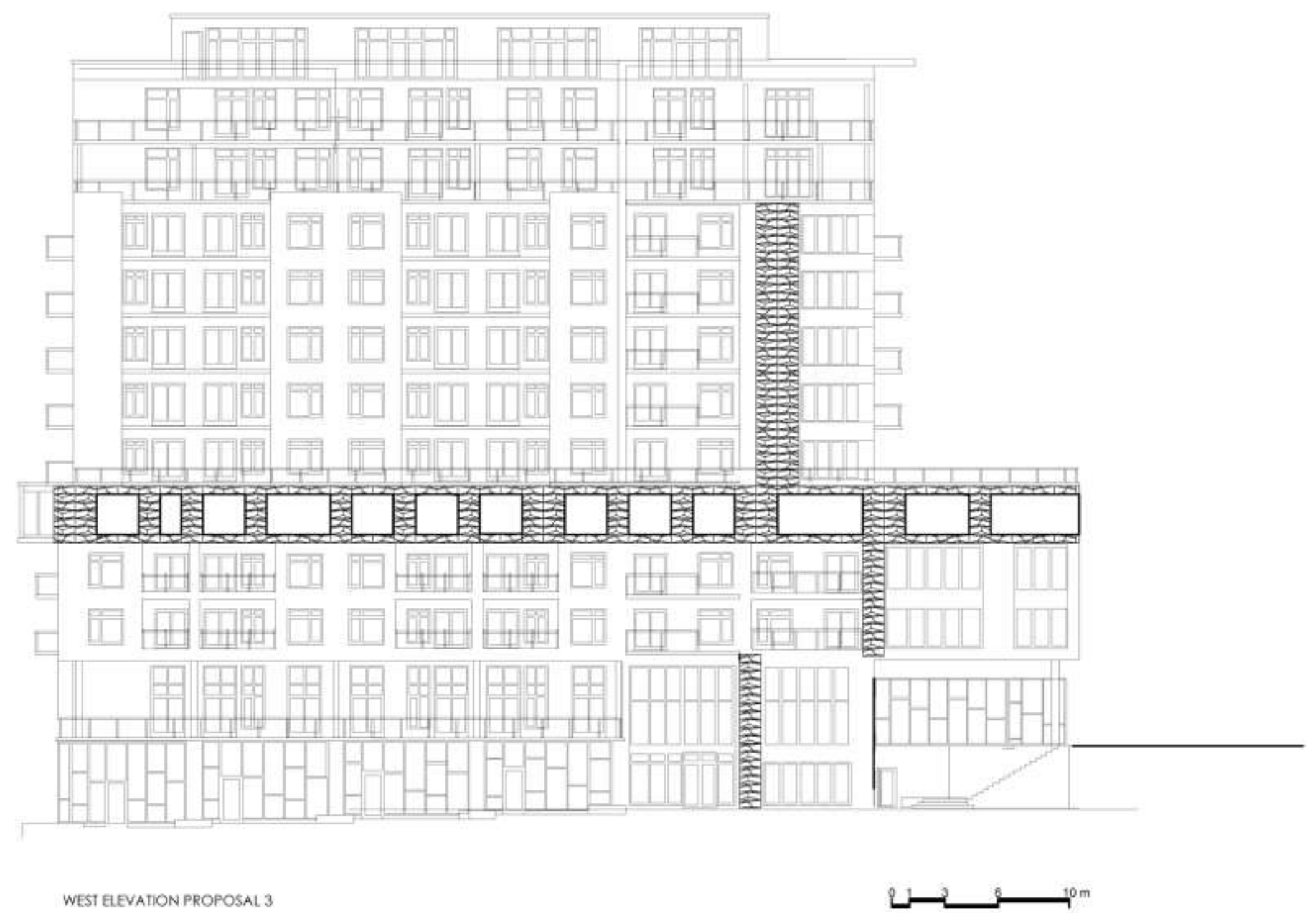




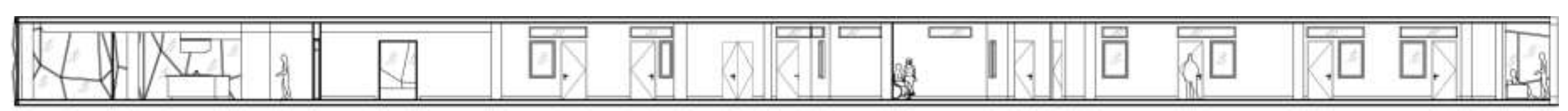

LONG SECTION A 

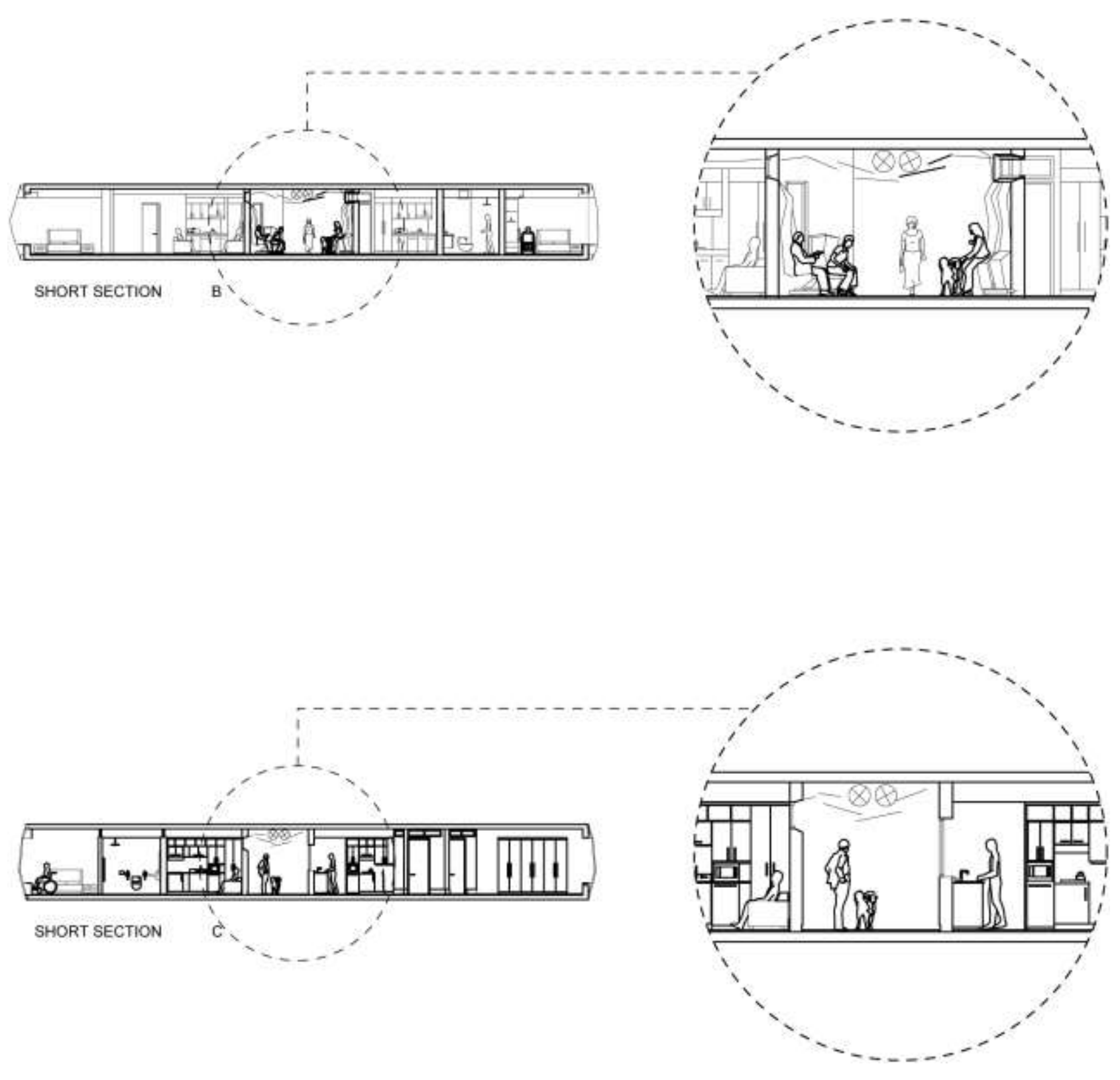


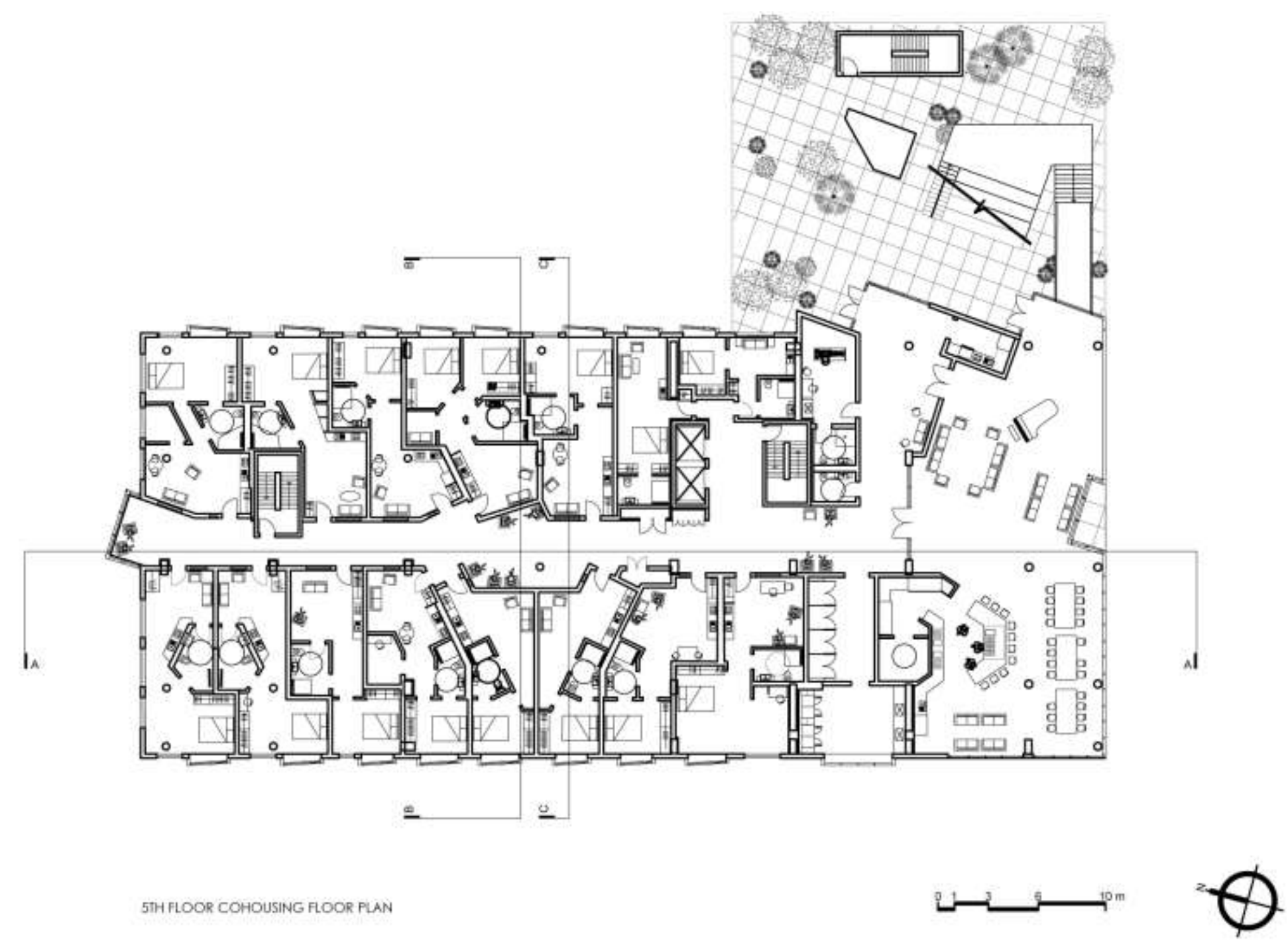


Unit Model A
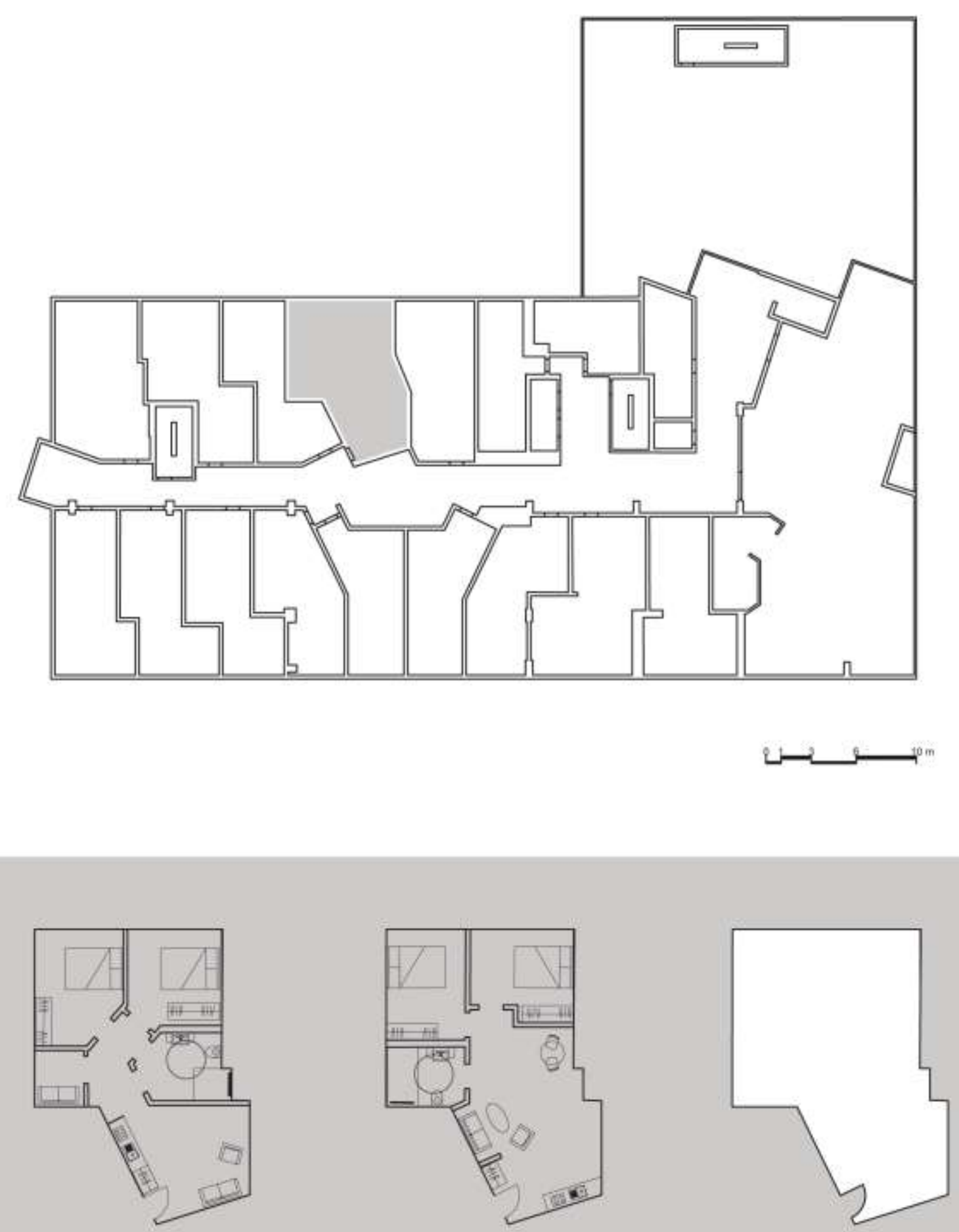
Unit Model B
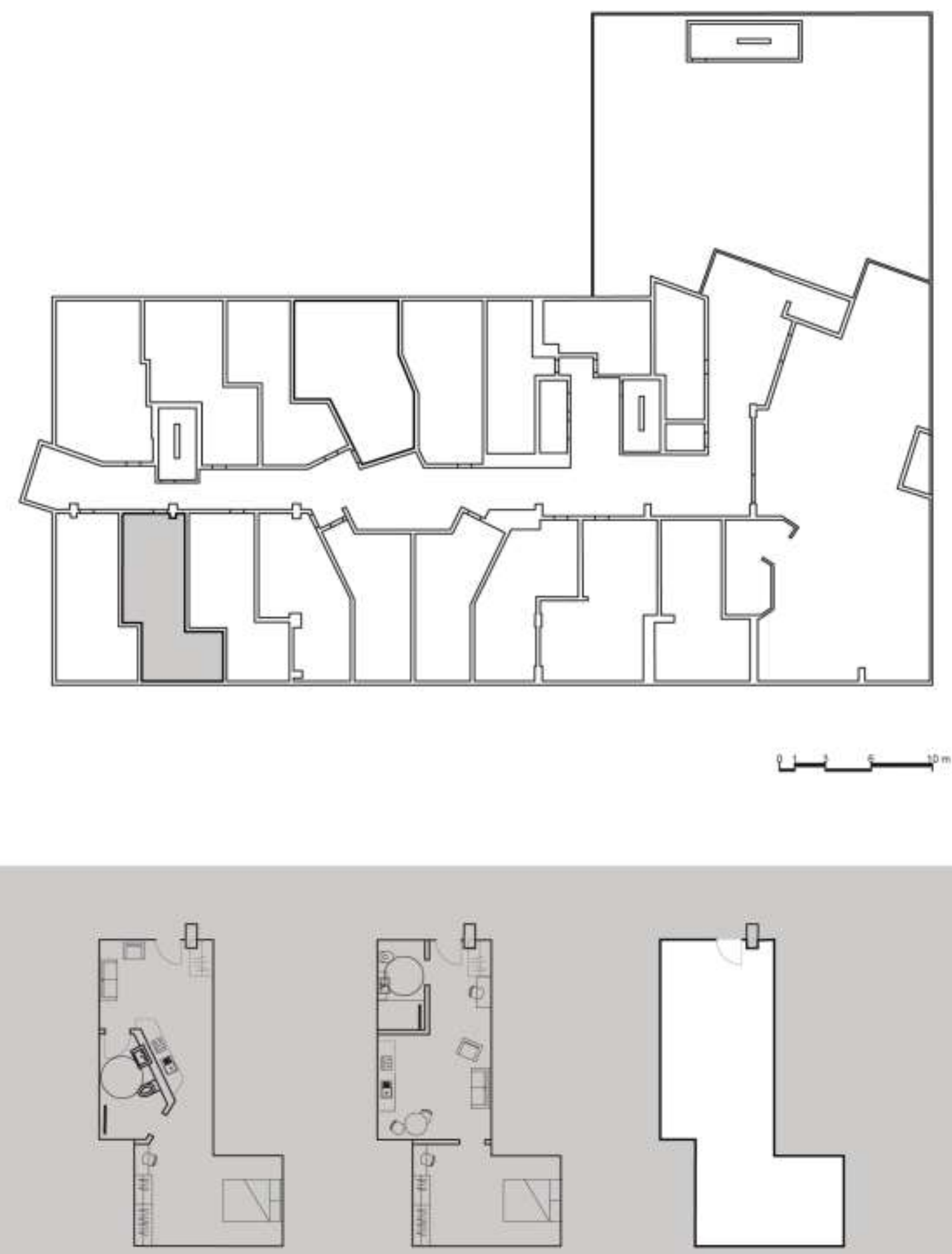
Unit Model C
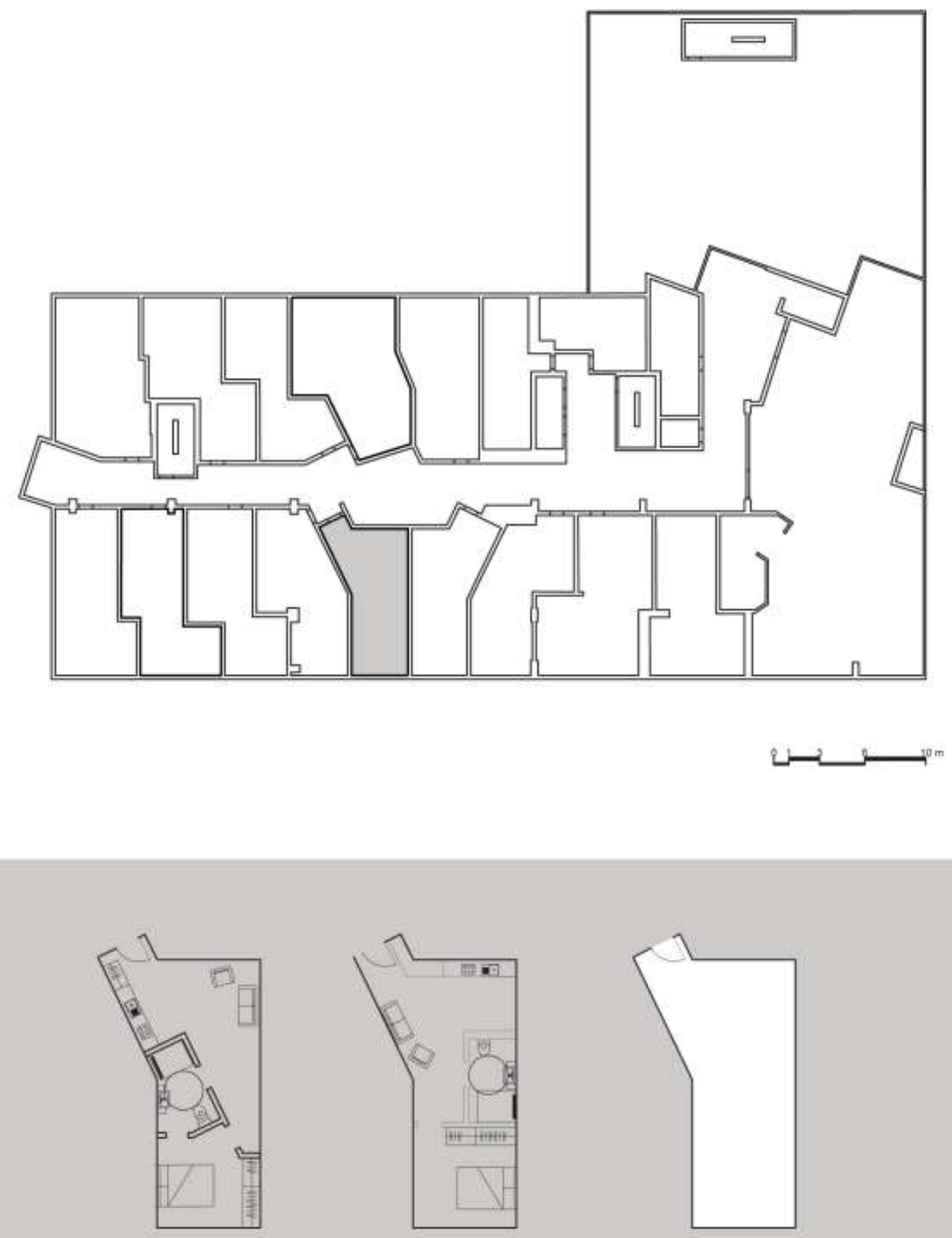


\section{Part 5 Reflections and Conclusions}

The evidence of isolation and disconnection of seniors is compelling and calls for action. Based on the emerging evidence, seniors cohousing has merit in terms of psychosomatic health for individuals and in terms of socio-economic value as an important housing option for seniors that will likely grow in popularity - a possible antidote to isolation and loneliness. In fact, at the time of writing, a development of a seniors cohousing model is being considered for the housing development project at 'Greystone Villages' as Deschâtelets, Old Ottawa East, by Greystone Development. The potential savings to the state discussed (Part3), for home care support costs, and value shown is promising and is significant enough to make the case for state funded support for such initiatives.

The reflections of this architectural exploration arrive at three main thematic areas. The first, is that of attitudes toward cohousing: what do people of today think about the potential application (on a wider scale and) of cohousing as another housing option? What is the level of interest?

The second related to questions of technical matters including policy frameworks, legal and financial mechanisms that may facilitate this kind of housing option. The third is that of the architectural challenges associated with developing a hybrid model.

One size does not fit all.... 
It appears that seniors cohousing must involve like-minded individuals - willing to commit, financial and time resources, and working collectively toward the development of a cohousing living arrangement. It is not surprising that the Canadian Cohousing Network uses the term 'intentional communities' to describe groups of individuals and cohousing projects in Canada and the USA. In other words, even if the evidence is compelling this particular housing option will generate favourable health and social outcomes, it would likely not succeed if imposed by a well-intentioned policy decision for a new type of aging in place - in fact this would contradict the very notion of cohousing model of living.

In general, the attitude toward cohousing among those consulted in the architectural exploration was favourable and enthusiastic. Plans and elevations were not developed and therefore not discussed hence only general reactions to the concept was solicited.

The impression this investigation has left is that cohousing would not necessarily be of interest to older seniors - attributed to generational norms on habitation. However, it is likely to generate interest among younger baby boomers 50+. Social norms are beginning to change, as we can see young people are choosing to establish shared living arrangements and finding this an attractive housing solution in reaction to the hyperinflated housing market in British Columbia95. It is likely then, that the cohousing movement will take a stronger hold in the near future, and so, it is worthy of working out some of issues of application - architects and architecture has a role to play here.

It is certainly feasible and practical to construct an augmented or hybrid model under one roof, from a developer's perspective. There are economies of scale at play when integrating such housing options and 
as long as profit margins are not affected, developers will likely to respond to new consumer demands. The issue of affordability and sustainability of a hybrid model leads to thematic area of technicality. The legal structures 96 and policies 97 that are mechanisms of maintaining the status quo and seemingly starve innovation from the air it needs to forge new ways housing options. A discussion about cohousing cannot be meaningfully had, without a discussion on existing policy, and the need for change that including the provision of greater incentives for new housing models that offer greater choice, as well as greater investments in affordable housing for seniors.

In the third and final thematic area - the architectural dimension - involves a range of design issues and challenges (which, so include some technical matters). The notion of architectural spaces supporting social architecture is particularly interesting. Can architecture create social architecture? The reverse certainly seems to be true in seniors cohousing. Social bonds between motivated individuals and collaboration lead to the formation of a physical space. Why not the other way around?

Social architecture needs to be at the forefront of our minds as architects and planners. 


\section{Insertion of a cohousing model}

Notwithstanding the suggestion that there are opportunities for leveraging developer investments, inserting cohousing into a conventional mixed-use development presents a number of architectural challenges. The first relates to use of a pre-defined canvas (i.e. a defined structural grid, floor plate and allocation of common amenity space). This establishes significant limits on spatial design preferences of end users that will only occupy a relatively small portion of the overall building. The second relates the infusion of a potentially different architectural design: language; scale, geometry; and material palette - into an established design proposal - and how this is resolved in a manner that is complimentary to the building's overall design. In this vein, the challenge of modifying a proposed program can be problematic. This is especially so in mixed-use buildings where ground floor units directed at commercial use are revenue generators for the developers. 


\section{Architectural Perspective: insertion strategy}

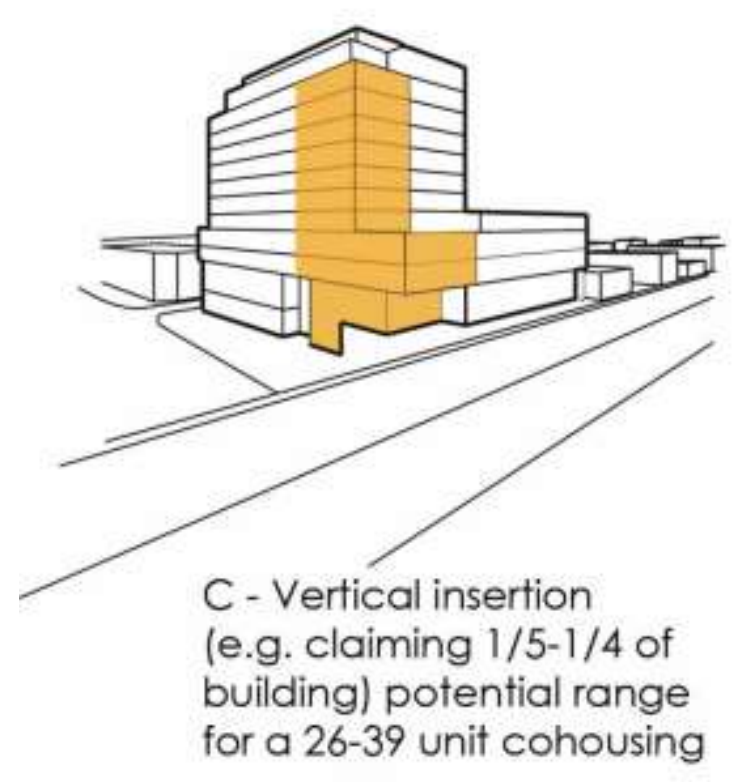

An important consideration in the design process was the insertion strategy for the cohousing model. The selection of the fifth floor was one of many possible permutations. The single floor level insertion strategy on the $5^{\text {th }}$ floor level was proposed, due to the opportunities for connection with others using amenity spaces. On reflection a vertical insertion, from the street level up (both City Avenue and Somerset Street) establishes a spatial relationship both literal and symbolic with residents and the surrounding community (Figure 50). This insertion approach may be more of an appropriate design consideration. 
Insertion of design ideas to the other parts of the building

Options for alternate points of intersection
Accepting the concept proposed by Avi Friedman, that improving living conditions for one group in society, through universal design, benefits all98. The design of architecture spaces facilitating social connection must surely be valuable for the overall well being of all residents in a subject mixed-use, perhaps similar to the constellation pattern shown earlier.

\section{Thesis Gaps and Areas for Further Enquiry}

Baby boomers will force changes in the socio-political, economic and cultural dynamic in which we live, including expectations for housing - this is the conclusion that the $\mathrm{CMHC}$ has reached. It would be hard not to agree with this position. There are likely to be differences in attitudes toward housing, preferences and consumer expectations, including 
alternative ways of dwelling such as co-habitation. Architectural research in this area would be invaluable for design and program design. What might these differences be? The needs and housing options for seniors in rural communities, beyond the scope of this enquiry, also requires attention. Given seniors' preference to remain in the communities that they are most familiar it is important to explore possible application of cohousing models in these communities. Another important area outside of the scope of this thesis was financial feasibility. This needs attention in order to assist in implementing a housing option of this kind.

This thesis, to all intents and purposes, has culminated in a discussion - through design and illustrations in the capacity of architecture to support social interaction and connection - an important aspect of human existence and healthy aging. To that end, the proposed architectural strategies tested show promise for application. This housing option is consistent with major policy recommendations and calls to action from organisations such as the CMHC and the National Seniors Council. It appears that it is possible to insert a cohousing model into a mixed-use development. The question remains whether sufficient interest will drive the change ahead. Architecture has a role here and must do its part to enable effective and new housing options to emerge. 


\section{Endnotes:}

'Canada Mortgate and Housing Corporation, , Research Highlights Report "Impacts of Aging of the Canadian Population on Housing and Communities", (2008) "Statistic Canada, Census in Brief, Age and Sex 2011 Census "Generations in Canada", http://www12.statcan.gc.ca/census-recensement/2011/as-sa/98-311-x/98-31 1x2011003 2-eng.pdf, Accessed on July 9, 2016

iii Department of Economic and Social Affairs, "World Population Ageing" (2015), United Nations

iv The term 'mixed-use' is the City of Ottawa's definition for urban development projects that contain residential, commercial, institutional and cultural uses.

http://ottawa.ca/en/residents/laws-licenses-and-permits/laws/city-ottawa-zoning-law/gm-general-mixed-use-zone-sec-187.

$\checkmark$ Joshua J. Mark "Heraclitus of Ephesus" Ancient History Encyclopedia, http://www.ancient.eu/Heraclitus of Ephesos/accessed: 9 July 9, 2016

vi A senior is an elderly person who is 65 years of age or older Martin Tourcotte, Grant Shellenberg, "A portrait of Seniors in Canada" Statistic Canada, http://www.statcan.gc.ca/pub/89-519-x/89-519-x2006001-eng.htm accessed on 19 July 2016

vii The Health Determinants, World Health Organization, http://www.who.int/hia/evidence/doh/en/, accessed on July 17, 2016

8 The International Federation on Aging, Final Report "Current and emerging issues facing older Canadians"(2012)

9 lbid.pgl 4

${ }^{10}$ Canada Mortgage and Housing Corporation, Research Highlights Report "Supportive Housing for Seniors" (2000)

11 Ottawa Neighborhood Study, combined averages of 'period construction of dwellings' pre-1960 to 1980, http://neighbourhoodstudy.ca/west-centretown/, accessed on August 15, 2016

12 Government of Ontario, Accessibility for Ontarians with Disabilities Act, 2005, S.O. 2005, c. 11, https://www.ontario.ca/laws/statute/05a11 accessed on August 15, 2016

${ }_{13}$ City of Ottawa, Planning and Development Department, "The Zoning Bylaw Amendment Proposal Summary" (2016), http://ottawa.ca/en/city-hall/publicconsultations/planning-and-infrastructure/secondary-dwelling-units-accessory, accessed on July 19, 2016.

${ }^{14}$ The Government of Canada, National Seniors Council, “Report on Social Isolation of Seniors 2013-2014, (October 2014) p 15,

15 In 2006 the Ontario Government health system transformation included the decentralization of certain health service funding (e.g. home care support for seniors),

contracting the delivery of care and monitoring health system performance. As a result of this change a network of Local Integrated Health Networks were created.

The Champlain Region Health Network covers a broad region of eastern Ontario.

${ }_{16}$ Acute Care - is a term used to describe hospital admissions that are associated with a short stay following treatment.

17 Access to Care for the Ontario Hospital Association, "Alternate Levels of Care" (2015) http://www.oha.com/News/Documents/OHA\%20Release\%20-

\%20ALC\%20March\%20Data.pdf accessed on July 14, 2016

$18 \mathrm{lbid}$.

19 lbid.

${ }^{20}$ Marco Frascari, "'De Beata Architectura: Places for Thinking" in The Cultural Role of Architecture: Contemporary and Historical Perspectives. Edited by Paul Emmons, John Hendrix and Jane Lomholt, Routledge 2012: 83-92

${ }^{21}$ Two example the examples of good practice published by the International Association of Homes and Services for the Ageing book entitles "Architecture for an Ageing Population" (2014); and Arian Mostaedi, "Residences for the Elderly" (2007)

22 Wong, marrieage, social networks and health at old ages, Journal of Population Aging 20 Journal of Population Ageing

March 2015, Volume 8, Issue 1, pp 7-25

${ }^{23} \mathrm{lbid}$. 
${ }^{24}$ National Seniors Council, "Consultation Highlights, The Impact of Social Isolation on Seniors' Quality of Life and Well-being", in Report on the Social Isolation of Seniors (2014), http://www.seniorscouncil.gc.ca/eng/research_publications/social isolation/page00.shtml, accessed on February 24, 2016

25 Julianne Holt-Lunstad, Timothy B. Smith, J. Bradley Layton, "Social Relationships and Mortality Risk: A Meta-analytic Review" (2010) PLosMed 7(7) http://journals.plos.org/plosmedicine/article?id=10.1371/journal.pmed.1000316, accessed on March 2016.

${ }^{26}$ National Seniors Council, "Consultation Highlights, The Impact of Social Isolation on Seniors' Quality of Life and Well-being", in Report on the Social Isolation of Seniors (2014), http://www.seniorscouncil.gc.ca/eng/research_publications/social_isolation/page00.shtml, accessed on February 24, 2016

27 National Seniors Council, "Report on the Social Isolation of Seniors 2013-2014" (2014) Government of Canada

28 social capital. Dictionary.com. Collins English Dictionary - Complete \& Unabridged 10th Edition. HarperCollins

Publishers.http://www.dictionary.com/browse/social-capital (accessed: July 20, 2016).

29 James Bryan "Late-life Social Activity and Cognitive Decline in Old Age" Journal of the International Neuropsychological Society (201 1), 17, 998-1005. Cambridge University Press; Yvonne Michael, "Neighborhood Social Capital and Achieved Mobility of Older Adults" (2014) Journal of Aging and Health, Vol. 26(8) 1301-1319, Sage Publications; Carolyn Cannuscio, "Social Capital and Successful Aging: The Role of Senior Housing" (2003), Annals of Internal Medicine, September 2003, Vol 139, No.5_part 2>

${ }^{30}$ Children's, Women's and Seniors Health Branch, "Social Isolation Among Seniors: An Emerging Issue" British Columbia Ministry of Health, Children

31 Linda Pollack, "Architecture As Infrastructure for Interactivity: The Need for Desire" in Imperfect health The Medicalization of Architecture, Edited by Giovanna Borasi, Mirko Zardine (2014), Canadian Centre for Architecture Lars Müller Publishers.

32 Roger Ulrich, "View through a window may influence recovery from surgery", (1984), American Association for the Advancement of Science, April 27, 1984 v224 $\mathrm{p} 420(2)$

33 Linda Pollack, "Architecture As Infrastructure for Interactivity: The Need for Desire" in Imperfect health The Medicalization of Architecture, Edited by Giovanna Borasi, Mirko Zardine (2014), Canadian Centre for Architecture Lars Müller Publishers.

34 United Nations, Department of Economic and Social Affairs, "World Population Ageing" (2015)

www.un.org/en/development/desa/population/.../pdf/ageing/WPA2015_Report.pdf

35 Statistic Canada, "Population Projections for Canada 2013-2063" (2013), http://www.statcan.gc.ca/pub/91-520-x/2014001/section02-eng.htm\#a2 access on July 9 , 2016

Statistics Canada, 2011 Census, "census subdivision of Ottawa", https://www12.statcan.gc.ca/census-recensement/201 1/as-sa/fogs-spg/Facts-csd-

eng.cfm? LANG=Eng\&GK=CSD\&GC=3506008 accessed on July 11, 2016

37 City of Ottawa, "A Portrait of Ottawa Older Adults: Demographic and Socio-Economic Characteristics" (20XX)

38 Canada Mortgage and Housing Corporation, Research Highlights Report "Impacts of Aging of the Canadian Population on Housing and Communities" (2008)

39 Richard Shillington, An Analysis of the Economic Circumstances of Canadian Seniors, 2016, Broadbent Institute

40 Margie Carlson, Presentation "Affordable Housing for Seniors: Impacts in Light of Social Housing End Dates and Provincial Strategies for Ontario's Seniors" (2013), http://irpp.org/wp-content/uploads/assets/Uploads/Carlson.pdf

${ }^{41}$ Under the City of Ottawa Affordable Housing Program, seniors with a total household income of $\$ 88,000$ or less are eligible to apply for funds to make upgrades and/or adaptations to suit physical needs, including the installation of hand or grab rails, ramps etc. Source: City of Ottawa Housing Development Officer (2016)

42 Government of Ontario "Living Long Living Well" 2012

43 International Federation on Aging, Current and Emerging Issues Facing Canadians, Report, 2012

${ }^{44}$ Ontario Ministry of Health, Dr Samir K Sinhan "Highlights and Recommendations" Living Long, Living Well, (2013) Seniors Strategy

${ }^{45}$ Canada Mortgage and Housing Corporation, Research Highlights Report "Impacts of the Aging of the Canadian Population on Housing and Communities" (2008)

${ }^{46}$ Ontario Ministry of Health, Dr. Samir K. Sinha "Highlights and Recommendations", Living Long, Living well Report (2013), Ontario's Seniors Strategy, pg2 http://healthcareathome.ca/centraleast/en/news/Documents/Seniors_Strategy.pdf

47 Dr. Samir Sinha, "Why the Elderly Could Bankrupt Canada and How Demographic Imperatives Will Force the Redesign of Acute Care Service Delivery", HealthcarePapers, 11(1) April 2011: 46-51.doi:10.12927/hcpap.2011.22252, http://www.longwoods.com/content/22252/print

48 Statistics Canada, "Demographic Change" (2015), http://www.statcan.gc.ca/pub/82-229-x/2009001/demo/intl-eng.htm, Accessed on July 11 , 2016

49 Reference here from labour force participation statistics from Stats Canada

50 Canada Mortgage and Housing Corporation, Research Highlights Report "Impacts of Aging of the Canadian Population on Housing and Communities", (2008) 
51 World Health Organization - add the rest of the reference

52 Statistics Canada "life expectancy at birth, by sex and province and territory" http://www.statcan.gc.ca/tables-tableaux/sum-som/l01/ind01//3 2966 2979eng.htm? hili none, accessed on July 13, 2016

${ }^{53}$ Ivan Illich, "The Medical Nemesis" The Expropriation of Health, , (1970) Pg

54 (GLOBE NEWSWIRE) -- A New Report Title "Anti-aging Market - Global Industry Analysis, Size, Share, Growth, Trends and Forecast 2013 - 2019". Albany, NY,

(May 21, 2015), http://www.transparencymarketresearch.com/anti-aging-market.html accessed on July 12, 2016

55 Statistics Canada, "Demographic Change" (2015), http://www.statcan.gc.ca/pub/82-229-x/2009001/demo/int1-eng.htm, Accessed on July 11, 2016

56 ageism. Dictionary.com. Dictionary.com Unabridged. Random House, Inc. http://www.dictionary.com/browse/ageism(accessed: July 20, 2016).

57 Revera Inc. Sheridan Centre for Elder Research "Revera Report on Ageism: Independence and Choice As We Age" (2016); ERDMAN B. PALMORE1, "Research note: Ageism in Canada and the United States" in Journal of Cross-Cultural Gerontology 19: 41-46, 2004

58 The 'backfire effect' is a political science term that describes a process in which factual information presented to displele misconceptions actuall have the opposite effect and result in a more entrenched views - this has been research Nyhan, B., \& Reifler, J. (2010). When corrections fail: The persistence of political misperceptions. Political Behavior, 32, 303-330. doi:10.1007/s1 1109-010-9112-2

59 Todd Nelson, Ageism: Steriotyping and Prejudice against Older Persons, preface pg $x$

60 Juhani Pallasmaa, "material and time" in The Eyes of The Skin Architecture of The Senses, (2012), John Whiley and Sons, p. 34

${ }^{61}$ City of Ottawa "Annual Development Report June 2015

62 lbid.

63 Deane Simpson, Young-Old, Urban utopias of an Aging Population $2015 \ldots$.

${ }^{64}$ City of Ottawa, "Building Liveable Communities" Official Plan, http://ottawa.ca/en/official-plan-0/25-building-liveable-communities accessed on July 18, 2016

${ }^{65}$ City of Ottawa "Annual Development Report June 2015, pgl6

66 Meeting with Saide Sayah, City of Ottawa Offordably Housing Unit.

67 Rosedale Developments, Baybridge Seniors Housing, Presentation "Seniors Housing Industry Overview", Canadian Builders Perspective Association (2012),

http://www.chba.ca/uploads/Marketing/June2012/04-Senior\%20Housing\%200verview\%20-\%20Builders\%20Perspective\%20 June\%202012.pdf accessed on July 22, 2016

6868 Deane, A Simpson, Young-Old Urban Utopias of an Aging Population 2015

69 The International Association of Housing and Services for the Ageing, http://globalageing.org/ access on July 22, 2016

70 A range of publications and articles have been written in the role of architectural design and dementia two of examples of which are: Gesine Marquardt, Dr-Ing

"Wayfinding for People With Dementia: A Review of the Role of Architectural Design" (2011) HEALTH ENVIRONMENTS RESEARCH \& DESIGN JOURNAL,

http://her.sagepub.com.proxy.library.carleton.ca/content/4/2/75.full.pdf+html: JOOST VAN HOOF, Designing a "Think-Along Dwelling" for People With Dementia: A Co-Creation Project Between Health Care and the Building Services Sector, Journal of Housing For the Elderly, 27:299-332, 2013; Edward Steifeld, Jordana Maisel,

"Universal Design, Creating Inclusive Spaces" (2012) John Wyle \& Sons.

71 New standards that related to building code such as accessibility requirements in Ontario Building Code; O. Reg. 368/13: BUILDING CODE filed December 27.

2013 under Building Code Act, 1992, S.O. 1992, c. 23

72 Collins English Dictionary - Complete and Unabridged, 12th Edition 2014. S.v. "epidemiology." Retrieved July 252016 fromhttp://www.thefreedictionary.com/epidemiology

73 Parachute (2015) "The Cost of Injuries in Canada, Parachute:Toronto Ontario p27

${ }^{74}$ More about the $\mathrm{CMHC}$ report on stairs and falls preventions can be found at the following link: https://www.cmhc-schl.gc.ca/en/co/acho/acho 012.cfm

75 Dictionary.com. The American Heritage ${ }^{\circledR}$ New Dictionary of Cultural Literacy, Third Edition. Houghton Mifflin Company,

2005. http://www.dictionary.com/browse/an-ounce-of-prevention-is-worth-a-pound-of-cure (accessed: July 25, 2016).

76 International Association of Homes and Services for the Ageing, The Global Ageing Netowrk. In Architecture for an Ageing Population, edited by

Faith Driss, Mulgrave, Vic.: Images Publishing Group, 2013.

77 Dean Simpson, Young-Old Urban Utopias of an Aging Population 2015

78 Deane, A Simpson, Young-Old Urban Utopias of an Aging Population 2015

${ }^{79}$ Canadian Cohousing Network, "what is cohousing?" , http://cohousing.ca/history-of-cohousing/, accessed July 25, 2016

${ }^{80}$ Charles Durrett, "The Senior cohousing handbook" 2009 New Society Publishers 
81 Danny Milman, "The History of Cousing", Canadian Cohousing Network, http://cohousing.ca/history-of-cohousing/, accessed July 25, 2016

82 Chares Durrett, The Seniors Cohousing Handbook, 2009 New Society Publishers

${ }^{83}$ Canadian Cohousing Network, "cohousing/sustainability?", http://cohousing.ca/cohousing-sustainability/ accessed July 25, 2016

${ }^{84}$ Ysseldyk "Group decision making: building social identity and enhancement cognitive performance among seniors (2014)

85 Margaret Critchlow Rodman, Presentation, "Co-caring in Seniors Cohousing" (2013), $11^{\text {th }}$ Annual International Communal Studies Association Conference, held at Findhourn Foundation, Scotland https://www.youtube.com/watch? $v=u U y m R$ JurxEw, accessed on March 16, 2016

86 Paul Williams, Presentation "Expanding Long Term Care in the Community: Can it be done?" (2016) IRPP/CRNCC Working Lunch, Ryerson University,

http://irpp.org/irpp-event/expanding-long-term-care-in-the-community/, accessed July 14, 2016

87 (Francesco Chiodellia* and Valeria Baglioneb, Living together privately: a cautious reading of cohousing. Urban Research \& Practice, 2014 Vol. 7, No. 1, 20-34, http://dx.doi.org/10.1080/17535069.2013.827905

${ }^{88}$ Kelly Grant, “No Place Like Home, A look inside Ontario's Home Care Shortcomings ” Globe and Mail, (2015),

http://www.theglobeandmail.com/news/national/no-place-like-home-investigating-ontarios-home-care-shortcomings/article25409974/, accessed on July 14, 2016.

89 Herman Hertzberger, Lesson For Students in Architecture, 1991, 101 Publishers

${ }^{90}$ City of Ottawa, Building liveable communities Ottawa 2031 Urban Land Issues at glance. 2011,

http://documents.ottawa.ca/sites/documents.ottawa.ca/files/documents/urban land en.pdf

${ }^{91} \mathrm{CMHC}$ Recommendations for design for an ageing population: "Design features which can prevent accidents should be included, such as bathroom grab bars, non-slip flooring, wider doonways, easily reached electrical outlets, hot water temperature controls, coloured safety stripping on stairs and handrails in hallways. Wide, level, snow-free pathways, as well as automatic doors, covered entrances and good lighting will increase safety around the outside of the building. - Assistive devices, such as shower seats and raised toilet seats, will increase safety and comfort, as will benches in common spaces such as elevator waiting areas. " "Parking" spaces for walkers will be needed in dining and lounge areas. (CHMC)

92 Please refer to the Retirement Home Act 2010 - Government of Ontario, Retirement Home Regulatory Authority, http://www.rhra.ca/en/governance/legislation-and-regulations/

${ }^{93}$ Charles Durrette, "the senior cohousing handbook" 2009 New Society Publishers

94 Walkability of neighborhood as defined by the Ottawa Neighborhood Study "refers to how friendly a neighbourhood is to pedestrians. Walkable neighbourhoods can increase physical activity and enhance social interaction and cohesion. They can also enhance the economic development of an area and increase safety.

Scores on each walkability component compare one neighbourhood to all other neighbourhoods in Ottawa. An average score is 50 . A higher score indicates better walkability. A score of 70 or above is excellent, and denotes that overall, the neighbourhood is doing better than most other neighbourhoods on that factor. A score of 30 or below means that the neighbourhood is below most other neighbourhoods on that factor and has lots of room for improvement".

http://neighbourhoodstudy.ca/variablesdefinitions/, accessed on July 30, 2016

Figure 36 alvar also - source archdaily.com http://www.archdaily.com/85390/ad-classics-villa-mairea-alvar-aalto/5037e79728ba0d599b0003a 1-ad-classics-villamairea-alvar-aalto-photo

${ }_{95}$ Aleksandra Sagan, CBC Report, Gen Y struggles in expensive housing, rental market, Oct 20, 2013, http://www.cbc.ca/news/canada/gen-y-struggles-in-expensivehousing-rental-market-1.2102109, access on August 22, 2016 
96 The Ontario's Condominium Act 199896, requires corporations to establish a reserve for future repairs and maintenance of the building common elements. However, the permitted investment vehicles for these funds do not keep pace with inflationary fluctuations in material costs. Hence, owners are required to pay for any shortfal that may arise resulting in increasing regular condo fees. This raises the question legal arrangement that would need to be created to facilitate the integration of cohousing community and its relationship with the condominium corporation board of directors.

97 From the City's perspective:

Section 37 of the Ontario Planning Act97 (i.e. the application for developments $7000 \mathrm{~m}^{2}$ and larger) allows the City to negotiate of public amenities of investment by the developers in physical infrastructure deemed of value to the community. In exchange, concessions can be made to zoning requirements (e.g. developers can exceed maximum allowable building heights). Development charges, which can amount to substantial costs, can also be waived in exchange. This may be one avenue to explore in the implementing a hybrid model of cohousing, especially to reduce the upfront construction costs that consumers would be required to finance.

Second, the City's Affordable Housing Program, which has cyclical 'Requests for Proposal' (RFP) and sponsor developments with upfront capital and operating subsidies (i.e. paying a portion of condo fees for units) may be possible. However, there was some reluctance expressed in entering legal agreement with for-profit developers and condominium corporations due to liability reasons (see endnote). However, not-for-profit developers may have better opportunities to seek this avenue for funding support from this program.

98 Avi Friedman referenced in Planning for Age-Friendly Communities A Call to Action June 18, 2009 Ontario Institute for Professional Planners, p 7, http://ontarioplanners.ca/PDF/Healthy-Communities/2009/Call-†o-Action-Age-Friendly-Communities-June-18-20.aspx, , accessed on 17 August 2016.

\section{Bibliography}

Bell, Victoria Ballard. Materials for Design, Princeton Architectural Press, 2006 
Pollack, Linda, Architecture As Infrastructure for Interactivity: The Need for Desire, in Imperfect Health, The Medicalization of Architecture, Canadian Centre for Architecture, Lars Müller Publishers (2012): 267-345

Eberhard, John. The Coexistence of Neuroscience and Architecture. Greenway Communications, 2007.

Durrett, Charles. The Senior Cohousing Handbook, New Society Publications 2009

Farrelly, Loraine. Designing for the Third Age: Architecture Redefined for A Generation of 'Active Agers', Architectural Design March/April 2014

Fatih, Driss. Architecture for an ageing population/International Association of Homes and Services for the Ageing, Images Publications 2014

Frascari, Marco. De Beata Arhitettura. Places for Thinking. in: The Cultural Role of Architecture: Contemporary and Historical Perspectives. Edited by Paul Emmons, John Hendrix and Jane Lomholt, Routledge 2012: 83-92.

Frascari, Marco. The Tell-the-Tale Detail. VIA 7 (1984): 22-37.

Illich, Ivan. The Limits of Medicine. Medical nemesis. The exproriation of Health. Marion Boyars 1976.

Mostaedi, Arian. Residences for the Elderly, Carlos Broto and Josep Ma Minguet Publishers (2005)

Pallasmaa, Juhani. The Eyes of the Skin: Architecture and the Senses. Chichester: Wiley-Academy, 2005.

Peréz-Goméz, Alberto. Attunement, 2016, MIT Press

Simpson, A, Deane, Young-Old Urban Utopias of an Aging Population 2015, Lars Müller Publishers

Steinfeld, Edward, Maisel Jordana. Universal Design: Creating Inclusive Environment, Wiley 2012

Sternberg, Esther. Healing Spaces. The Science of Place and Wellbeing. Belknap Press 2010.

Ulrich Roger, "View through a window may influence recovery from surgery", (1984), American Association for the Advancement of Science, April 27, 1984 v224 p420(2) 